al. 2009) verwiesen. Im Rahmen des internationalen Forschungs- und Städtenetzwerks CLIP $^{13}$ haben Kohlbacher \& Fassmann (2011) nach einem einheitlichen Kriterienraster eine Erhebung zur Ethnic Entrepreneurship in Wien durchgeführt.

Als einen Schritt in die Richtung einer besseren Kenntnis der räumlichen (kleinräumigen) Verteilung der Migrant Economy in Wien beinhaltet die vorliegende Studie auch eine kartographische Erhebung und die vergleichende Analyse der Geschäftsinfrastruktur zweier traditioneller Wiener Einkaufsstraßen (Taborstraße, Klosterneuburger Straße) (vgl. Kapitel 3.4).

Die lückenhafte Datenlage bringt es mit $\operatorname{sich}^{14}$, dass bislang nur wenige quantitative Erhebungen zum „Immigrant Business“ in Österreich durchgeführt wurden. Ein Meilenstein in der Quantifizierung und Strukturanalyse migrantischer Ökonomie in Wien wurde 2007 mit der Studie „Ethnische Ökonomien - Bestand und Chancen für Wien“ von Enzenhofer et al. ${ }^{15}$ gesetzt. In dieser wurde erstmals versucht, zumindest auf Basis von Schätzungen und Namensanalysen, quantitative Aussagen zum Status quo dieses Teils der Wiener Wirtschaft zu tätigen. Im Rahmen des Projektes „Entrepreneurship von Personen mit Migrationshintergrund“ (Schmid et al. 2006; vgl. auch Haberfellner 2011) im Auftrag des AMS Österreich wurde eine Sonderauswertung der quartalsmäßig durchgeführten Konjunkturbeobachtung im Bereich Gewerbe und Handwerk der KMU FORSCHUNG AUSTRIA durchgeführt und rund 4.000 Unternehmen befragt. Hierbei wurde bis zur 3. Generation - also einem möglichen Migrationshintergrund bis zu den Großeltern - recherchiert. Die Sonderauswertung umfasst nur solche Unternehmen, die sich mehrheitlich im Eigentum von Personen mit Migrationshintergrund befinden, die selbst oder deren Vorfahren nicht in einem Land der EU-15 geboren wurden.

\title{
3 Empirische Analysen
}

\subsection{Einleitung}

Die Kernforschungsfrage des vom Jubiläumsfonds finanzierten Projektes lautete: Warum gibt es in den größten Migrantengruppen in Wien nur so wenige Unternehmer? In konsequenter Fokussierung auf diese Frage wurden die Analysen wienzentriert durchgeführt und basieren zunächst auf einer Auswertung amtlicher Daten in Form der Abgestimmten Erwerbsstatistik. Weiters auf den Resultaten der von uns

13 www.eurofound.europa.eu/areas/populationandsociety/clipethnicentrepreneurshipcases.htm.

14 Dazu und zum Status quo der Forschung vgl. die umfassende Darstellung von Haberfellner (2012: 26 f.).

15 Die Studie basiert auf einer Kooperation von Wirtschaftskammer Wien (WKW) mit den Magistratsabteilungen 17, 18 und 27. 
durchgeführten 11 Experteninterviews und auch den im Sommer 2012 in unserem Auftrag von TRICONSULT durchgeführten Unternehmerbefragungen $(\mathrm{n}=30) .15$ türkische und 15 exjugoslawische Unternehmer und Unternehmerinnen wurden zur ihren Einschätzungen bezüglich der Opportunity Structures, spezifischen Herausforderungen des Unternehmerseins in Wien, ihren Problemen in der Start-up-Phase und nach der Etablierung ihres Geschäftes, aber auch besonders positiven Aspekten der Selbständigkeit in Wien befragt. Die Befragten decken eine große Bandbreite an Wirtschaftsbranchen ab. Im Sample waren sowohl Einpersonenunternehmen als auch etwas größere betriebliche Einheiten repräsentiert. Die halbstandardisierten Interviews verhalfen uns dazu, die zentrale Forschungsfrage aus einem anderen Blickwinkel, jenem der Unternehmer mit Migrationshintergrund, zu beantworten. Deren Perspektiven wurden um die Resultate der Experteninterviews ergänzt, um damit zu einem möglichst umfassenden Bild der Gesamtproblematik zu gelangen. Aufgrund der Struktur der Interviews dominierten in diesem Abschnitt qualitativ inhaltsanalytische Auswertungsmethoden (vgl. Glaser \& Strauss 2008; Mayring 2010).

Der lokal- und wirtschaftspolitische Kontext, in welchem sich Unternehmen von Migranten in den jeweiligen Städten entwickeln und die Institutionen, die die Einhaltung der relevanten Regeln kontrollieren, sowie Unternehmensfördermaßnahmen bilden Bestandteile der Opportunity Structures, deren Auswirkungen auf Unternehmer mit Migrationshintergrund in diesem Projekt untersucht wurden. Unsere Analyseansätze basierten auf der Wichtigkeit der Gruppenressourcen der Immigranten und deren Wechselwirkungen mit den strukturellen Kontextbedingungen des Aufnahmelandes. Individuelle Eigenschaften und der sozioökonomische Hintergrund der Unternehmer wurden ebenso berücksichtigt wie individuelle Entscheidungen und Berufsbiographien.

Der räumliche Aspekt der Opportunity Structures fand in einer kartographischen Analyse der Geschäftsinfrastruktur in zwei ausgewählten Wiener Einkaufsstraßen (Taborstraße, Klosterneuburger Straße) seinen Niederschlag. Die darauf bezogenen raumwissenschaftlichen Analysen bilden eine Ergänzung des wienbezogenen Parts der vorliegenden Studie. Die hohe Zeitintensität dieser Erhebungen gestattete jedoch keine Ausdehnung derselben auf eine größere Zahl von Einkaufsstraßen. Grundlegende Tendenzen und Entwicklungen konnten aber auch aus der Status-quo-Analyse der Situation in den beiden gewählten Straßen abgeleitet werden

\subsection{Die Migrantenökonomie im urbanen Kontext}

Sowohl auf der EU- als auch der nationalen und den munizipalen Ebene wird dem Unternehmertum von Immigranten etwa seit den späten 1990er-Jahren steigendes Augenmerk geschenkt. Es sei hierbei nur auf die „European Charter for Small Enterprises" der EU aus dem Jahre $2000^{16}$ verwiesen. Rath \& Swagerman (2011: 85) betonten

16 Siehe http://ec.europa.eu/enterprise/enterprise_policy/charter/index_en.htm\#charta. 
die beträchtliche Variationsbreite der Rahmenbedingungen, in die die urbanen ,,migrant economies " eingebettet sind. Die europäischen Staaten weisen traditionell unterschiedliche Migrationsregime und historische Abläufe der $\mathrm{Zu}$ - und Abwanderung auf. Sie unterscheiden sich weiters traditionell in ihren wohlfahrtsstaatlichen Systemen und rechtlichen Regelungen, die ausländischen Staatsbürgern den Zugang zur Selbständigkeit ermöglichen.

Abbildung 1: Anteil der selbständigen Erwerbstätigkeit von im Inland und im Ausland Geborenen an der Gesamterwerbstätigkeit, OECD 2007-2008 (in \%)

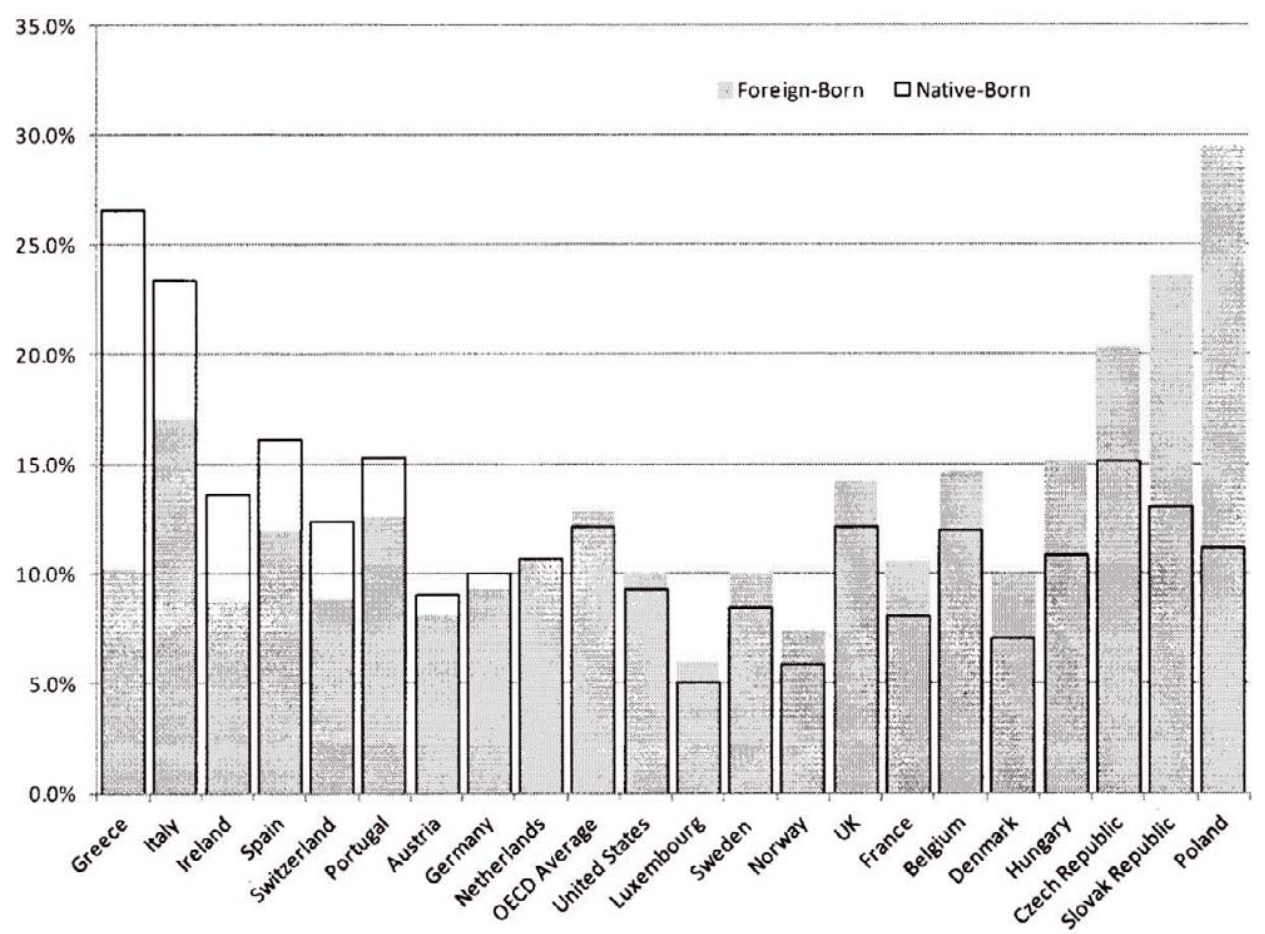

Quelle: Eurostat LFS Survey, 2007-2008. US CPS March Supplement, 2007-2008 (Mestres 2010: 6 in Rath \& Swagerman 2011: 85).

Die länderspezifischen Unterschiede hinsichtlich der selbständigen Erwerbstätigkeit sind, wie etwa aus dem International Migration Outlook hervorgeht, erheblich. ${ }^{17}$ Dies gilt sowohl für die Bevölkerung mit als auch für jene ohne Migrationshintergrund. In Staaten wie Großbritannien, Frankreich, Belgien, Dänemark, Schweden und Norwegen ist die Selbständigenquote für Personen mit Migrationshintergrund höher

17 Nach OECD (2012). 
als bei „natives “, in Österreich, Portugal, Irland, Deutschland und der Schweiz ist diese niedriger (vgl. Abbildung 1). ${ }^{18}$ Darüber hinaus existieren auch durchgängige Regelhaftigkeiten. Die geschlechtsspezifischen Unterschiede sind zum Teil erheblich. Frauen sind in nahezu allen Herkunftsgruppen, Städten und Wirtschaftssektoren schwächer vertreten als männliche Unternehmer. Demgegenüber sind später zugewanderte Immigranten der ersten Generation stärker unternehmerisch orientiert als frühere Zuwanderungswellen.

Tabelle 1: Entwicklung des Anteils der Selbständigen an der Gesamtbeschäftigung nach Geburtsort in OECD Ländern, 1998-2008 (in \%)

\begin{tabular}{|c|c|c|c|c|c|c|c|c|}
\hline & \multicolumn{4}{|c|}{ im Ausland Geborene } & \multicolumn{4}{|c|}{ im Inland Geborene } \\
\hline & $\begin{array}{r}1998- \\
2000\end{array}$ & $\begin{array}{r}2001- \\
2003 \\
\end{array}$ & $\begin{array}{r}2004- \\
2006 \\
\end{array}$ & $\begin{array}{r}2007- \\
2008 \\
\end{array}$ & $\begin{array}{r}1998- \\
2000 \\
\end{array}$ & $\begin{array}{r}2001- \\
2003 \\
\end{array}$ & $\begin{array}{r}2004 \\
2006 \\
\end{array}$ & $\begin{array}{r}2007- \\
2008 \\
\end{array}$ \\
\hline Österreich & 6,1 & 6,8 & 8,0 & 8,1 & 7,6 & 8,1 & 9,0 & 9,0 \\
\hline Belgien & 16,1 & 15,4 & 14,8 & 14,7 & 13,5 & 12,4 & 11,9 & 12,0 \\
\hline Schweiz & - & 9,9 & 9,5 & 8,8 & - & 11,5 & 12,5 & 12,4 \\
\hline Tschech. Rep. & - & 22,5 & 24,5 & 20,3 & - & 15,8 & 15,4 & 15,1 \\
\hline Deutschland & 8,0 & 7,9 & 9,6 & 9,3 & 9,1 & 9,3 & 10,3 & 10,0 \\
\hline Dänemark & 9,8 & 8,7 & 8,4 & 10,0 & 6,9 & 6,6 & 6,7 & 7,0 \\
\hline Spanien & 19,9 & 14,2 & 10,3 & 11,9 & 16,7 & 15,6 & 15,7 & 16,1 \\
\hline Frankreich & 10,4 & 10,0 & 10,9 & 10,6 & 8,3 & 7,6 & 7,8 & 8,0 \\
\hline Griechenland & 11,8 & 9,8 & 11,0 & 10,2 & 28,1 & 26,9 & 26,7 & 26,5 \\
\hline Ungarn & 15,5 & 17,3 & 16,1 & 15,2 & 13,0 & 11,8 & 12,0 & 10,8 \\
\hline Irland & 16,8 & 14,4 & 11,0 & 8,7 & 12,4 & 12,3 & 12,6 & 13,6 \\
\hline Italien & 17,7 & 15,9 & 17,9 & 17,0 & 23,3 & 22,6 & 24,2 & 23,4 \\
\hline Luxemburg & 6,5 & 6,0 & 6,7 & 6,0 & 7,6 & 5,9 & 6,3 & 5,0 \\
\hline Niederlande & 7,6 & 7,7 & 9,8 & 10,7 & 8,4 & 9,0 & 9,6 & 10,7 \\
\hline Norwegen & 7,4 & 5,9 & 7,6 & 7,4 & 4,7 & 4,8 & 5,5 & 5,8 \\
\hline Polen & - & - & 24,8 & 29,4 & - & - & 11,3 & 11,2 \\
\hline Portugal & 14,9 & 14,3 & 12,7 & 12,6 & 17,4 & 17,7 & 16,1 & 15,3 \\
\hline Schweden & 12,1 & 10,7 & 10,5 & 10,0 & 8,6 & 8,1 & 8,5 & 8,5 \\
\hline Slowakei & - & 7,6 & 19,9 & 23,6 & - & 9,6 & 12,2 & 13,0 \\
\hline Großbritannien & 15,5 & 14,2 & 14,1 & 14,2 & 10,8 & 11,0 & 11,6 & 12,1 \\
\hline USA & 9,4 & 8,6 & 9,3 & 10,0 & 8,9 & 8,8 & 9,5 & 9,2 \\
\hline Durchschnitt OECD & 12,1 & 11,4 & 12,7 & 12,8 & 12,1 & 11,8 & 12,2 & 12,1 \\
\hline
\end{tabular}

Quelle: Eurostat LFS Survey, 2008. US CPS March Supplement, 2007-2008 (Mestres 2010: 7).

18 Vgl. auch Tubergen (2005). 
Der Anteil der Selbständigen an allen Beschäftigten war in Österreich im OECDVergleich niedriger als in anderen Staaten. Er lag 2007/08 bei Personen mit Migrationshintergrund bei $8,1 \%$, bei Inländern ohne Migrationshintergrund bei $9 \%$. Im selben Jahr betrug der Selbständigenanteil bei Personen mit Migrationshintergrund in Belgien $14,7 \%$, in Italien $17 \%$ und in den EU-Newcomer-Staaten Ungarn $15,2 \%$ sowie in der Slowakei sogar 23,6\% (vgl. Tabelle 1). Mit einem Anteil von rund 10\% der Erwerbstätigen waren in Österreich Personen mit Migrationshintergrund im Jahr 2009 deutlich seltener selbständig als die österreichische Bevölkerung (14\%). Allerdings wiesen Zuwanderer aus den EU- und EWR-Staaten sowie der Schweiz ähnliche Selbständigenquoten auf wie Inländer ohne Migrationshintergrund. Vergleicht man nur die Selbständigen außerhalb der Landwirtschaft ${ }^{19}$, so liegt die Selbständigenquote bei Migranten allerdings über jener der Bevölkerung ohne Migrationshintergrund! Die Wahrscheinlichkeit, selbständig zu werden, divergiert je nach Migrationshintergrund. Zuwanderer aus dem Nahen Osten, aus den alten EU-Ländern sowie Afrika sind häufiger als Österreicher selbständig erwerbstätig. Bei Immigranten aus dem ehemaligen Jugoslawien und der Türkei war Selbständigkeit allerdings deutlich seltener, insbesondere unter den Frauen aus diesen Herkunftsländern. ${ }^{20}$ Im Schnitt ist auch die Selbständigenquote der inländischen Frauen in allen EU-Staaten niedriger als jene der Männer. In Österreich ist sie am höchsten unter Frauen aus der „alten“ EU, aber auch Frauen aus Asien und Afrika sind häufiger selbständig erwerbstätig als Österreicherinnen ohne Migrationshintergrund.

Österreich wies bis in die zweite Hälfte der 2000er-Jahre im Vergleich mit anderen OECD-Ländern auch eine relativ geringe Gründungsrate auf (vgl. European Commission $2007 \mathrm{a}+\mathrm{b}$, Apfelthaler 2008 sowie Segert 2010: 17). Die Unternehmensgründungen stiegen seither allerdings an. Die im internationalen Vergleich höheren Überlebensquoten von neu gegründeten Unternehmen in Österreich sind als Positivum hervorzuheben (ebenda). In vielen Bundesländern wurde eine rückläufige Gründungsrate der gebürtigen Österreicher durch das Wachstum von Gründungen durch Migranten ausgeglichen oder in der Gesamttendenz zumindest abgeschwächt (CFE/SME 2009, Leicht et al. $2005 \mathrm{a}, \mathrm{c})$.

Verlässt man die nationale Ebene und wendet sich der städtischen zu, so zeigen die Daten zur räumlichen Verteilung der Migrant Economy in den Nationalstaaten, dass die selbständige Erwerbstätigkeit von Migranten größtenteils auf urbane Agglomerationen beschränkt ist und im ländlichen Raum kaum in Erscheinung tritt. „Ohne eine Einbettung in den städtischen Kontext können migrantische Ökonomien nicht funktionieren und sie bieten diesem städtischen Kontext zugleich etwas an, das zu deren innerster Eigenschaft beiträgt: zu deren Urbanität. Die Be- und Verarbeitung des Fremden in der Stadt, der Umgang mit ,Differenz', ist ein Kernelement des Städtischen“ (Hillmann

19 Im Agrarsektor ist der Zuwandereranteil sehr gering.

20 Statistik Austria (2010). 
2011b: 13). Damit ist auch bereits auf die besondere Bedeutung migrantischer Ökonomien für die europäischen Städte hingewiesen. Die Unternehmer mit Migrationshintergrund können nicht unabhängig von dem Kontext (Stichwort „opportunity structu-

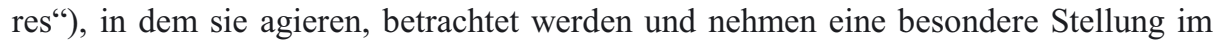
ökonomischen Geflecht der Stadt sowie auf dem städtischen Arbeitsmarkt ein. Neben nationalen Unterschieden bestehen auch welche zwischen den Städten im selben EULand sowie sogar auf den räumlichen Subebenen von städtischen Bezirken, Wohnvierteln und Stadtteilen und selbstverständlich zwischen den Wirtschaftssektoren. Nachteilig ist vor allem auch, dass für diese räumlichen Subkategorien nur in wenigen Städten einigermaßen valide Daten verfügbar sind (vgl. BMVBS 2010). Die Ökonomie von Migranten tritt als lokaler wirtschaftlicher Gestaltungsfaktor besonders stark in Vierteln mit hohen Anteilen von Bevölkerung mit Migrationshintergrund auf.

Abgesehen von den Analysen zu „Etablierten“ und Außenseitern von Elias \& Scotson (2002) spielte der räumliche Kontext der Stadt in der Migrationsforschung lange eine eher untergeordnete Rolle. Erst im Zuge der Globalisierung rückte die Stadt als Ort der Konzentration und Integration von Migranten stärker (vgl. Sassen 1990, 2000) in den Fokus von Analysen. Etwa im selben Zeitraum hat sich die Ökonomie der Immigranten aus einer eher als marginal wahrgenommenen Nischenposition hin zu einer zentraleren Positionierung in der Wirtschaft, als Arbeitgeber und für die städtische Entwicklung generell, verschoben. Migranten als Unternehmer sind ein wichtiger Aspekt in der urbanen Wirtschaftsstruktur, der in Zeiten allgemeiner ökonomischer Krisen und Arbeitsmarktprobleme immer mehr an Bedeutung gewinnt. Unternehmer mit Migrationshintergrund leisten einen immer wichtiger werdenden Beitrag zur generellen Wirtschaftsentwicklung sowie zur Prosperität in vielen Wirtschaftssektoren. Zugleich ist die Migrantenökonomie ein wichtiger Faktor der ökonomischen und somit strukturellen Integration.

Niederländische und britische Stadtverwaltungen waren auf dem Sektor der Migrant Economy besonders (früh) aktiv und haben eine Vielzahl an Maßnahmen zur Förderung von Migrantenunternehmen gesetzt. In einigen Metropolen, z.B. in Amsterdam, setzte die Förderung der Migrant Economy bereits in den frühen 1990er-Jahren ein. In den Agglomerationen Ostmittel- und Südeuropas, wie etwa in Prag, Budapest, Lissabon oder Barcelona, besteht in dieser Hinsicht auch aktuell vielfach noch deutlicher Aufholbedarf. In Wien hat die Forcierung der Selbständigkeit von Migranten zwar später eingesetzt als etwa in Amsterdam, die österreichische Bundeshauptstadt hat aber in Bezug auf das Maßnahmen- und Förderungsspektrum vor allem im Verlauf der unmittelbar letzten Dekade sehr stark aufgeholt.

In Wien ist gegenwärtig die Bedeutung der Migrantenökonomie im Rahmen der Entwicklung der Gesamtwirtschaftskraft hoch anzusetzen (vgl. L\&R Sozialforschung/ Enzenhofer et al. 2007, Statistik Austria 2010), Anteile und Vielfalt der Migrantenunternehmen sind in Wien größer als in jeder anderen österreichischen Stadt. Schätzungen des Anteils der Migrantenökonomien an der Wiener Unternehmenslandschaft belaufen sich auf ein Drittel. In Orientierung an der Gründungsstatistik der Wirtschaftskammer ist in den vergangenen Jahren in Wien die Zahl der Herkunftsländer von Grün- 
dern gewachsen. 2009 wurden 91 Herkunftsländer registriert (vgl. Wirtschaftskammer Wien 2010a: 3).

In Ermangelung aktueller valider Daten musste leider auch zum Zeitpunkt der Erstellung dieser Studie für Wien nach wie vor mit Schätzungen gearbeitet werden, sieht man von den Daten der Abgestimmten Erwerbsstatistik einmal ab. Diese Schätzungen variieren zwar, bewegen sich aber inzwischen bei rund einem Drittel der Wiener Unternehmen. L\&R Sozialforschung/Enzenhofer et al. (2007: 14 f.) hatten für die Einzelunternehmen den Anteil von 18\% Unternehmern mit ausländischen Staatsbürgerschaften angegeben sowie weitere 11\% Unternehmer mit Migrationshintergrund. Differenziert man jedoch nach Herkunftsgruppen, so stellt sich jene Frage, deren Beantwortung im Fokus des empirischen Teils dieses Berichts stehen soll: Laut Abgestimmter Erwerbsstatistik 2009 waren in Wien von 37.736 in der Türkei geborenen Erwerbstätigen nur 6,1\% selbständig, bei den Exjugoslawen lag der entsprechende Anteil sogar bei bescheidenen 3,8\% (vgl. Kapitel 3.3).

Variierende Selbständigenanteile bei unterschiedlichen Herkunftsgruppen sind allerdings kein auf Wien beschränktes Phänomen. So liegt etwa in Amsterdam der Anteil der Selbständigen in der türkischen Community bei $18 \%$ und damit deutlich über jenem der niederländischen Bevölkerung (15\%), bei Surinamesen/Antillianern sowie Marokkanern bei jeweils rund 10\% (Regionale Enquête Beroepsbevolking in van Heelsum 2011: 17). In Lissabon reicht die Bandbreite der Präsenz von Unternehmern von einem Spitzenwert von 36\% in der chinesischen Community, über 23\% bei Briten und $13,5 \%$ bei Brasilianern bis zu bescheidenen 6,7\% bei diversen afrikanischen Herkunftsgruppen. Das Schlusslicht bilden in der portugiesischen Hauptstadt die Ukrainer mit 1,5\% (Pires 2012: Tab. 16). 49\% der Unternehmer mit Migrationshintergrund in Dublin stammten 2008 aus Mittel- oder Osteuropa, 28\% aus dem afrikanischen Kontinent, 18\% aus Asien und 5\% waren ,sonstiger" Herkunft (Tarantino 2012: 18). Eine Studie der Industrie- und Handelskammer Frankfurt am Main (2009) hat die Unternehmer nach 27 Nationalitäten aufgeschlüsselt. Die Mehrheit (4.044) waren polnische Staatsbürger, gefolgt von Türken (1.897), Italienern (957), US-Bürgern (555) und Griechen (464) (Lüken-Klaßen \& Pohl 2011: 18 f.).

In dem sich verstärkenden Trend zur Selbständigkeit spiegeln sich makroökonomische Trends wie Entwicklungen auf dem Arbeitsmarkt ebenso wider wie spezielle Zuwanderungsregulierungen für bestimmte Immigrantengruppen und vor allem auch städtische Spezifika. Last, but not least spielen aber auch traditionelle kulturelle und normative Prägungen der unterschiedlichen Herkunftsgruppen hinsichtlich des ökonomischen Erwerbsverhaltens eine Rolle, die in Wechselwirkungen zu den lokalen Opportunity Structures in den urbanen Wirtschaftssystemen treten. Der in vielen Städten feststellbare Trend der Zunahme der Gewerbeanmeldungen von Personen mit Migrationshintergrund ist vor allem auch in der zweiten und dritten Zuwanderergeneration deutlich erkennbar, wenngleich statistisch meist nur ungenügend dokumentiert. Gerade diese bereits im Aufnahmeland aufgewachsenen Selbständigen mit Migrationshintergrund verlassen sehr häufig auch die ,,migrant niche economy“ und werden in den verschiedensten Wirtschaftsbranchen erfolgreich unternehmerisch aktiv. 


\subsection{Die Selbständigkeit von Migranten aus dem ehemaligen Jugoslawien und der Türkei in Wien im Spiegel der Abgestimmten Erwerbsstatistik}

Über die Problematik der Erfassung der Selbständigkeit von Migranten in offiziellen Datenquellen wurde bereits berichtet. Seit 2008 hat sich die Lage in Österreich durch die Implementierung der Abgestimmten Erwerbsstatistik deutlich gebessert. Diese wird jährlich erstellt, wurde im Rahmen der Probezählung zur registerbasierten Volkszählung 2006 entwickelt und basiert auf Administrativdaten zum Stichtag 31.10. zu Merkmalen der ökonomischen Aktivität der österreichischen Wohnbevölkerung. Sie ist als Vollerhebung konzipiert und ermöglicht damit erstmals die jährliche Zählung von Erwerbstätigen, Arbeitslosen und Nichterwerbspersonen auf regional kleinräumiger Ebene (Gemeinden), wie es zuvor nur alle zehn Jahre auf Basis der Ergebnisse der Volkszählung möglich war. Inhaltlich richtet sich die Abgestimmte Erwerbsstatistik daher nach den Empfehlungen der Conference of European Statisticians (CES Recommendations) sowie der EU-Verordnung für Volks- und Wohnungszählungen und deckt alle darin geforderten Themen ab. Zur Abbildung der Merkmale werden insgesamt rund 30 administrative und statistische Datenquellen, zum Teil auf Personenebene, zum Teil auf der Ebene der Beschäftigungsverhältnisse bzw. der Registereinträge sowie zum Teil auf der Ebene von Unternehmen verknüpft. Ziel ist die Integration aller verfügbaren Administrativdaten und statistischen Register zu einem umfassenden Datenkörper der Erwerbsstatistik. Die folgenden Auswertungen zur Erwerbstätigkeit in Wien basieren auf dem aktuellsten verfügbaren Stand (Stichtag 31. 10. 2009) zum Beginn unseres Projektes.

Tabelle 2: Wohnbevölkerung nach dem Migrationshintergrund in Wien, 2009

\begin{tabular}{lrr}
\hline & abs. & in \% \\
\hline Wohnbevölkerung insgesamt & $\mathbf{1 . 6 9 0 . 8 3 7}$ & $\mathbf{1 0 0 , 0}$ \\
ohne Migrationshintergrund & 1.141 .433 & 67,5 \\
mit Migrationshintergrund & 549.404 & 32,5 \\
darunter: im Ausland geborene ausländische Staatsangehörige & 299.570 & 17,7 \\
$\quad$ Eingebürgerte & 206.357 & 12,2 \\
$\quad$ Zweite Generation & 43.477 & 2,6 \\
\hline
\end{tabular}

Quelle: Abgestimmte Erwerbsstatistik 2009. Eingebürgerte = im Ausland geborene österreichische Staatsangehörige; zweite Generation = in Österreich geborene ausländische Staatsangehörige.

Tabelle 2 zeigt, dass sich der Anteil der Wiener Wohnbevölkerung mit Migrationshintergrund (nach den Kriterien Staatsangehörigkeit und Geburtsland auf der individuellen Ebene) im Jahr 2009 auf 32,5\% belief, die Mehrheit (17,7\%) besteht aus Personen, die zugewandert sind und (noch) nicht die österreichische Staatsbürger- 
schaft besitzen. Die hier verwendete Definition ist vergleichsweise eng gesteckt, da im Vergleich zu anderen Konzepten - der Geburtsort der Eltern (oder gar der Großeltern) nicht einbezogen wird, sondern nur die beiden Dimensionen in Bezug zum Individuum selbst. Dies resultiert u.a. in einer geringen Zahl von Angehörigen der Zweiten Generation, da alle Eingebürgerten, deren Eltern aus dem Ausland zuwanderten, per definitionem ausgeschlossen sind.

Tabelle 3: Migranten aus dem ehemaligen Jugoslawien und der Türkei nach dem Migrationshintergrund in Wien, 2009 ${ }^{21}$

\begin{tabular}{lrr}
\hline & abs. & in \% \\
\hline Ehemaliges Jugoslawien & $\mathbf{1 7 1 . 0 6 4}$ & $\mathbf{1 0 0 , 0}$ \\
in Exjugoslawien geborene exjugoslawische Staatsangehörige & 94.739 & 55,4 \\
Eingebürgerte & 56.811 & 33,2 \\
Zweite Generation & 19.514 & 11,4 \\
Türkei & $\mathbf{7 2 . 4 1 8}$ & $\mathbf{1 0 0 , 0}$ \\
in der Türkei geborene türkische Staatsangehörige & 34.510 & 47,7 \\
Eingebürgerte & 30.867 & 42,6 \\
Zweite Generation & 7.041 & 9,7 \\
\hline
\end{tabular}

Quelle: Abgestimmte Erwerbsstatistik 2009. Eingebürgerte = in Exjugoslawien bzw. der Türkei geborene österreichische Staatsangehörige; Zweite Generation = in Österreich geborene exjugoslawische bzw. türkische Staatsangehörige.

Tabelle 3 weist beträchtliche Unterschiede in der Struktur zwischen den beiden größten (Anteil an allen Wienern mit Migrationshintergrund: 44,3\%) und in Wien am längsten ansässigen Zuwanderergruppen aus dem ehemaligen Jugoslawien und der Türkei nach. Der Anteil der eingebürgerten Personen ist in der türkischen Herkunftsgruppe anteilig um nahezu 10 Prozentpunkte höher als unter den Exjugoslawen. Während die Unterschiede in der Kategorie der Zweiten Generation (hier nur die Untergruppe der Nichteingebürgerten) nur schwach ausgeprägt sind, ist die Präsenz der im Ausland (also im ehemaligen Jugoslawien oder der Türkei) geborenen und nicht Eingebürgerten unter den Exjugoslawen um rund 8\% höher als in der türkischen Herkunftsgruppe. Weiters zeigt sich, dass mit mehr als 171.000 die gesamte Gruppe mit exjugoslawischem Migrationshintergrund in Wien rund zweieinhalbmal größer ist als jene mit tür-

21 Es sei darauf hingewiesen, dass jene, die in einem anderen Land als dem ehemaligen Jugoslawien oder der Türkei geboren wurden, jedoch eine der beiden Staatsbürgerschaften besitzen sowie diejenigen, die zwar in den betreffenden Ländern zur Welt kamen, aber eine andere Staatsbürgerschaft haben, hier keine Berücksichtigung finden konnten. Ihre Zahl ist allerdings sehr gering. Weiters ist eine Aufschlüsselung nach den heutigen Nachfolgestaaten im Falle Jugoslawiens nicht möglich. 
kischem Migrationshintergrund. Der Anteil an Staatsbürgern der jeweiligen Herkunftsländer ist in beiden Gruppen nach wie vor beträchtlich. Da Auswertungen zur Erwerbstätigkeit nur anhand eines Kriteriums (Geburtsland oder Staatsbürgerschaft) durchgeführt werden können, ist die Entscheidung auf das Geburtsland gefallen, da damit gemäß der verwendeten Definition rund $90 \%$ der Personen aus beiden Gruppen analysiert werden können.

Tabelle 4: Bevölkerung nach dem Erwerbsstatus in Österreich und Wien, 2009

\begin{tabular}{lrrrr}
\hline & \multicolumn{2}{c}{ Österreich } & \multicolumn{2}{c}{ Wien } \\
& abs. & in \% & abs. & in \% \\
\hline Bevölkerung insg. & $\mathbf{8 . 3 6 1 . 4 7 5}$ & $\mathbf{1 0 0 , 0}$ & $\mathbf{1 . 6 9 0 . 8 3 7}$ & $\mathbf{1 0 0 , 0}$ \\
Erwerbspersonen insg. & $\mathbf{4 . 2 1 1 . 2 7 7}$ & $\mathbf{5 0 , 4}$ & $\mathbf{8 1 7 . 3 0 1}$ & $\mathbf{4 8 , 3}$ \\
darunter: erwerbstätig & 3.947 .986 & 47,2 & 740.134 & 43,8 \\
arbeitslos & 263.291 & 3,1 & 77.167 & 4,6 \\
Nichterwerbspersonen insg. & $\mathbf{4 . 1 5 0 . 1 9 8}$ & $\mathbf{4 9 , 6}$ & $\mathbf{8 7 3 . 5 3 6}$ & $\mathbf{5 1 , 7}$ \\
darunter: Personen unter 15 Jahren & 1.247 .596 & 14,9 & 241.138 & 14,3 \\
\multicolumn{1}{c}{ Personen mit Pension } & 1.780 .606 & 21,3 & 358.130 & 21,2 \\
Schüler, Studenten & 354.309 & 4,2 & 82.639 & 4,9 \\
sonstige & 767.687 & 9,2 & 191.629 & 11,3 \\
\hline
\end{tabular}

Quelle: Abgestimmte Erwerbsstatistik 2009. Schüler: ohne Personen unter 15 Jahre.

Tabelle 4 bietet einen ersten Überblick über den Erwerbsstatus der Bevölkerung insgesamt für Wien und Österreich im Vergleich. In Wien liegen Zahl und Anteil der Nichterwerbstätigen (51,7\%) über den Werten der im Erwerbsleben Stehenden (48,3\%). Darin manifestiert sich ein Spezifikum der Bundeshauptstadt im bundesweiten Vergleich. Wie in allen großstädtischen Agglomerationen ist der Anteil der Arbeitslosen an der Bevölkerung in Wien mit 4,6\% deutlich höher als auf Bundesebene mit nur $3,1 \%$. Etwa jeder fünfte Österreicher (und auch Wiener) bezog 2009 eine Pension.

Unterzieht man die 740.134 Erwerbstätigen der Bundeshauptstadt einer detaillierteren Analyse, so fällt der mit 9,6\% (im internationalen Vergleich) nicht sehr hohe Selbständigenanteil auf (vgl. Tabelle 5). Mehr als $46 \%$ der Wiener weisen einen Angestelltenstatus auf, nur noch $26 \%$ sind in Arbeiterpositionen tätig, wobei dieser Anteil unter den männlichen Erwerbstätigen mit nahezu einem Drittel wesentlich höher ist als bei den Frauen. Letztere arbeiten viel öfter im Angestelltenstatus als Männer. Für die Fragestellungen unseres Projektes interessiert vor allem die Gruppe der Selbständigen. Von diesen führt das Gros Unternehmen im gewerblichen Sektor, wobei hier die Männer anteilsmäßig ganz klar vor den Frauen liegen. Der Anteil der selbständigen Männer ist auch insgesamt nahezu doppelt so hoch wie bei den Frauen. Das relativ rezente Phänomen der „,neuen Selbständigkeit“ ist bei beiden Geschlechtern in etwa gleichermaßen vorhanden. 
Tabelle 5: Erwerbstätige nach dem Geschlecht und der Stellung im Beruf in Wien, 2009

\begin{tabular}{|c|c|c|c|c|c|c|}
\hline & \multicolumn{2}{|c|}{ insgesamt } & \multicolumn{2}{|c|}{ Männer } & \multicolumn{2}{|c|}{ Frauen } \\
\hline & abs. & in $\%$ & abs. & in $\%$ & abs. & in $\%$ \\
\hline Erwerbstätige insg. & 740.134 & 100,0 & 383.244 & 100,0 & 356.890 & 100,0 \\
\hline Unselbständige insg. & 669.059 & 90,4 & 336.464 & 87,8 & 332.595 & 93,2 \\
\hline Arbeiter & 193.995 & 26,2 & 122.070 & 31,9 & 71.925 & 20,2 \\
\hline Lehrlinge (Arbeiter) & 10.138 & 1,4 & 7.880 & 2,1 & 2.258 & 0,6 \\
\hline Angestellte & 343.157 & 46,4 & 149.294 & 39,0 & 193.863 & 54,3 \\
\hline Lehrlinge (Angestellte) & 6.962 & 0,9 & 2.864 & 0,7 & 4.098 & 1,1 \\
\hline Freie Dienstnehmer & 14.827 & 2,0 & 6.638 & 1,7 & 8.189 & 2,3 \\
\hline Vertragsbedienstete & 36.856 & 5,0 & 12.078 & 3,2 & 24.778 & 6,9 \\
\hline Beamte & 57.336 & 7,7 & 30.875 & 8,1 & 26.461 & 7,4 \\
\hline unbekannt & 1.848 & 0,2 & 842 & 0,2 & 1.006 & 0,3 \\
\hline Grundwehr-, Zivildienst & 3.940 & 0,5 & 3.923 & 1,0 & 17 & 0,0 \\
\hline Selbständige insgesamt ${ }^{1}$ & 71.075 & 9,6 & 46.780 & 12,2 & 24.295 & 6,8 \\
\hline gewerblich & 49.912 & 6,7 & 34.749 & 9,1 & 15.163 & 4,2 \\
\hline freiberuflich & 6.394 & 0,9 & 4.228 & 1,1 & 2.166 & 0,6 \\
\hline Neue Selbständigkeit & 12.944 & 1,7 & 6.928 & 1,8 & 6.016 & 1,7 \\
\hline Betriebsführer Landwirts. & 880 & 0,1 & 517 & 0,1 & 363 & 0,1 \\
\hline mithelfende Familienang. & 945 & 0,1 & 358 & 0,1 & 587 & 0,2 \\
\hline
\end{tabular}

Quelle: Abgestimmte Erwerbsstatistik 2009. Anm. 1: inklusive mithelfende Familienangehörige.

Wie die Tabelle 6 veranschaulicht, ist die Erwerbsbeteiligung unter den Wienern, die im Ausland geboren wurden, um rund 7 Prozentpunkte höher als in der Gruppe ohne Migrationsgeschichte. Unterzieht man das Phänomen der Nichterwerbstätigkeit einer näheren Analyse, so ist diese in den Herkunftsgruppen unterschiedlich stark vertreten. Am höchsten ist der Anteil der Nichterwerbspersonen (Schüler, Studenten, Pensionisten etc.) unter den Österreichern (53,9\%), mit nicht ganz 39\% mit Abstand am niedrigsten bei den Migranten aus dem ehemaligen Jugoslawien und nur geringfügig höher in der türkischen Gruppe mit 42,4\%. Deutlich darüber liegt der Anteil der Nichterwerbspersonen bei den EU-Bürgern, und zwar in beiden Gruppen, den EU-12 sowie den EU14. In summa sind Nichtösterreicher deutlich öfter erwerbstätig als Österreicher.

Von zentralem Interesse für die Fragestellungen dieser Studie ist die Analyse nach dem Kriterium der selbständigen Erwerbstätigkeit (vgl. Tabelle 7). So zeigen sich bereits auf den ersten Blick gravierende Unterschiede hinsichtlich der Präsenz der einzelnen Herkunftsgruppen in der selbständigen Erwerbstätigkeit. Der Selbständigenanteil bei den in einem EU-12-Land Geborenen ist nahezu dreimal so hoch wie bei den im ehemaligen Jugoslawien Geborenen. Letztere bilden das Schlusslicht unter den in diesem Zusammenhang analysierten Gruppen. 
Tabelle 6: Wohnbevölkerung nach dem Erwerbsstatus und dem Geburtsland in Wien, 2009

\begin{tabular}{lrrrrrr}
\hline & \multicolumn{2}{c}{ insg. } & \multicolumn{2}{c}{ Erwerbspersonen } & \multicolumn{2}{c}{$\begin{array}{c}\text { Nicht- } \\
\text { erwerbspersonen } \\
\end{array}$} \\
& abs. & in \% & abs. & in \% & abs. & in \% \\
\hline Österreich & $\mathbf{1 . 1 8 4 . 9 1 0}$ & $\mathbf{1 0 0 , 0}$ & $\mathbf{5 4 5 . 9 7 0}$ & $\mathbf{4 6 , 1}$ & $\mathbf{6 3 8 . 9 4 0}$ & $\mathbf{5 3 , 9}$ \\
Nicht-Österreich insg. & $\mathbf{5 0 5 . 9 2 7}$ & $\mathbf{1 0 0 , 0}$ & $\mathbf{2 7 1 . 3 3 1}$ & $\mathbf{5 3 , 6}$ & $\mathbf{2 3 4 . 5 9 6}$ & $\mathbf{4 6 , 4}$ \\
EU-14 & 60.267 & 100,0 & 30.055 & 49,9 & 30.212 & 50,1 \\
EU-12 & 107.379 & 100,0 & 52.589 & 49,0 & 54.790 & 51,0 \\
Ehem. Jugoslawien & 153.563 & 100,0 & 93.893 & 61,1 & 59.670 & 38,9 \\
Türkei & 65.709 & 100,0 & 37.874 & 57,6 & 27.835 & 42,4 \\
sonstige & 119.009 & 100,0 & 56.920 & 47,8 & 62.089 & 52,2 \\
\hline
\end{tabular}

Quelle: Abgestimmte Erwerbsstatistik 2009. Erwerbspersonen = Erwerbstätige + Arbeitslose.

Zwar sind mit 6,1\% wesentlich mehr in der Türkei geborene Personen als Unternehmer tätig als bei Zuwanderern aus dem ehemaligen Jugoslawien, doch liegt auch die erstgenannte Herkunftsgruppe in Bezug auf die selbständige Erwerbstätigkeit weit hinter den EU-14 und vor allem den in einem EU-12-Staat Geborenen zurück. 95,4\% der im ehemaligen Jugoslawien geborenen Erwerbstätigen sind unselbständig erwerbstätig - der höchste Anteil unter allen analysierten Herkunftsgruppen! Demgegenüber sind sie aber deutlich seltener arbeitslos als etwa in der Türkei Geborene.

Tabelle 7: Erwerbspersonen nach der Stellung im Beruf und dem Geburtsland in Wien, 2009

\begin{tabular}{lrrrrrrrrrr}
\hline & \multicolumn{2}{c}{$\begin{array}{c}\text { insg. } \\
\end{array}$} & abs. & in \% & abselbständige & \multicolumn{2}{c}{ Selbständige } & \multicolumn{2}{c}{ Mithelfende } & \multicolumn{3}{c}{ Arbeitslose $^{1}$} \\
& $\mathbf{5 4 5 . 9 7 0}$ & $\mathbf{1 0 0 , 0}$ & $\mathbf{4 9 3 . 8 3 3}$ & $\mathbf{9 0 , 5}$ & $\mathbf{4 7 . 7 4 9}$ & $\mathbf{8 , 7}$ & $\mathbf{6 3 2}$ & $\mathbf{0 , 1}$ & $\mathbf{3 . 7 5 6}$ & $\mathbf{0 , 7}$ \\
\hline Österreich & $\mathbf{5 4 0}$ & abs. & in \% & abs. & in \% & abs. & in \% \\
Nicht-Öst. & $\mathbf{2 7 1 . 3 3 1}$ & $\mathbf{1 0 0 , 0}$ & $\mathbf{2 4 2 . 1 5 4}$ & $\mathbf{8 9 , 2}$ & $\mathbf{2 4 . 1 5 8}$ & $\mathbf{8 , 9}$ & $\mathbf{3 1 4}$ & $\mathbf{0 , 1}$ & $\mathbf{4 . 7 0 5}$ & $\mathbf{1 , 7}$ \\
EU-14 & 30.055 & 100,0 & 26.212 & 87,2 & 3.637 & 12,1 & 35 & 0,1 & 171 & 0,6 \\
EU-12 & 52.589 & 100,0 & 43.306 & 82,3 & 8.665 & 16,5 & 107 & 0,2 & 511 & 1,0 \\
Ehem. Jugosl. & 93.893 & 100,0 & 89.541 & 95,4 & 3.596 & 3,8 & 48 & 0,1 & 708 & 0,8 \\
Türkei & 37.874 & 100,0 & 34.318 & 90,6 & 2.312 & 6,1 & 36 & 0,1 & 1.208 & 3,2 \\
sonstige & 56.920 & 100,0 & 48.777 & 85,7 & 5.948 & 10,4 & 88 & 0,2 & 2.107 & 3,7 \\
\hline
\end{tabular}

Quelle: Abgestimmte Erwerbsstatistik 2009. 1: arbeitslos - Stellung im Beruf unbekannt oder erstmalig Arbeit suchend.

Unterzieht man nun die Gruppe der Selbständigen einer weiteren Analyse nach räumlichen Kriterien (vgl. Tabelle 8), so lässt sich im Rahmen eines Vergleichs zwischen der Bundeshauptstadt und Gesamtösterreich nachweisen, dass das Unternehmertum von Migranten sehr stark auf Wien konzentriert ist, so wie dies für die Bevölke- 
rung mit Migrationshintergrund insgesamt ja auch gilt. Während nur 13,4\% der österreichischen Unternehmer (Geburtsland) in Wien ansässig sind, sind es bei den EU-12 mehr als die Hälfte $(51,2 \%)$. In den ehemaligen Gastarbeitergruppen belaufen sich die Anteile bei den Exjugoslawen auf mehr als 46\%, bei den in der Türkei Geborenen auf nahezu 44\%. Bereits ein Drittel aller in Wien im Jahr 2009 aktiven Unternehmer und Unternehmerinnen wurde im Ausland geboren (gesamtösterreichischer Anteil 13,1\%).

Tabelle 8: Selbständig Erwerbstätige nach dem Geburtsland in Österreich und Wien, 2009 (ohne mithelfende Familienangehörige)

\begin{tabular}{lrrrrr}
\hline & \multicolumn{2}{c}{ Österreich } & \multicolumn{2}{c}{ Wien } & Wien \\
& abs. & in \% & abs. & in \% & Anteil \\
\hline Österreich & 357.527 & 86,9 & 47.749 & 66,4 & 13,4 \\
Nicht-Österreich & 53.953 & 13,1 & 24.158 & 33,6 & 44,8 \\
insgesamt & $\mathbf{4 1 1 . 4 8 0}$ & $\mathbf{1 0 0 , 0}$ & $\mathbf{7 1 . 9 0 7}$ & $\mathbf{1 0 0 , 0}$ & $\mathbf{1 7 , 5}$ \\
darunter: EU-14 & 13.155 & 3,2 & 3.637 & 5,1 & 27,6 \\
\multicolumn{1}{c}{ EU-12 } & 16.930 & 4,1 & 8.665 & 12,1 & 51,2 \\
\multicolumn{1}{c}{ Ehem. Jugosl. } & 7.736 & 1,9 & 3.596 & 5,0 & 46,5 \\
\multicolumn{1}{c}{ Türkei } & 5.278 & 1,3 & 2.312 & 3,2 & 43,8 \\
sonstige & 10.854 & 2,6 & 5.948 & 8,3 & 54,8 \\
\hline
\end{tabular}

Quelle: Abgestimmte Erwerbsstatistik 2009.

Beide betrachteten Gruppen zusammen stellten im Jahr 2009 insgesamt 13.014 Selbständige in Österreich, davon stammte ein Anteil von 68,4\% aus dem ehemaligen Jugoslawien und nur 31,6\% aus der Türkei. Die Analyse der Verteilung nach Wirtschaftsklassen für Österreich (vgl. Tabelle 9) dokumentiert die ausgeprägte Konzentration türkischer Unternehmer auf nur wenige Branchen, vor allem Gastronomie und Handel, wo 53,3\% aller in der Türkei geborenen Selbständigen tätig sind. Von weiterer Bedeutung ist daneben noch das Verkehrswesen. Die BKS-Gruppe verteilt sich im Vergleich dazu auf eine erheblich größere Brandbreite an Wirtschaftsklassen, wobei Baugewerbe, Handel und Gastronomie nahezu gleichrangig nebeneinander rangieren, weiters sind das Verkehrswesen und darüber hinaus aber auch freiberuflich/technische Dienstleistungen mit $8 \%$ sowie sonstige wirtschaftliche Dienste mit 7,6\% bereits von einiger Relevanz. Das heißt also, dass zwar eine gewisse Branchenkonzentration in beiden ehemaligen „Gastarbeiter"-Herkunftsgruppen nachweisbar ist, diese bei den Exjugoslawen aber deutlich abgeschwächt zutage tritt. Die türkische Herkunftsgruppe hat den „Sprung aus der Nische“ noch in viel geringerem Ausmaß vollzogen, als dies bei den Migranten aus dem ehemaligen Jugoslawien der Fall ist. In anderen europäischen Städten haben türkische Unternehmer den Weg von der Nische ins Zentrum der Wirtschaft bereits viel häufiger geschafft (vgl. Integrationsbeauftragter der Senatsverwaltung von Berlin 2005). 
Tabelle 9: Selbständige Migranten aus dem ehemaligen Jugoslawien und der Türkei (Geburtsland) nach Wirtschaftsklassen in Österreich, 2009

\begin{tabular}{lrrrr}
\hline & \multicolumn{2}{c}{ Ehem. Jugoslawien } & \multicolumn{2}{c}{ Türkei } \\
& abs. & in \% & abs. & in \% \\
\hline insgesamt & $\mathbf{7 . 7 3 6}$ & $\mathbf{1 0 0 , 0}$ & $\mathbf{5 . 2 7 8}$ & $\mathbf{1 0 0 , 0}$ \\
Land- und Forstwirtschaft & 107 & 1,4 & 19 & 0,4 \\
Bergbau & $(1)$ & 0,0 & 0 & 0,0 \\
Herstellung von Waren & 247 & 3,2 & 192 & 3,6 \\
Energieversorgung & 0 & 0,0 & $(2)$ & 0,0 \\
Wasser- und Abfallversorgung & 16 & 0,2 & $(5)$ & 0,1 \\
Bau & 1.431 & 18,5 & 441 & 8,4 \\
Handel & 1.359 & 17,6 & 1.254 & 23,8 \\
Verkehr & 798 & 10,3 & 640 & 12,1 \\
Beherbergung, Gastronomie & 1.378 & 17,8 & 1.555 & 29,5 \\
Information, Kommunikation & 147 & 1,9 & 125 & 2,4 \\
Finanz-, Versicherungsleistungen & 119 & 1,5 & 52 & 1,0 \\
Grundstücks-, Wohnungswesen & 69 & 0,9 & 38 & 0,7 \\
Freiberufliche/Technische Dienstleist. & 616 & 8,0 & 279 & 5,3 \\
Sonst. wirtschaftl. Dienstleistungen & 589 & 7,6 & 197 & 3,7 \\
Öffentliche Verwaltung & $(1)$ & 0,0 & 0 & 0,0 \\
Erziehung, Unterricht & 52 & 0,7 & 31 & 0,6 \\
Gesundheits-, Sozialwesen & 206 & 2,7 & 64 & 1,2 \\
Kunst, Unterhaltung, Erholung & 254 & 3,3 & 72 & 1,4 \\
Sonstige Dienstleistungen & 323 & 4,2 & 309 & 5,9 \\
Private Haushalte & 23 & 0,3 & $(3)$ & 0,1 \\
\hline
\end{tabular}

Quelle: Abgestimmte Erwerbsstatistik 2009. Klammerausdrücke: Swapping (Datenschutz).

Tabelle 10 beinhaltet die Verteilung der Selbständigen nach Wirtschaftsklassen für die Bundeshauptstadt Wien, ebenfalls für das Jahr 2009. Die Kategorie der exjugoslawischen Selbständigen ist hier um rund 1.300 Personen größer als jene der türkischen. Wie auch für Gesamtösterreich feststellbar, ist die Konzentrationstendenz bei den Exjugoslawen deutlich schwächer als in der Gruppe mit türkischem Migrationshintergrund. Der höchste Anteil der BKS-Unternehmer entfällt auf den Handel, danach folgen mit geringem Abstand und ex aequo die Gastronomie und das Bauwesen. Stärker repräsentiert sind weiters das Verkehrswesen sowie die freiberuflich/technischen Dienste. Von nennenswerter Bedeutung sind darüber hinaus die sonstigen wirtschaftlichen Dienstleistungen. In den weiteren Wirtschaftsklassen finden sich jeweils 
nur sehr geringe Anteile von BKS-Unternehmern. In der türkischen Herkunftsgruppe fällt die Konzentration auch in Wien beträchtlich stärker aus. Fast die Hälfte der türkischstämmigen Unternehmer ist in Handel oder Gastronomie aktiv. Von den weiteren Wirtschaftsklassen erreicht dann bloß noch das Verkehrswesen einen Wert von über 14\%, die anderen Branchen sind durch sehr geringe Anteilswerte gekennzeichnet.

Tabelle 10: Selbständige Migranten aus dem ehemaligen Jugoslawien und der Türkei (Geburtsland) nach Wirtschaftsklassen in Wien, 2009

\begin{tabular}{lrrrr}
\hline & \multicolumn{2}{c}{ Ehem. Jugoslawien } & \multicolumn{2}{c}{ Türkei } \\
& abs. & in $\%$ & abs. & in \% \\
\hline insgesamt & $\mathbf{3 . 5 9 6}$ & $\mathbf{1 0 0 , 0}$ & $\mathbf{2 . 3 1 2}$ & $\mathbf{1 0 0 , 0}$ \\
Land- und Forstwirtschaft & $(3)$ & 0,1 & $(3)$ & 0,1 \\
Bergbau & $(1)$ & 0,0 & 0 & 0,0 \\
Herstellung von Waren & 110 & 3,1 & 83 & 3,6 \\
Energieversorgung & 0 & 0,0 & 0 & 0,0 \\
Wasser- und Abfallversorgung & $(5)$ & 0,1 & $(2)$ & 0,1 \\
Bau & 556 & 15,5 & 159 & 6,9 \\
Handel & 619 & 17,2 & 631 & 27,3 \\
Verkehr & 437 & 12,2 & 331 & 14,3 \\
Beherbergung, Gastronomie & 558 & 15,5 & 491 & 21,2 \\
Information, Kommunikation & 93 & 2,6 & 80 & 3,5 \\
Finanz-, Versicherungsleistungen & 53 & 1,5 & 17 & 0,7 \\
Grundstücks-, Wohnungswesen & 45 & 1,3 & 15 & 0,6 \\
Freiberufliche/Technische Dienstleist. & 348 & 9,7 & 161 & 7,0 \\
Sonst. wirtschaftl. Dienstleistungen & 313 & 8,7 & 84 & 3,6 \\
Öffentliche Verwaltung & $(1)$ & 0,0 & 0 & 0,0 \\
Erziehung, Unterricht & 24 & 0,7 & 12 & 0,5 \\
Gesundheits-, Sozialwesen & 98 & 2,7 & 29 & 1,3 \\
Kunst, Unterhaltung, Erholung & 141 & 3,9 & 31 & 1,3 \\
Sonstige Dienstleistungen & 176 & 4,9 & 182 & 7,9 \\
Private Haushalte & 15 & 0,4 & $(1)$ & 0,0 \\
\hline
\end{tabular}

Quelle: Abgestimmte Erwerbsstatistik 2009. Klammerausdrücke: Swapping (Datenschutz).

Zum Abschluss vermag Tabelle 11 noch eine Antwort auf die Frage zu geben, welche Rolle die Einbürgerung als Einflussfaktor auf die Neigung zum Unternehmertum spielt. Von einer Interpretation der Zahlen für die zweite Generation, die sehr gering ausfallen, wird aufgrund der sehr engen Definition abgesehen, da Personen, die eingebürgert wurden, aber der zweiten Generation angehören, statistisch nicht erfasst 
werden können. Die Statistik spiegelt also die in den Interviews mehrfach angesprochene stärkere Präsenz der zweiten Generation in der selbständigen Erwerbstätigkeit für die beiden analysierten Herkunftsgruppen nicht wider.

Tabelle 11: Selbständige Migranten aus dem ehemaligen Jugoslawien und der Türkei nach dem Migrationshintergrund in Wien, 2009

\begin{tabular}{lrr}
\hline & abs. & in \% \\
\hline Ehemaliges Jugoslawien & $\mathbf{3 . 6 7 9}$ & $\mathbf{1 0 0 , 0}$ \\
in Exjugoslawien geborene exjugoslawische Staatsangehörige & 1.797 & 48,8 \\
Eingebürgerte & 1.737 & 47,2 \\
Zweite Generation & 145 & 3,9 \\
Türkei & $\mathbf{2 . 3 4 1}$ & $\mathbf{1 0 0 , 0}$ \\
in der Türkei geborene türkische Staatsangehörige & 772 & 33,0 \\
Eingebürgerte & 1.522 & 65,0 \\
Zweite Generation & 47 & 2,0 \\
\hline
\end{tabular}

Quelle: Abgestimmte Erwerbsstatistik 2009. Eingebürgerte = in Exjugoslawien bzw. der Türkei geborene österreichische Staatsangehörige.

Die Tabelle dokumentiert die interne Struktur der Unternehmer mit Migrationshintergrund aus beiden Herkunftsgebieten. Hierbei zeigen sich erhebliche Unterschiede, da der Anteil der eingebürgerten Exjugoslawen mit 47,2\% bereits nahezu gleich hoch ist wie jener der BKS-Staatsbürger. Deutlich wird allerdings die schwächere Neigung der eingebürgerten Exjugoslawen zur Aufnahme einer unternehmerischen Tätigkeit im Vergleich zu den Türken. Von den Selbständigen mit türkischem Migrationshintergrund verfügen bereits fast zwei Drittel über die österreichische Staatsbürgerschaft, nur ein Drittel weist die türkische Staatsangehörigkeit auf.

Die Einbürgerung dürfte also als Stimulans zur Aufnahme einer Unternehmertätigkeit in der Gruppe mit türkischem Migrationshintergrund eine viel wichtigere Rolle spielen als bei den BKS-Immigranten. Da Aufenthaltsdauer und Einbürgerungswahrscheinlichkeit in einer Relation zueinander stehen, handelt es sich bei einem Großteil der türkischen Unternehmer wohl um bereits länger in Österreich ansässige Immigranten.

\subsection{Kartographische Erhebungen und vergleichende Strukturanalysen zweier Wiener Einkaufsstraßen}

Zusätzlich zur Datenanalyse haben wir auch eine räumliche Erhebung und Analyse vorgenommen. Die Auswahl erfolgte einerseits nach soziodemographischen Kriterien, z.B. Anteilen ausländischer Staatsbürger und Bevölkerung mit Migrationshintergrund auf Bezirks- und Zählbezirksebene, andererseits waren wir vor allem auch am Status 
quo der Migrant Economy in weniger häufig frequentierten Geschäftsstraßen und in stärker durch Immigration gekennzeichneten Wiener Bezirken interessiert. Daher fiel unsere Wahl nicht auf eine der großen Einkaufsstraßen, wie Mariahilfer Straße, Favoritenstraße etc., sondern auf:

- die Taborstraße (von Schwedenbrücke bis Am Tabor) und

- die Klosterneuburger Straße (von Gaußplatz bis Wexstraße).

Karte 1: Erhebungsgebiete Taborstraße und Klosterneuburger Straße

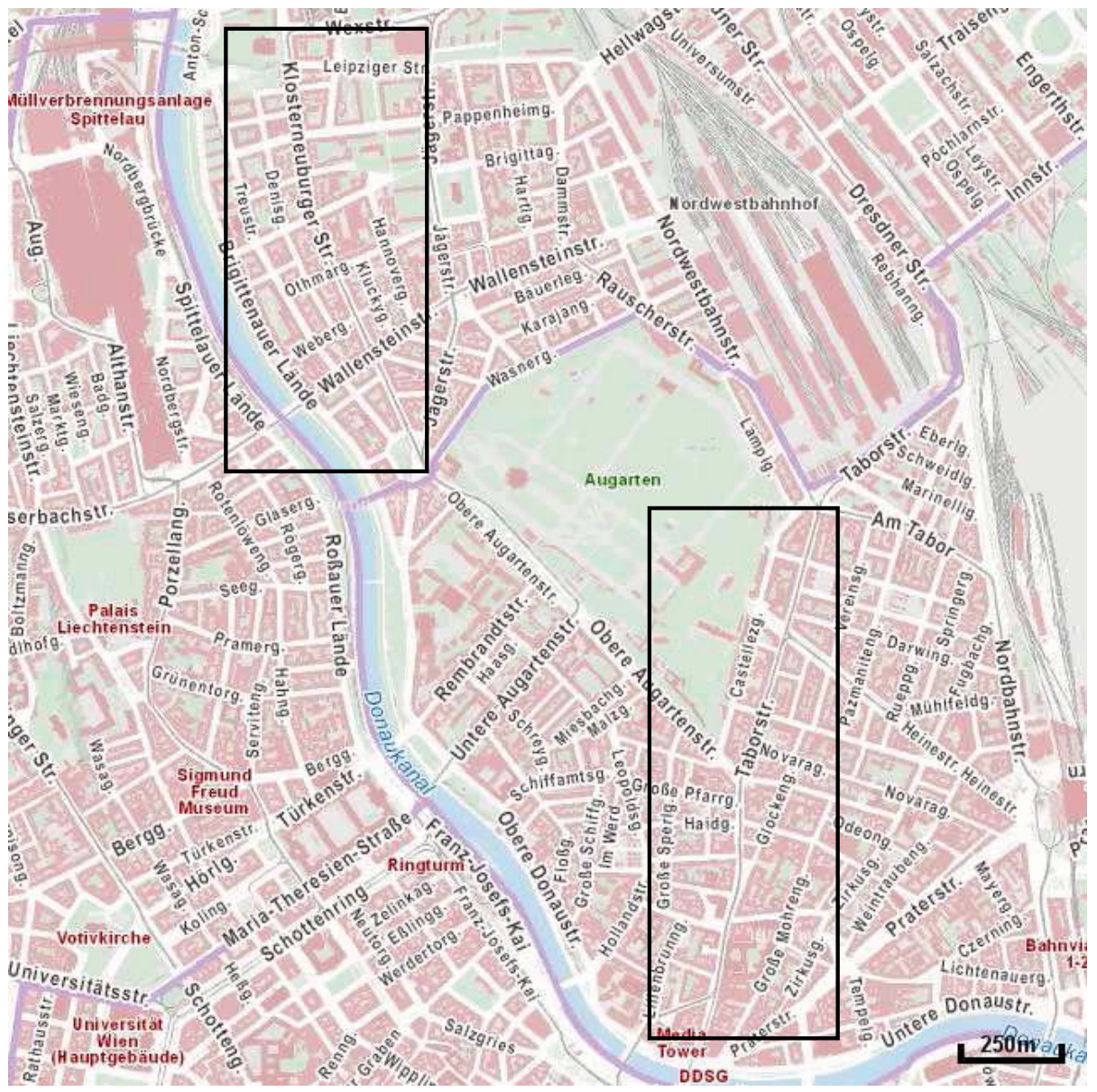

Quelle: Stadt Wien - ViennaGIS http://www.wien.gv.at/viennagis.

In die systematische Erhebung und Analyse konnten aus Gründen der Zugänglichkeit ausschließlich Geschäftslokale im Erdgeschoss einbezogen werden. 
Abbildung 2: Geschäftsimpressionen aus der Taborstraße
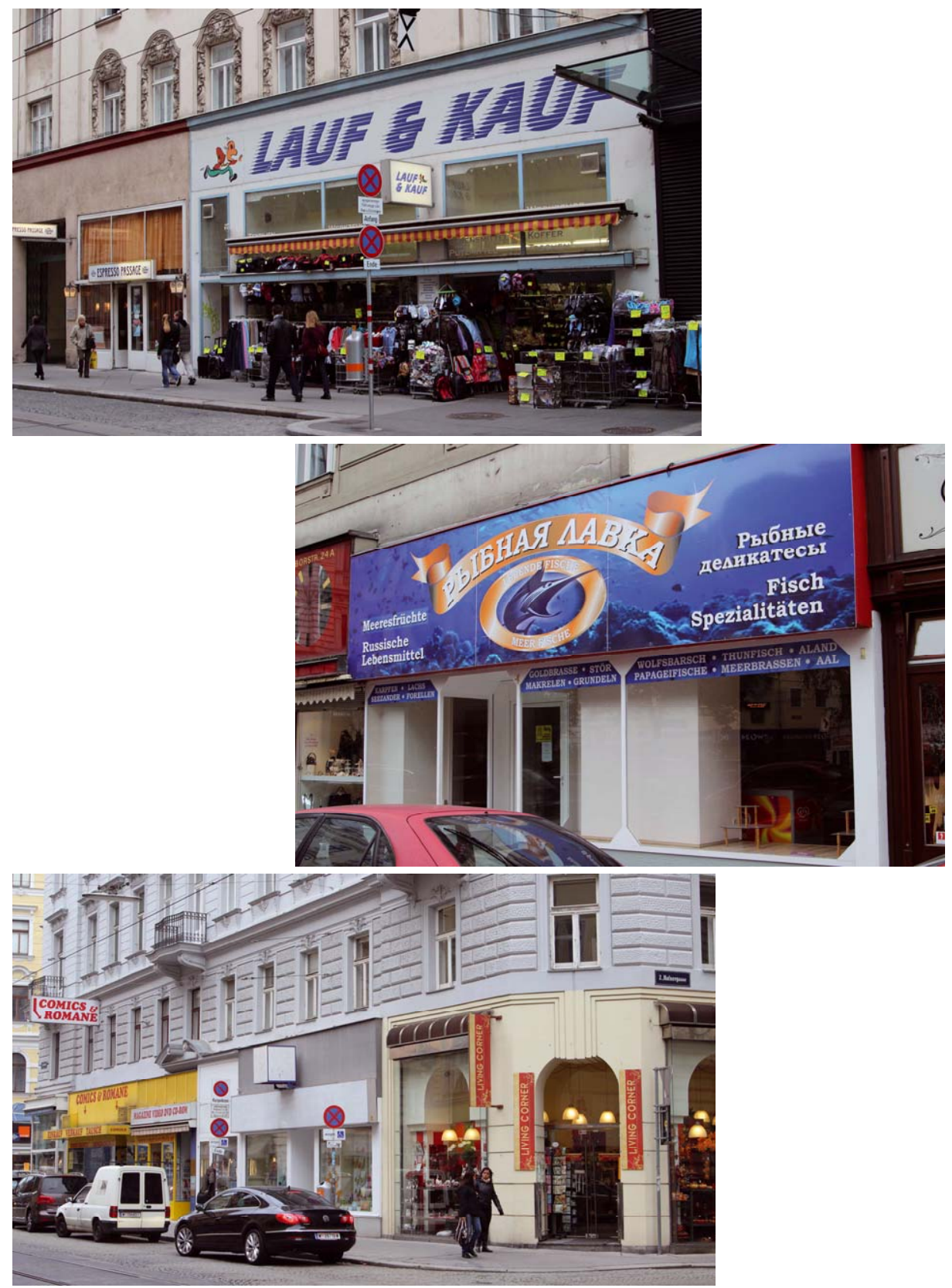

Quelle: Andreas Hasibeder 2012. 
Abbildung 3: Geschäftsimpressionen aus der Klosterneuburger Straße
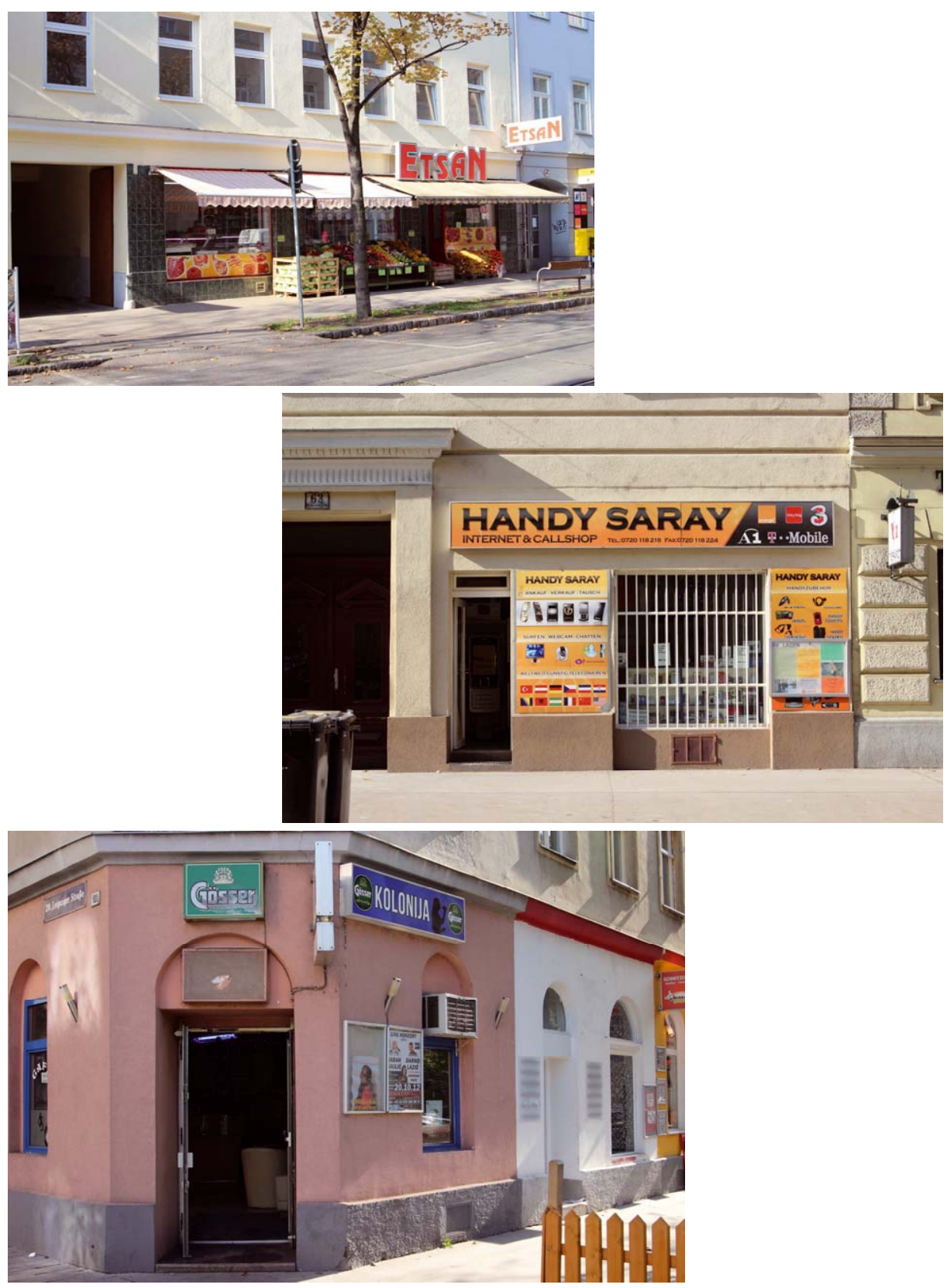

Quelle: Andreas Hasibeder 2012. 
Die rund 2,5 km lange Taborstraße $\mathrm{e}^{22}$ liegt im 2. Wiener Gemeindebezirk, der Leopoldstadt, und nimmt in direkter Nachbarschaft zum 1. Bezirk, von dem sie nur durch den Donaukanal getrennt ist, ihren Anfang am Schwedenplatz, von wo sie aus nach Norden verläuft. Viele der Unternehmen auf der Taborstraße, dem Karmelitermarkt und in der Umgebung haben sich zu einem Verein zusammengeschlossen, um die Menschen, die hier wohnen, auf sich aufmerksam zu machen. Aus diesem Grund veranstalten engagierte Unternehmer mit und ohne Migrationshintergrund hier Feste und bieten Aktionen. Die Geschäftsinfrastruktur ist sehr gemischt und umfasst alteingesessene Fachgeschäfte wie auch Billigshops der verschiedensten Branchen.

Die Klosterneuburger Straße erstreckt sich im 20. Bezirk, der durch starke Zuwanderung geprägten Brigittenau, vom Gaußplatz und verläuft weitgehend parallel zum Donaukanal. Der lokalen Bevölkerungsstruktur entsprechend haben sich hier zahlreiche Unternehmen der Migrant Economy, vor allem im tiefpreisigen Segment, angesiedelt.

Wie Tabelle 12 belegt, ist in der stärker frequentierten und zentrumsnäheren Taborstraße mit 5,7\% der Anteil leer stehender Geschäftslokale signifikant niedriger als in der Klosterneuburger Straße (18,8\%). Die folgenden Analysen basieren auf 183 Geschäftslokalen in der Taborstraße und auf 108 in der Klosterneuburger Straße. Leerstehungen wurden also nicht weiter berücksichtigt.

Tabelle 12: Leerstände - Vergleich Taborstraße und Klosterneuburger Straße, 2012

\begin{tabular}{lrrrr}
\hline & \multicolumn{2}{c}{ Taborstraße } & \multicolumn{2}{c}{ Klosterneuburger Straße } \\
& abs. & in $\%$ & abs. & in \% \\
\hline in Betrieb & 183 & 94,3 & 108 & 81,2 \\
Leerstand & 11 & 5,7 & 25 & 18,8 \\
insgesamt & 194 & 100,0 & 133 & 100,0 \\
\hline
\end{tabular}

Quelle: eigene Erhebung 2012.

Tabelle 13 dokumentiert den Unterschied in der Präsenz der Migrant Economy in beiden Straßen. Während in der Brigittenau bereits fast 54\% der Geschäfte der Migrantenökonomie hinzuzurechnen sind, liegt deren Anteil in der „besseren“ Taborstraße bei nur etwas über $36 \%$. Interessant sind auch die Divergenzen hinsichtlich der Herkunft der Unternehmer (soweit eindeutig feststellbar). Selbständige mit BKS- oder türkischem Migrationshintergrund bilden in beiden Straßen nur eine Minderheit, allerdings ist die Präsenz der Erstgenannten in der Klosterneuburger Straße mit 10,2\% fast viermal so hoch wie in der Leopoldstadt. Türkische Geschäfte sind in beiden Straßen häufiger anzutreffen als exjugoslawische. Ihr Anteil ist im 20. Bezirk erheblich, um mehr als vier Prozentpunkte, höher als im zweiten Bezirk.

22 Vgl. http://www.taborstrasse.at/. 
Tabelle 13: Migrationshintergrund der Geschäftsinhaber - Vergleich Taborstraße und Klosterneuburger Straße, 2012

\begin{tabular}{lrrrr} 
& \multicolumn{2}{c}{ Taborstraße } & \multicolumn{2}{c}{ Klosterneuburger Straße } \\
& abs. & in $\%$ & abs. & in \% \\
\hline Exjugoslawien & 5 & 2,7 & 11 & 10,2 \\
Türkei & 16 & 8,7 & 14 & 13,0 \\
anderes Land & 45 & 24,6 & 33 & 30,6 \\
Österreich & 117 & 63,9 & 50 & 46,3 \\
insgesamt & 183 & 100,0 & 108 & 100,0 \\
\hline
\end{tabular}

Quelle: eigene Erhebung 2012.

Beträchtliche Unterschiede zwischen den beiden Einkaufsstraßen manifestieren sich hinsichtlich der Präsenz unterschiedlicher Branchen. Die Konzentrationstendenz auf einige wenige stark überrepräsentierte Branchen ist in der Klosterneuburger Straße wesentlich stärker ausgeprägt als in der Leopoldstadt. So ist nahezu ein Drittel der in der Brigittenauer Geschäftsstraße ansässigen Unternehmen der Gastronomie zuzurechnen, fast 16\% gehören zum Sektor der Körperpflege/Reinigung und jeweils 13\% zum Lebensmittelhandel sowie der Kommunikationsbranche (in erster Linie Handyshops). Äußerst schwach vertreten sind der Finanzsektor sowie die Branche „Freizeit“". Kontrastierend dazu führt in der Taborstraße die Bekleidungsbranche mit mehr als $22 \%$, während die Gastronomie hier nur einen Anteil von über $17 \%$ repräsentiert. Stark vertreten sind in der traditionsreichen Leopoldstädter Einkaufsstraße auch die Branchen Köperpflege/Reinigung, Freizeit und der Lebensmitteleinzelhandel.

Tabelle 14: Branchenverteilung - Vergleich Taborstraße und Klosterneuburger Straße, 2012

\begin{tabular}{lrrrr}
\hline & \multicolumn{2}{c}{ Taborstraße } & \multicolumn{3}{c}{ Klosterneuburger Straße } \\
& abs. & in \% & abs. & in \% \\
\hline Einzelhandel Nahrungs-, Genussmittel & 20 & 10,9 & 14 & 13,0 \\
Gastronomie & 32 & 17,5 & 33 & 30,6 \\
Information, Kommunikation & 9 & 4,9 & 14 & 13,0 \\
Körperpflege, Heilbedarf, Reinigung & 27 & 14,8 & 17 & 15,7 \\
Wohnen & 16 & 8,7 & 9 & 8,3 \\
Finanz-, Versicherungswesen & 9 & 4,9 & 4 & 3,7 \\
Bekleidung, Accessoires & 41 & 22,4 & 10 & 9,3 \\
Freizeit, künstlerischer Bedarf & 22 & 12,0 & 3 & 2,8 \\
sonstiges & 7 & 3,8 & 4 & 3,7 \\
insgesamt & 183 & 100,0 & 108 & 100,0 \\
\hline
\end{tabular}

Quelle: eigene Erhebung 2012. 
Tabelle 15: Einzel- und Filialunternehmen - Vergleich Taborstraße und Klosterneuburger Straße, 2012

\begin{tabular}{lrrrr}
\hline & \multicolumn{2}{c}{ Taborstraße } & \multicolumn{2}{c}{ Klosterneuburger Straße } \\
& abs. & in $\%$ & abs. & in \% \\
\hline Filialunternehmen & 55 & 30,1 & 21 & 19,4 \\
Einzelunternehmen & 128 & 69,9 & 87 & 80,6 \\
insgesamt & 183 & 100,0 & 108 & 100,0 \\
\hline
\end{tabular}

Quelle: eigene Erhebung 2012.

In beiden Erhebungsgebieten dominieren die Einzelunternehmen (vgl. Tabelle 15). Der Anteil der Filialen ist in der Taborstraße um rund 10 Prozentpunkte höher als in der Brigittenau. Welche Unterschiede bestehen nun hinsichtlich der Branchenverteilung zwischen den inländischen und den migrantischen Geschäften?

Tabelle 16: Branchenverteilung nach der Herkunft in der Taborstraße, 2012

\begin{tabular}{|c|c|c|c|c|c|}
\hline & $\begin{array}{r}\text { Exjugo- } \\
\text { slawien } \\
\text { in \% }\end{array}$ & $\begin{array}{l}\text { Türkei } \\
\text { in \% }\end{array}$ & $\begin{array}{r}\text { anderes } \\
\text { Land } \\
\text { in \% }\end{array}$ & $\begin{array}{r}\text { Migran- } \\
\text { ten insg. } \\
\text { in } \%\end{array}$ & $\begin{array}{l}\text { Öster- } \\
\text { reich } \\
\text { in \% }\end{array}$ \\
\hline Einzelhandel Nahrungs-, Genussmittel & 20,0 & 12,5 & 4,4 & 7,6 & 12,8 \\
\hline Gastronomie & 40,0 & 25,0 & 20,0 & 22,7 & 14,5 \\
\hline Information, Kommunikation & 0,0 & 6,2 & 13,3 & 10,6 & 1,7 \\
\hline Körperpflege, Heilbedarf, Reinigung & 0,0 & 6,2 & 6,7 & 6,1 & 19,7 \\
\hline Wohnen & 20,0 & 0,0 & 6,7 & 6,1 & 10,0 \\
\hline Finanz-, Versicherungswesen & 0,0 & 0,0 & 0,0 & 0,0 & 7,7 \\
\hline Bekleidung, Accessoires & 20,0 & 43,8 & 40,0 & 39,4 & 12,8 \\
\hline Freizeit, künstlerischer Bedarf & 0,0 & 6,2 & 8,9 & 7,6 & 14,5 \\
\hline sonstiges & 0,0 & 0,0 & 0,0 & 0,0 & 6,0 \\
\hline insgesamt absolut & 5 & 16 & 45 & 66 & 117 \\
\hline in $\%$ & 100,0 & 100,0 & 100,0 & 100,0 & 100,0 \\
\hline
\end{tabular}

Quelle: eigene Erhebung 2012.

Die Migrant Economy der Taborstraße (vgl. Tabelle 16) weist ein deutliches Schwergewicht (rund 40\%) im Bekleidungssektor auf. Danach folgt mit deutlichem Abstand das Gastgewerbe, dem 22,7\% der Geschäfte der lokalen Migrantenökonomie zuzurechnen sind. Bei den von Inländern geführten Geschäften handelt es sich zu rund einem Fünftel um solche der Körperpflege/Reinigung. Mit einem Wert von 14,5\% ex aequo an zweiter Stelle liegen die Gastronomie sowie der Freizeitsektor. Mit geringem Abstand folgen dann die Bekleidungsbranche und der Lebensmittelhandel. Die Bran- 
chenkonzentration in der Taborstraße ist also bei den Geschäften der Migrant Economy viel stärker ausgeprägt, die Branchenvielfalt im inländischen Segment höher. Wird innerhalb der Migrant Economy noch nach der Herkunft der Entrepreneurs unterschieden, so verdeutlichen sich offensichtliche Unterschiede zwischen der Branchenkonzentration türkischer versus BKS-Entrepreneurs. Die wenigen in der Taborstraße ansässigen BKS-Unternehmer verteilen sich auf zahlreichere Branchen. Im Falle der Unternehmer mit türkischem Migrationshintergrund tritt die Branchenkonzentration viel stärker zutage: Nahezu 44\% sind im Bereich Bekleidung tätig, ein Viertel führt gastronomische Betriebe. Ergebnisse, welche die Analysen der Abgestimmten Erwerbsstatistik auch auf der kleinräumigen Ebene von Einkaufsstraßen bestätigen.

Tabelle 17: Branchenverteilung nach der Herkunft in der Klosterneuburger Straße, 2012

\begin{tabular}{|c|c|c|c|c|c|}
\hline & $\begin{array}{r}\text { Exjugo- } \\
\text { slawien } \\
\text { in \% } \\
\end{array}$ & $\begin{array}{l}\text { Türkei } \\
\text { in \% } \\
\end{array}$ & $\begin{array}{r}\text { anderes } \\
\text { Land } \\
\text { in \% } \\
\end{array}$ & $\begin{array}{l}\text { Migran- } \\
\text { ten insg. } \\
\text { in } \% \\
\end{array}$ & $\begin{array}{r}\text { Öster- } \\
\text { reich } \\
\text { in \% }\end{array}$ \\
\hline Einzelhandel Nahrungs-, Genussmittel & 0,0 & 21,4 & 3,0 & 6,9 & 20,0 \\
\hline Gastronomie & 72,7 & 14,3 & 36,4 & 37,9 & 22,0 \\
\hline Information, Kommunikation & 9,1 & 21,4 & 30,3 & 24,1 & 0,0 \\
\hline Körperpflege, Heilbedarf, Reinigung & 0,0 & 14,3 & 12,1 & 10,3 & 22,0 \\
\hline Wohnen & 0,0 & 14,3 & 3,0 & 5,2 & 12,0 \\
\hline Finanz-, Versicherungswesen & 0,0 & 0,0 & 0,0 & 0,0 & 8,0 \\
\hline Bekleidung, Accessoires & 0,0 & 14,3 & 12,1 & 10,3 & 8,0 \\
\hline Freizeit, künstlerischer Bedarf & 0,0 & 0,0 & 3,0 & 1,7 & 4,0 \\
\hline sonstiges & 18,2 & 0,0 & 0,0 & 3,4 & 4,0 \\
\hline insgesamt absolut & 11 & 14 & 33 & 58 & 50 \\
\hline in $\%$ & 100,0 & 100,0 & 100,0 & 100,0 & 100,0 \\
\hline
\end{tabular}

Quelle: eigene Erhebung 2012.

Im Vergleich ist die branchenmäßige Konzentration in der Klosterneuburger Straße (vgl. Tabelle 17) sowohl bei inländischen als auch bei Geschäften von Migranten deutlicher ausgeprägt als in der innenstadtnahen Taborstraße. Darüber hinaus ist auch im 20. Bezirk eine viel stärkere Branchenkonzentration im Segment der Migrant Economy als bei inländischen Geschäften festzustellen. So konzentrieren sich nahezu 38\% der Unternehmen der hier ansässigen Migrant Entrepreneurs auf die Gastronomie, fast ein Viertel auf den Kommunikationssektor. Mit jeweils rund 10\% sind Bekleidung sowie Körperpflege in einem noch nennenswerten Maß repräsentiert. Auf die anderen Branchen entfallen nur sehr geringe Werte. Die Geschäfte inländischer Unternehmer gehören zu je 22\% in die Kategorien Gastgewerbe sowie Körperpflege, ein Fünftel zum Lebensmitteleinzelhandel. Wohnen, das Finanzwesen sowie die Bekleidungs- 
branche sind ebenfalls mit nennenswerten Anteilen repräsentiert. In der Klosterneuburger Straße ist im Vergleich zur Taborstraße vor allem die Zahl der BKS-Unternehmen deutlich höher und als weiteres bemerkenswertes Faktum die Konzentration auf das Gastgewerbe mit fast $73 \%$ besonders hoch. Türkische Selbständige sind hier in erster Linie im Einzelhandel sowie in der Kommunikationsbranche aktiv, die Konzentration ist aber schwächer als bei den lokal unternehmerisch tätigen Exjugoslawen sowie bei den türkischen Unternehmen in der Taborstraße. Zu jeweils gleichen Anteilen sind türkische Entrepreneurs auch in Gastronomie, Reinigung, Wohnen und Bekleidung aktiv.

Analysiert man die Geschäftsstruktur der Taborstraße nach dem Kriterium der Herkunft der Ladeninhaber, so fällt im südlichen Abschnitt (vgl. Karte 2) zunächst eine insgesamt relativ geringe Präsenz der Migrant Economy, verglichen mit Geschäften österreichischer Inhaber, auf. Das Analoge gilt vor allem für die stadtauswärts betrachtet rechte Straßenseite. Die wenigen rechtsseitig lokalisierten Läden von Migranten befinden sich kaum in türkischem oder BKS-Besitz, sondern gehören Zuwanderern diversen migrantischen Hintergrunds. Auf der linken Straßenseite ist die Zahl der Geschäfte von Immigranten insgesamt deutlich höher, wobei sich deren Präsenz aber erst ab der Negerlegasse stadtauswärts zu verdichten beginnt. Die drei Geschäfte von BKS-Migranten sind zwischen Karmelitergasse und Rotensterngasse situiert, die türkischen Unternehmen finden sich im innenstadtnäheren Abschnitt der Taborstraße, zwischen Negerlegasse und Karmelitergasse, hier ist auch eine größere Zahl von Geschäften von Zuwanderern anderer Herkunft ansässig. Zwischen Tandelmarktgasse und Blumauergasse dünnt die Zahl ethnischer Geschäfte dann wieder aus. Im Nordteil der Taborstraße, d.h. nördlich der gleichnamigen U-Bahnstation, sind Geschäftslokale von BKS-Entrepreneurs nur sehr verstreut und in äußerst geringer Zahl vorzufinden (vgl. Karte 3). Häufiger sind Geschäfte von türkischen Unternehmern (insgesamt 10), von denen sich das Gros zwischen der U-Bahnstation und der Konradgasse akkumuliert. In summa ist hier die Migrant Economy viel präsenter und konzentrierter als im Südteil der Taborstraße. Ab der Kreuzung Klanggasse/Heinestraße und bis Am Tabor werden die Geschäfte von Migranten wieder deutlich seltener und dünnt die Geschäftsinfrastruktur in summa beträchtlich aus.

Wie die Karte 4 dokumentiert, verteilt sich die Migrant Economy über die gesamte Länge der Klosterneuburger Straße. Der südlichste Abschnitt vom Gaußplatz bis zur Staudingergasse wird weitgehend von Unternehmen von Migranten dominiert, österreichische Geschäfte sind hier nur in geringer Zahl vorhanden. Es regiert ein Gemisch von Läden mit Eigentümern unterschiedlichster Herkunft. Zwischen Wallensteinstraße und Othmarstraße ist eine größere Zahl türkischer Läden ansässig, zudem Geschäfte von Betreibern unterschiedlichsten ethnischen Hintergrunds, aber nur sehr vereinzelt solche von Exjugoslawen. Zwischen Webergasse und Gerhardusgasse findet sich auch eine größere Zahl an Geschäftsinhabern ohne Migrationshintergrund und eingestreut solche der Migrant Economy. Deren Läden verteilen sich entlang des gesamten Südabschnitts dieser Straße und auf beiden Straßenseiten. 
Das Dichtemuster von Geschäften der Migrantenökonomie reicht etwa bis in die Höhe der Romanogasse (vgl. Karte 5), danach beginnt die Zahl der Geschäfte erheblich auszudünnen. Die wenigen türkischen Läden sind vor allem auf der - stadtauswärts gesehen - linken Seite der Klosterneuburger Straße lokalisiert. Eine Akkumulation von Geschäften der Migrant Economy befindet sich unmittelbar an den AntonKummerer-Park angelagert und auch auf der gegenüberliegenden Straßenseite. Hier finden sich drei eindeutig als türkische Geschäfte identifizierbare Unternehmen, ein exjugoslawisches sowie drei weitere Läden der Migrantenökonomie. Weiter stadtauswärts, zwischen Leipziger Straße und Wexstraße, konnte nur mehr ein Geschäft eindeutig einem Migrant Entrepreneur zugeordnet werden. Hier, in der Höhe des Hallenbades Brigittenau, dünnt die Geschäftsinfrastruktur insgesamt stark aus.

Unterzieht man die Branchenstruktur der Taborstraße einer kartographischen Analyse (vgl. Karten 6 und 7), so fällt auf, dass bis etwa in Höhe der Einmündung der Karmelitergasse eine Konzentration von Läden der Migrant Economy der Branchenzugehörigkeit „Bekleidung/Accessoires“ festzustellen ist. Die im Südabschnitt der Taborstraße dominierende Ökonomie von Nichtmigranten weist eine viel heterogenere Branchenverteilung auf, ist aber am häufigsten der Wirtschaftsabteilung „Körperpflege/Reinigung“ hinzuzurechnen. Etwa ab Höhe der Karmelitergasse stadtauswärts steigt die Zahl der gastronomischen Betriebe, vor allem von Selbständigen mit Migrationshintergrund. Dazu kommen auch einige Bekleidungsgeschäfte. Insgesamt ist aber die Branchenstruktur der Migrant Economy äußerst homogen und somit beträchtlich weniger vielfältig als bei den Läden, die Besitzer ohne Migrationshintergrund aufweisen. Das Dichtemuster an Geschäften setzt sich auch nördlich der U-Bahnstation und zu beiden Seiten der Taborstraße weiter fort. Abermals ist die Konzentration der Läden auf die Sektoren Bekleidung/Accessoires sowie die Gastronomie offensichtlich. Nach der Kreuzung Klanggasse/Heinestraße beginnt die Geschäftsinfrastruktur, sowohl jene der Ethnic Entrepreneurs als auch insgesamt, erheblich auszudünnen (vgl. Karte 7). Von hier bis Am Tabor finden sich aber einige typische Einzelhandelsgeschäfte von Migranten mit Nahrungs- und Genussmitteln sowie Läden der Kategorie „Körperpflege/Reinigung“".

Die Karten 8 und 9 spiegeln in ihrem Verteilungsbild die gänzlich andere Branchenstruktur der Klosterneuburger Straße im Gegensatz zur höherwertigen Geschäftsstraße Taborstraße wider. Die auf beiden Seiten der Klosterneuburger Straße dicht angesiedelte Migrant Economy setzt sich vom Gaußplatz bis etwa in Höhe der Othmargasse vor allem aus gastronomischen Unternehmen sowie Geschäften der Branche „Information/Kommunikation“ zusammen. Die hier ansässigen Unternehmer mit Migrationshintergrund gehören in erster Linie der Kategorie „Einzelhandel mit Lebensund Genussmitteln“ sowie „Körperpflege/Reinigung“ an. Geschäfte von Migranten mit höherwertigem Sortiment sind nur ganz vereinzelt zu finden. Zwischen Othmargasse und Gerhardusgasse finden sich einige Vertreter der Branchen „Körperpflege/Reinigung“ sowie „Bekleidung/Accessoires“, wobei ein Teil der Eigentümer Migrationshintergrund aufweist. 
Karte 2: Geschäfte im südlichen Teil der Taborstraße nach der Herkunft der Unternehmer, 2012

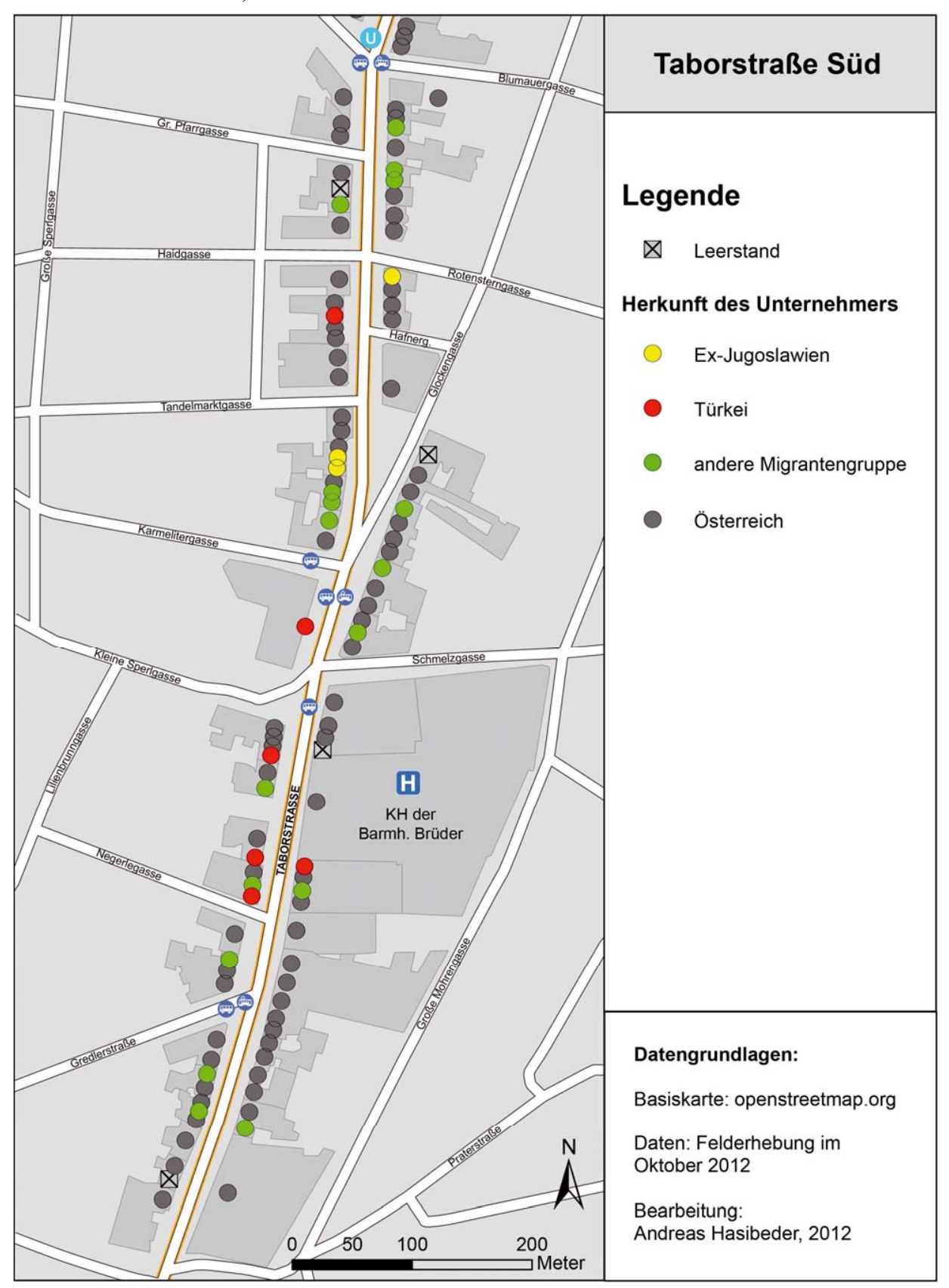


Karte 3: Geschäfte im nördlichen Teil der Taborstraße nach der Herkunft der Unternehmer, 2012

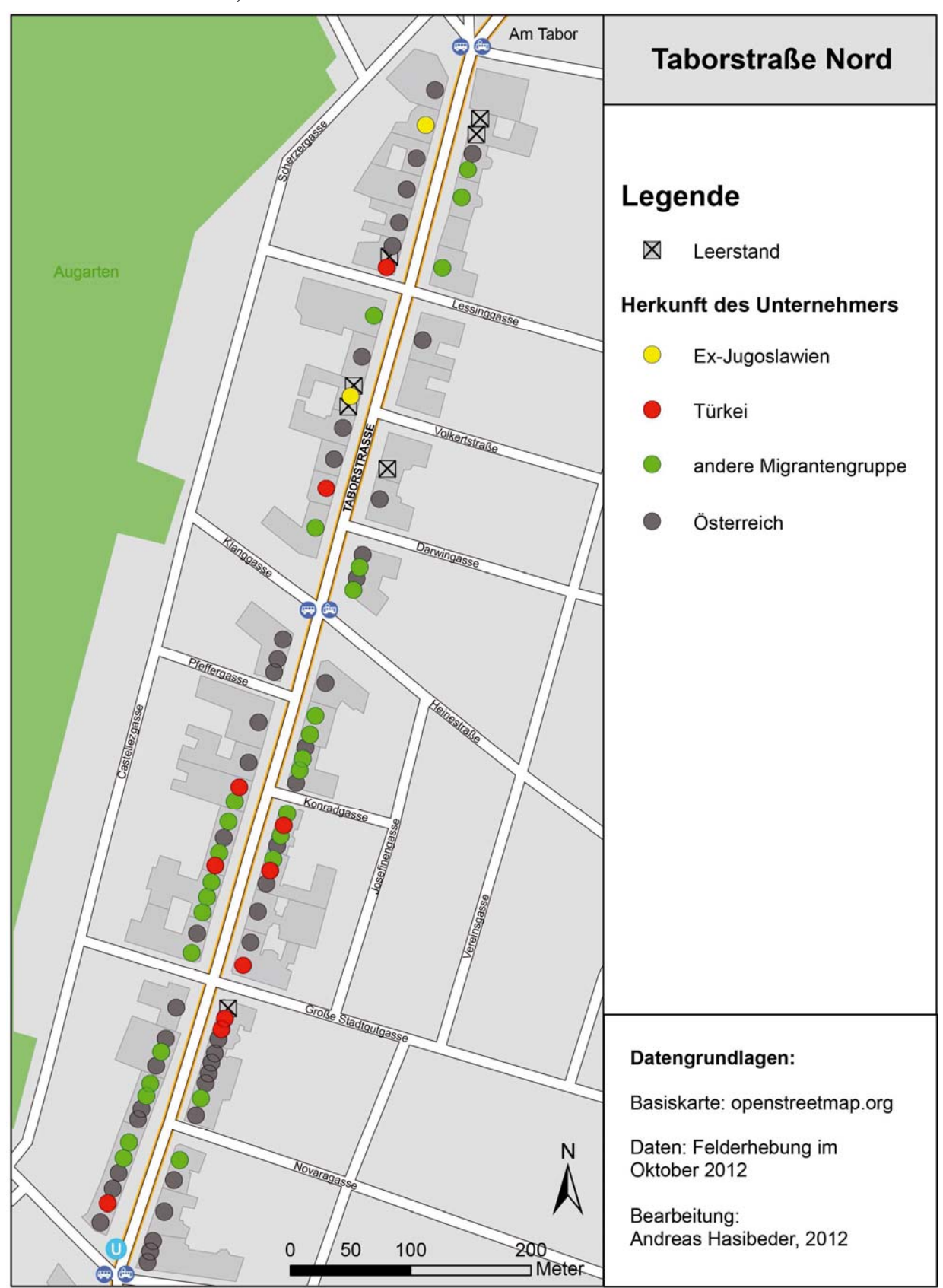


Karte 4: Geschäfte im südlichen Teil der Klosterneuburger Straße nach der Herkunft der Unternehmer, 2012

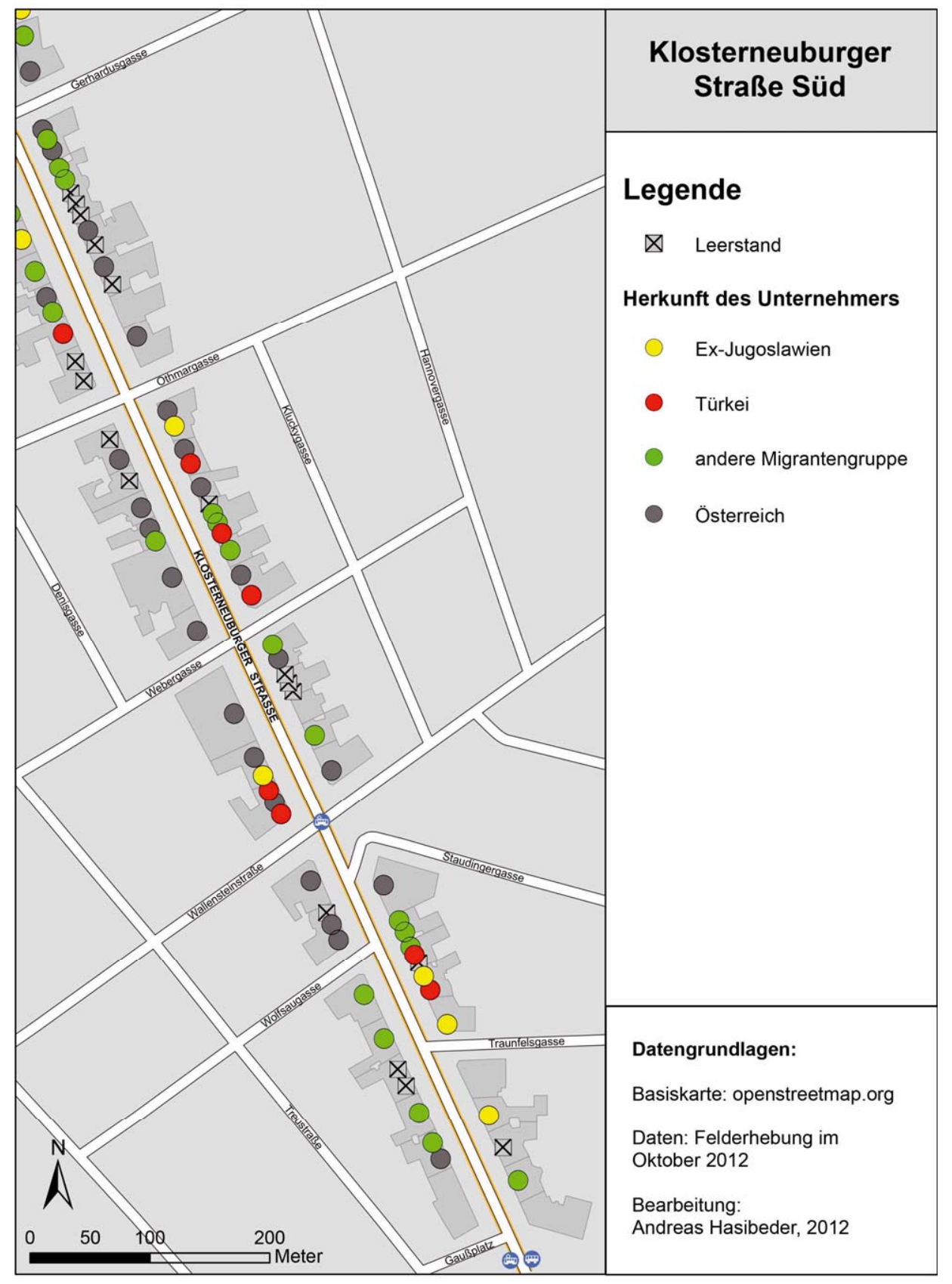


Karte 5: Geschäfte im nördlichen Teil der Klosterneuburger Straße nach der Herkunft der Unternehmer, 2012

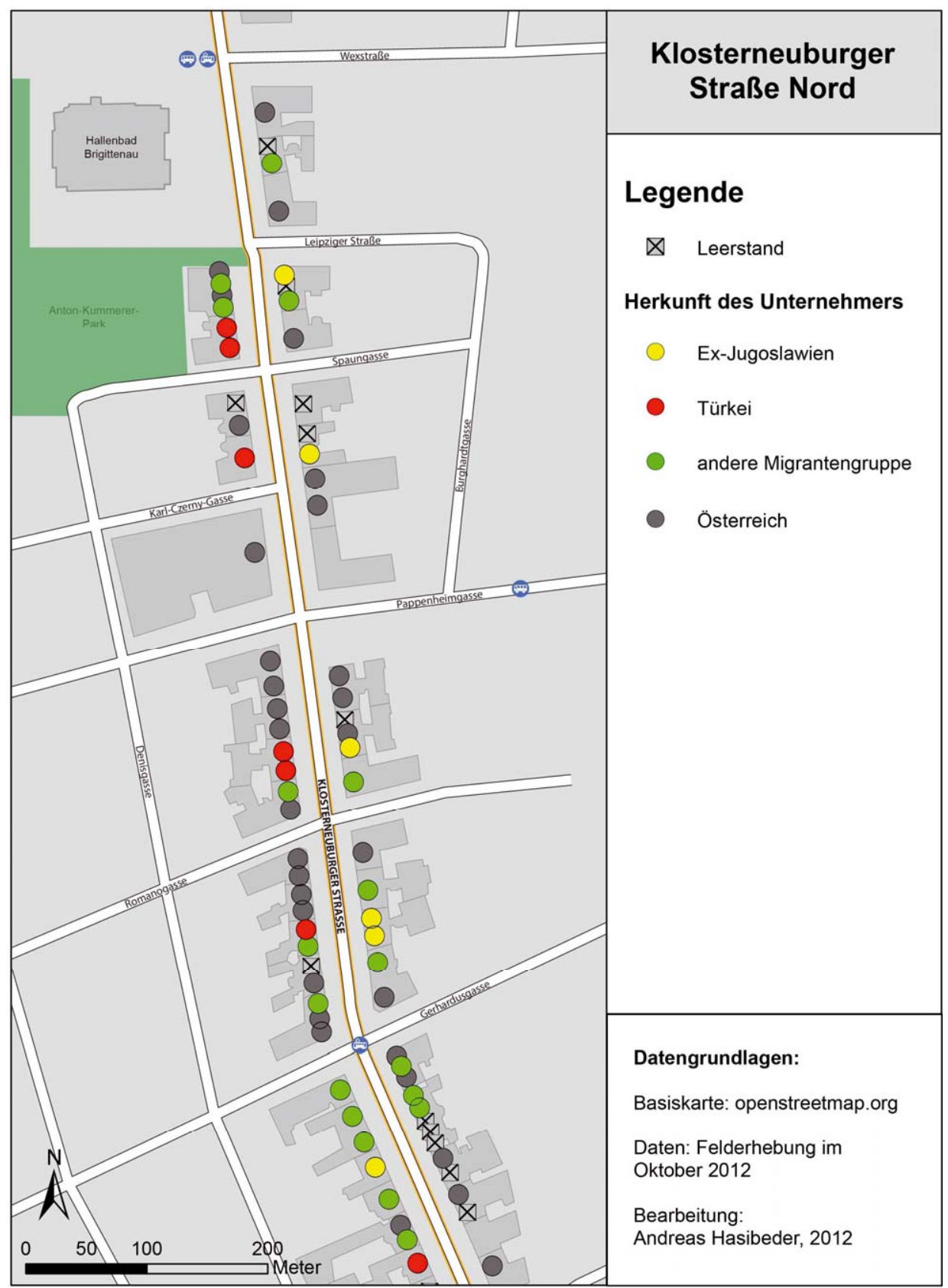


Karte 6: Branchenstruktur der Geschäfte im südlichen Teil der Taborstraße, 2012

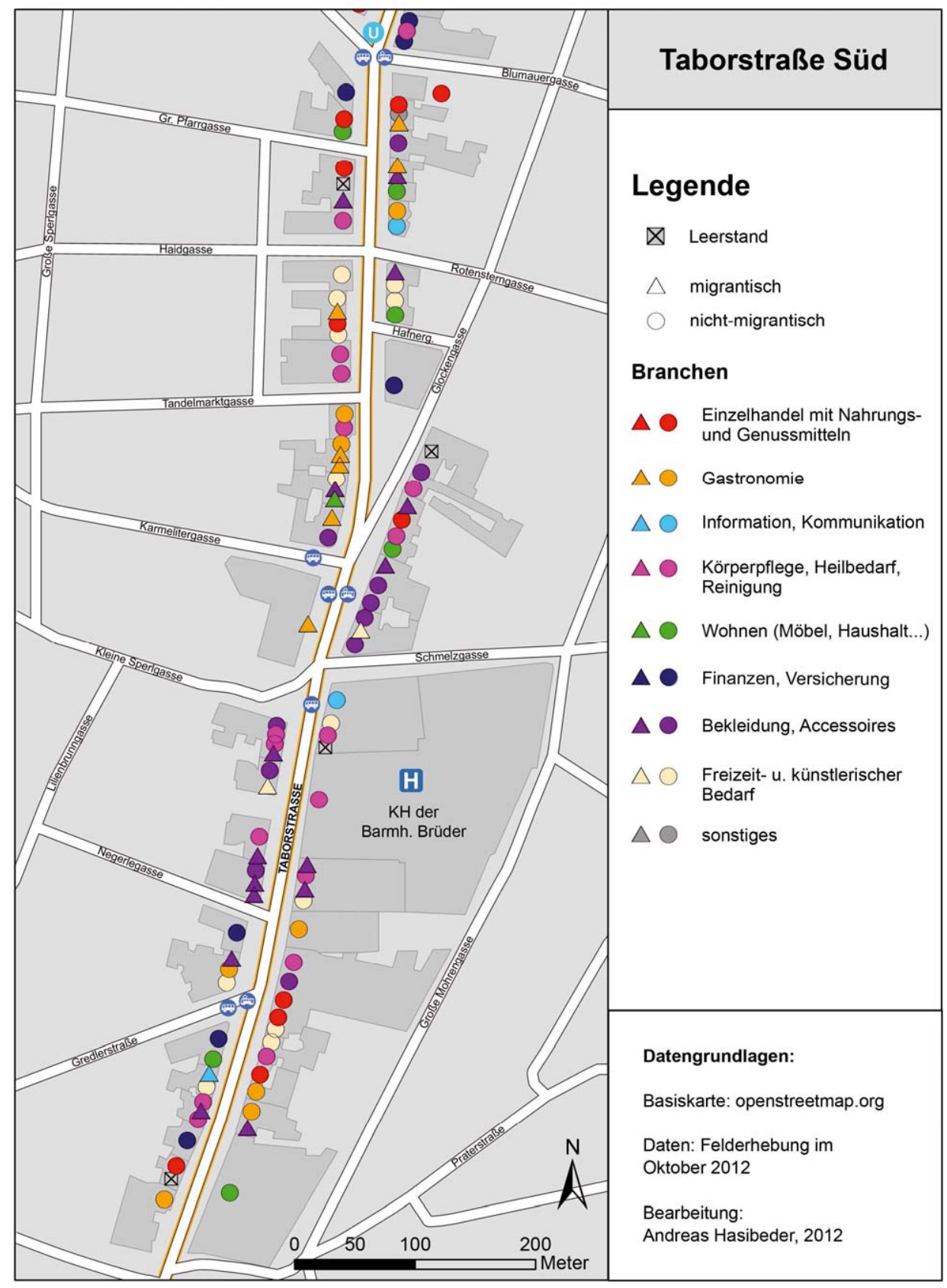


Karte 7: Branchenstruktur der Geschäfte im nördlichen Teil der Taborstraße, 2012

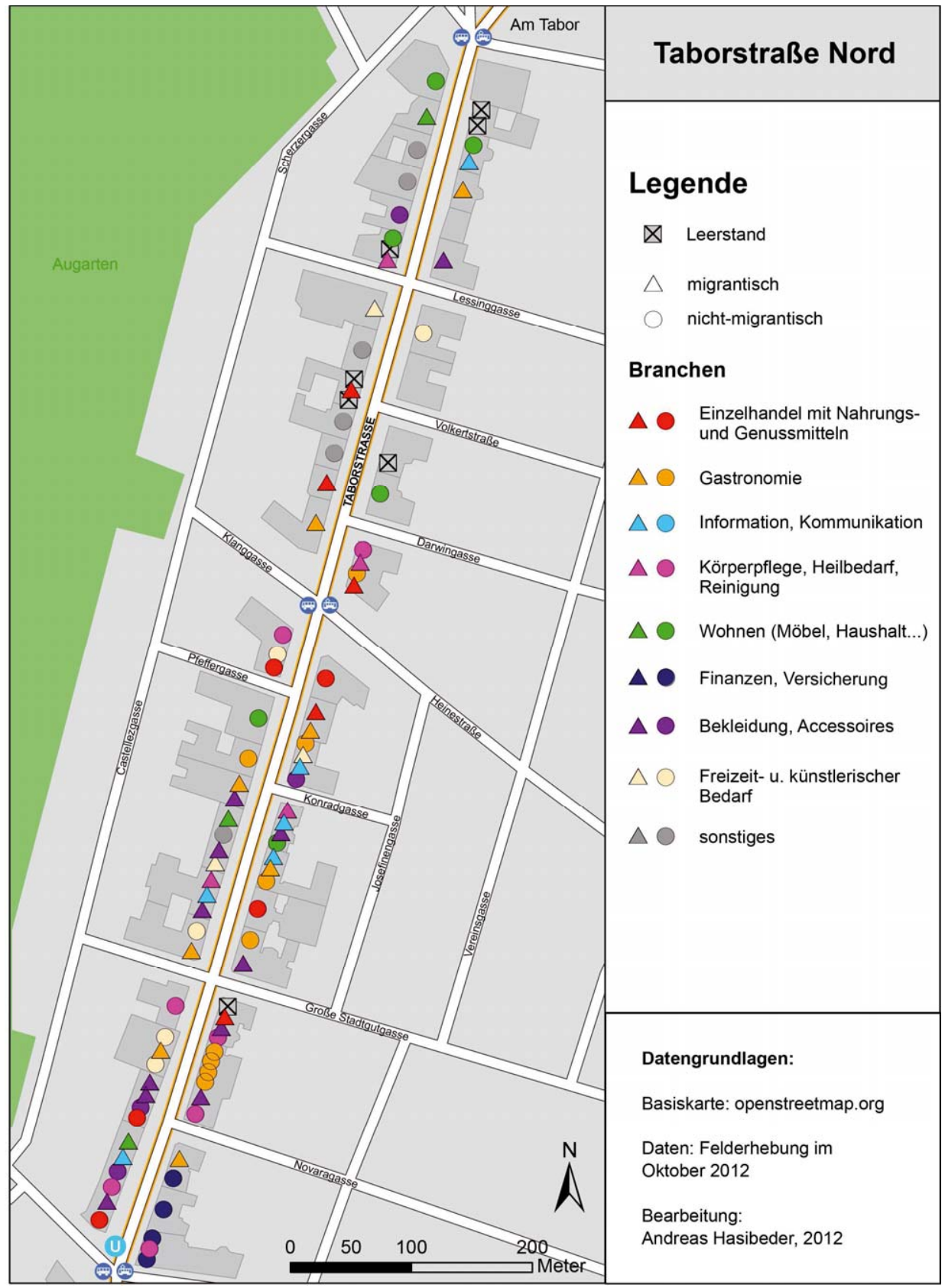


Karte 8: Branchenstruktur der Geschäfte im südlichen Teil der Klosterneuburger Straße, 2012

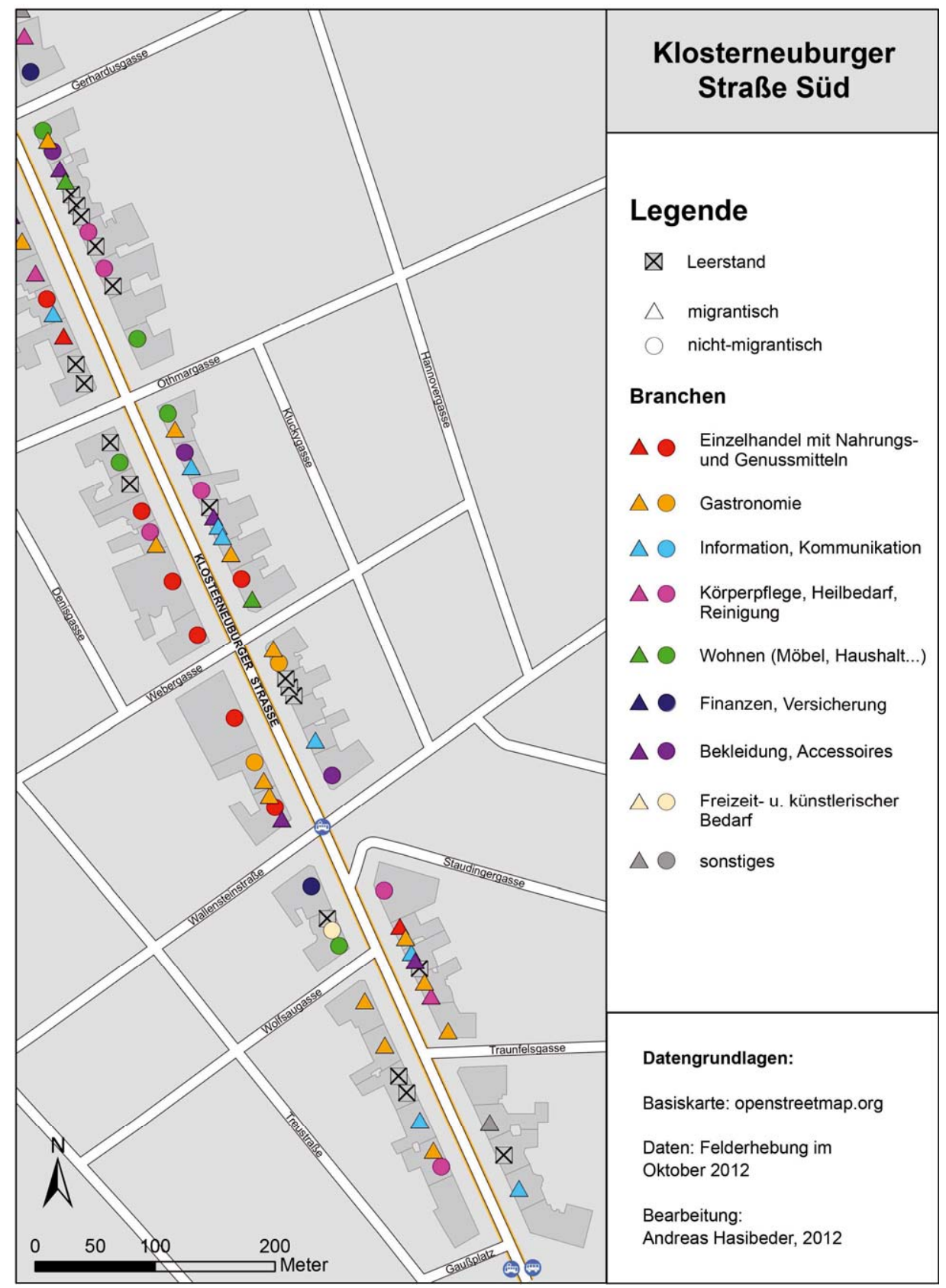


Karte 9: Branchenstruktur der Geschäfte im nördlichen Teil der Klosterneuburger Straße, 2012

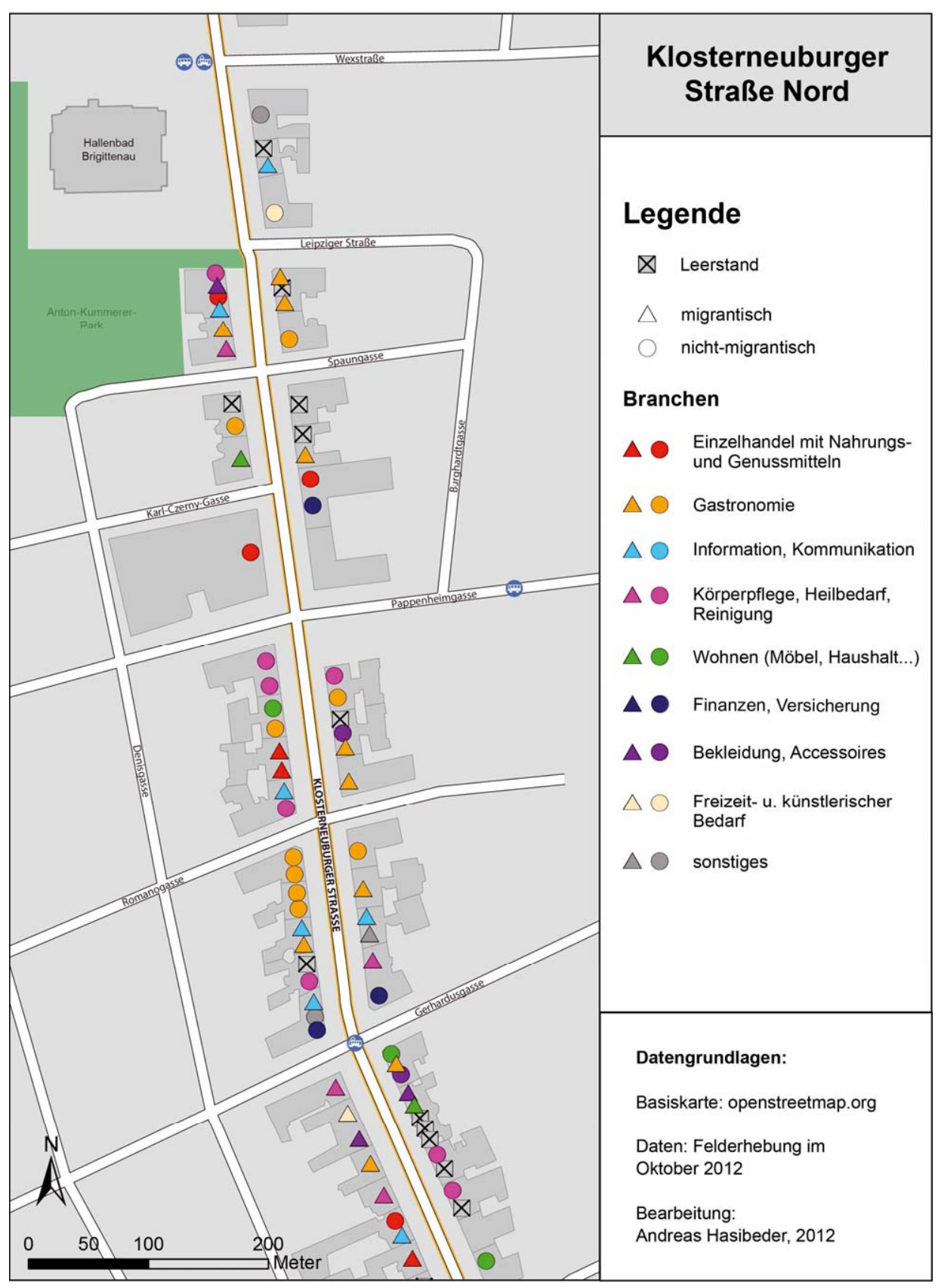


In nördlicher Richtung, zwischen Gerhardus- und Pappenheimgasse, findet sich eine Akkumulation gastgewerblicher Unternehmen der unterschiedlichsten Richtungen und teils der Migrant Economy teils der nichtmigrantischen Ökonomie zugehörig. In diesem Abschnitt der Klosterneuburger Straße sind auch einige von Personen ohne Migrationshintergrund geführte Geschäfte der Branche „Körperpflege/Reinigung“ ansässig.

Im weiteren Verlauf der Klosterneuburger Straße bis etwa in Höhe der Einmündung der Leipziger Straße ist die Ladeninfrastruktur nach wie vor zahlreich und hinsichtlich der Branchenzugehörigkeit bunt gemischt. Der Abschnitt bis zum Hallenbad Brigittenau wird durch Gastronomie, Nahrungsmitteleinzelhandel und die Branche „Körperpflege/Reinigung“ dominiert. In der Nähe des Anton-Kummerer-Parks fällt eine Häufung gastgewerblicher Unternehmen auf, die meisten davon von Migrant Entrepreneurs geführt. Das Gros dieser Läden wird von Migranten geführt, es treten aber auch inländische Geschäfte in Erscheinung. Zwischen Leipziger Straße und Wexstraße dünnt die Geschäftsinfrastuktur sodann beträchtlich aus.

Der nun folgende Abschnitt widmet sich den Resultaten der beiden Befragungen: den Unternehmer- sowie den Experteninterviews. Beide Datenquellen bilden die eigentliche Basis zur Beantwortung unserer Projektkernfragen zur verhältnismäßig geringen Präsenz türkischer und vor allem BKS-Zuwanderer in der Migrant Economy Wiens. Diese Frage konnte anhand der amtlichen Daten nicht zufriedenstellend beantwortet werden.

\subsection{Unternehmer mit exjugoslawischem und türkischem Migrationshintergrund in Wien im Spiegel einer Unternehmerbefragung sowie der Experteninterviews}

\subsubsection{Basisstruktur des Samples}

Die folgenden Ausführungen basieren auf einer im August 2012 durch das Meinungsforschungsinstitut Triconsult durchgeführten Befragung $(\mathrm{n}=30)$ von 15 Unternehmern mit türkischem und 15 mit BKS-Migrationshintergrund auf Basis eines semistandardisierten Fragebogens. Es erübrigt sich eigentlich, darauf hinzuweisen, dass die Resultate aufgrund der geringen Samplegröße keine Repräsentativität beanspruchen können. Basierend auf den Methoden qualitativer Inhaltsanalyse (vgl. Mayring 2010; Kuckartz 2012) zur Auswertung von Leitfadeninterviews (Schmidt 2000) sollen anhand charakteristischer Aussagen einzelner Individuen auch gewisse Trends aufgezeigt werden und diese wurden, soweit möglich, in einen breiteren komparativen Kontext zu anderen Analysen in diesem Forschungsfeld sowie den Aussagen in den Experteninterviews gestellt. Die breit gefächerte Branchenstruktur der Befragten ist aufgrund eines Quotenplans, der auf Ergebnissen der amtlichen Statistik beruht, zustande gekommen (vgl. Tabelle 18).

Die Resultate der Unternehmerbefragung werden durch elf Experteninterviews ergänzt (vgl. die Liste im Anhang). In der Auswahl der Experten und Expertinnen trach- 
teten wir eine große Spannweite an Perspektiven abzudecken: besonders erfolgreiche Repräsentanten aus den Migrant Communities, Sozialwissenschaftler, Vertreter und Funktionäre unternehmerischer Interessenvertretungen, Mitarbeiter von Beratungsinstitutionen sowie der munizipalen Verwaltung. ${ }^{23}$

Tabelle 18: Quotenplan der Unternehmerbefragung

\begin{tabular}{lcr}
\hline Quotenvorgabe & BKS & Türkei \\
\hline Bau & 3 & 1 \\
Handel & 2 & 3 \\
Verkehr & 1 & 2 \\
Gastronomie & 2 & 4 \\
technische Dienstleistungen & 1 & 1 \\
sonstige wirtschaftliche Dienstleistungen & 1 & 0 \\
sonstige Dienstleistungen & 1 & 1 \\
anderes & 4 & 3 \\
insgesamt & 15 & 15 \\
\hline
\end{tabular}

Quelle: ISR und Triconsult.

Die Respondenten des Unternehmersamples befanden sich im Alter zwischen 18 und 59 Jahren. Mit 25 Männern gegenüber nur 5 Frauen lag ein deutliches Schwergewicht bei den männlichen Selbständigen, was aber durchaus der Realität der Entrepreneurship in den beiden Herkunftsgruppen - nicht nur in Wien (vgl. Hillmann 1998, 2011; Leicht et al. 2012; Müller 2004) - entspricht. Der zweiten Generation sind nur zwei türkische Selbständige zuzuordnen, diesbezügliche Aussagen können also keine getätigt werden. In Bezug auf den Zuwanderungszeitpunkt kristallisiert sich eine beträchtliche Bandbreite heraus, die von 1968 bis 2009 reicht. Der „klassischen“ Gastarbeitermigration der 1960er- und 1970er-Jahre sind nur drei türkische Befragte, aber kein Exjugoslawe zuzurechnen. Das Gros der Befragten ist in den 1980er- bzw. den 1990er-Jahren nach Österreich gekommen. Von den Exjugoslawen sind auffallend viele im Gefolge der Balkankriege, also in der ersten Hälfte der 1990er-Jahre, immigriert. Während die Gastarbeitermigration in erster Linie ungelernte Arbeitskräfte nach Österreich führte, bedingten die kriegerischen Geschehnisse der 1990er-Jahre in besonders hohem Ausmaß auch eine Flucht qualifizierter Arbeitskräfte. Die Befragten stammen vornehmlich aus den exjugoslawischen Nachfolgerepubliken Bosnien und Serbien, nur wenige aus Kroatien:

23 Auf Wunsch einzelner Experten werden die Zitate aus den Interviews generell anonymisiert angeführt. 
„Die Herkunftsrepublik spielt da schon auch eine Rolle. Es gibt Unterschiede zwischen Kroaten, Serben und Bosniern. „Echte“ Kroaten aus Kroatien sind immer nur wenige ausgewandert, [...] Kroaten fanden durch Fremdenverkehr und Industrie auch in Kroatien leichter Arbeit. Wenn man hier sagt Kroate, dann sind das meist katholische, kroatische Minderheiten aus Bosnien und die kamen erst durch den Krieg nach Österreich. Dadurch haben aber Kroaten mehr an unternehmerischem Denken, weil in Kroatien immer Fremdenverkehr, Gastronomie, Hotellerie, d.h. Privatunternehmen, vorhanden waren und daher bleiben sie in Kroatien. Serben und Bosnier konnten eigentlich kein unternehmerisches Denken entwickeln. “

Viele Indikatoren sprechen dafür, dass das Bildungsniveau eine wichtige Determinante für den Gang in die Entrepreneurship und vor allem den Erfolg als Unternehmer darstellt. Diese Hypothese wurde auch in den Experteninterviews immer wieder verbalisiert, wenngleich der Konnex auch nicht eindeutig ist:

„Ich glaube, das ist ziemlich gleich für Türken oder Jugoslawen, Unternehmer zu sein. Nicht der Ursprung ist entscheidend, sondern, wie gesagt, die Bildung. Ohne Bildung, keine Jobchancen. Daher sehen viele Ungebildete nur die Kebabbude als einzige Jobchance. "

„Es fällt zum Beispiel schon auf, dass jene Gruppen mit den niedrigsten Quoten an Selbständigen auch den höchsten Anteil in den niedrigeren Bildungsabschlüssen haben. Ob das kausal ist, ist eine andere Frage, aber man kann dies so nebeneinander hinstellen."

„Es gibt unterschiedliche Fähigkeiten, sich anzupassen, was mit Bildung und Community-Spezifischem zusammenhängt. In vielen Fällen liegt es an der Bildung, dass sie offensichtlich nicht die Fähigkeit haben, das Unternehmen zu transformieren."

Seitens jener Experten, die selber auch als Unternehmer tätig sind, wird auf jeden Fall ein fundierter ausbildungsmäßiger Background als vorteilhaft propagiert:

„Es ist halt zu leicht, ein Unternehmen zu gründen. Man kann sich einfach eine Konzession ausleihen, dann geht man in einem Jahr in Konkurs und richtet großen Schaden an. Ich habe die Konzessionsprüfung für Speditionsgewerbe gemacht und vorher einen WU-Abschluss. "

Bezüglich der Unternehmensgröße herrscht eine erhebliche Variationsbreite, die von Einpersonenunternehmen bis zu einer Firma mit mehr als 150 Mitarbeitern reichte, zahlenmäßig dominierten allerdings kleinere Einheiten. Vom Alter und Geschlecht einmal abgesehen war das Bildungsniveau die einzige unabhängige soziodemographische Variable, nach der Analysen sinnvollerweise durchgeführt wurden. Jeweils sechs türkische und sechs BKS-Unternehmer weisen ein gehobenes Bildungsniveau (Reifeprüfung und/oder Hochschule/Universität/Fachhochschule) auf. Der Anteil Gebildeter ist damit in unserem Sample bei weitem höher, als in der amtlichen Statistik für die erwerbstätigen Exjugoslawen und Türken insgesamt ausgewiesen wird. Ein weiterer 
Beleg für die überragende Bedeutung der Ausbildung für die Entrepreneurship von Immigranten. Eine Expertin beurteilt den Konnex folgendermaßen:

„,Das hat nicht nur mit dem formalen Bildungsabschluss zu tun, sondern auch in Bezug auf PISA mit Lesefähigkeit, der Fähigkeit mit Informationen umzugehen und Ähnlichem. Gerade in den Migrantencommunities haben Leute oft den Vorteil, auf Gruppenressourcen zurückgreifen und dies zum Teil ausgleichen zu können. Ob dies jedoch in der Masse so gut wirken kann, ist die Frage. Es braucht auch immer eine gewisse kritische Masse, die ein bestimmtes Bildungsniveau und Knowhow besitzt. Dies dürfte in manchen Gruppen nicht so ausgeprägt sein. “

Die Zusammenhänge sind jedoch auch wissenschaftlich nicht eindeutig belegt, wie folgendes Zitat aus einem Experteninterview dokumentiert:

„Es gab eine in Österreich durchgeführte Studie über Gründer. Diese ist zu dem Ergebnis gekommen, dass die Wahrscheinlichkeit ein Gründungsvorhaben tatsächlich umzusetzen nicht mit dem Bildungsabschluss zusammenhängt und es in Wahrheit darüber keine Effekte gibt. Für ganz unwahrscheinlich halte ich dies jedoch nicht, da die Hürden zum Teil doch sehr groß sind. Wenn gewisse Bildungsabschlüsse nicht vorhanden sind, wird vieles sehr schwierig. "

Zusätzlich zum formalen Bildungsniveau spielt für eine Unternehmertätigkeit insbesondere auch die fachspezifische Ausbildung, die in einem mehr oder minder unmittelbaren Zusammenhang mit der Wirtschaftsbranche steht, eine wichtige und möglicherweise sogar wichtigere Rolle als das allgemeine Bildungslevel, wie dies eine Expertin ausdrückte:

„Der große Irrtum von vielen Migranten und auch Österreichern: Sie glauben, wenn man vor der Theke steht, könnten sie auch ein guter Wirt sein. Hier liegen Welten zwischen den zu bewältigenden Anforderungen. Das ist keine Besonderheit von Migranten. “

Die Bandbreite von Fachausbildungen reicht vom spezifischen Universitätsstudium bis hin zur Taxiprüfung in Wien oder dem Besuch von Kursen zur Betriebsführung. Acht türkische und ebenso viele exjugoslawische Unternehmer geben an, ihre Fachausbildung in Wien absolviert zu haben. Einige verfügen über keinerlei spezielle Ausbildung (fünf Befragte aus der Türkei und drei aus dem ehemaligen Jugoslawien), insgesamt sechs Interviewpartner haben ihre Ausbildung im Herkunftsland absolviert. Hinsichtlich der Deutschkenntnisse, für die eine Selbsteinschätzung abgefragt wurde, besteht ein feststellbarer Zusammenhang mit dem Bildungsniveau, d.h. mit höheren Bildungsabschlüssen gehen tendenziell eher mittelmäßige bis gute Deutschkenntnisse einher. Dieser Zusammenhang wurde auch in den Experteninterviews bestätigt.

Die Unternehmensstandorte verteilten sich auf zwölf Wiener Bezirke. Fragt man nach der Dauer der Selbständigkeit, so manifestiert sich eine erhebliche Variationsbreite. 13 Unternehmen bestanden erst sehr kurze Zeit ( 0 bis 3 Jahre), acht waren vor vier bis neun Jahren gegründet worden und bei neun Befragten lag der Eintritt in die Selbständigkeit bereits länger als zehn Jahre zurück. 
Ein wesentliches Kriterium der Bewertung von Unternehmen stellt deren Größe, ausgedrückt in der Mitarbeiterzahl (Umsatzzahlen konnten verständlicherweise nicht erhoben werden), dar. Der Vergleich der Mitarbeiterstruktur von Firmen türkischer und exjugoslawischer Eigentümer zeigt, dass sieben der fünfzehn befragten türkischen Unternehmer größere Firmen mit zehn und mehr Mitarbeitern führen, während die exjugoslawischen Unternehmer im Sample mehrheitlich kleine Firmen innehaben (so z.B. sieben Unternehmen mit weniger als fünf Mitarbeitern). Es zeigt sich ein deutlicher Zusammenhang zwischen dem Bildungsniveau des Unternehmers und der Unternehmensgröße. Das heißt, ein höheres Bildungsniveau geht mit einer zahlenmäßig größeren Belegschaft einher (von den zwölf Unternehmern mit einem höheren Bildungsniveau verfügen immerhin acht über insgesamt zehn oder mehr Mitarbeiter).

Ein wesentlicher Aspekt der Mitarbeiterstruktur, der gerade in der Ökonomie der Migranten eine wichtige Rolle spielt, ist die Mitarbeiterrekrutierung aus Familie und Bekanntenkreis sowie darüber hinaus aus der eigenen Herkunftsgruppe (vgl. Davis \& Tagiuri 1994): Sehr deutlich wird hier, dass mithelfende Familienangehörige in den Unternehmen der türkischen Selbständigen eine bedeutendere Rolle spielen, sofern überhaupt Personal beschäftigt wird: Elf von 15 befragten Türken arbeiten (unter anderem) mit Verwandten zusammen, bei den Exjugoslawen sind es nur vier von 15. Die Bedeutung der eigenen Community im Rahmen der Mitarbeitersuche wird auch von den Experten angesprochen:

,Wir haben eine gewisse Personalakquisition innerhalb der exjugoslawischen Community, aber nur als eine unter anderen. Serbische Unternehmen beschäftigen gerne vor allem Serben, aber nicht so stark wie bei den Türken. Türken arbeiten nicht gerne bei Serben oder in einem österreichischen Betrieb. Und wenn, dann nur vorübergehend. "

Die herkunftsbezogene Diversität der Mitarbeiter hängt auch mit der Betriebsgröße zusammen. Für die türkischen Unternehmen lässt sich festhalten, dass sechs der 15 Unternehmer ausschließlich Mitarbeiter selber Herkunft eingestellt haben (Mitarbeiterzahl insgesamt zwischen zwei und zehn), bei den BKS-Unternehmen gilt dasselbe ebenfalls für sechs (Mitarbeiterzahl insgesamt zwischen drei und acht). Je größer die Belegschaft, desto eher werden auch Mitarbeiter von außerhalb der eigenen Migrant Community eingestellt. Einer unserer Experten, der auch ein sehr erfolgreiches und wachsendes Unternehmen führt, weist in diesem Konnex auch auf Probleme hin:

„Und unser türkischer Mitarbeiter hat das einfach nicht akzeptiert - na, weil sie eine Frau ist. Er nimmt keine Anweisungen von Frauen entgegen. Das ist ein Problem. “

„Diese Verwandtschaftsbeziehungen und die Netzwerke sind zu berücksichtigen. Wir in unserem Unternehmen haben am Anfang fast ausschließlich mit türkischen Mitarbeitern gearbeitet, denn mit denen haben wir uns anfangs leichter getanhaben wir geglaubt." 


\subsubsection{Die Unternehmensgründung}

\subsubsection{Motivationen, Qualifikationen, Entscheidungsfindungsprozesse}

Als Hauptmotive für den Sprung in die Selbständigkeit wurden die erhofften besseren Verdienstmöglichkeiten sowie die Aussicht, endlich nicht mehr auf die Anweisungen anderer hören zu müssen, verbalisiert:

„,Ich habe mir gedacht, dass ich viel Geld verdienen könnte. “ (T 11)

„Wenn ich selbständig bin, kann ich mein eigener Chef sein und mir die Zeit selbst einteilen. “(BKS 1)

Auch die von uns befragten Experten argumentierten in diese Richtung:

„,Bei den Türken gibt es sehr viele kleine Betriebe, halt so Einmannbetriebe, denn der Türke will immer Chef sein, will auch kein Gesellschafter sein oder so, sondern macht eigenes Geschäft auf. “

„Keinen Chef mehr zu haben, der eigene Chef zu sein und womöglich in der Regel aber auch Mitarbeiter/-innen zu haben ist ein Status, den sie sich hier erarbeiten. [...] Es ist natürlich ein sozialer Aufstieg, wo auf einmal die anderen auf einen hinaufschauen. [...] das ist mein Unternehmen und ich arbeite für mich selbst."

„Nach meiner Erfahrung, bezogen auf die Türkei und Exjugoslawien, war dies generell eher positiv besetzt. Hier kann ich mich nicht an große Unterschiede erinnern. Es war mit einem stärkeren Selbstwert verbunden. Die Leute haben sich auch als Steuerzahler und Beitragende wahrgenommen. Dass sie dies vorher aber auch schon waren, haben sie nicht bemerkt. Als Selbständiger ist man unmittelbar damit konfrontiert, was man von seinem Einkommen abgibt. Es gibt das Gefühl etwas beizutragen und auch ein wertvolleres Mitglied der Gesellschaft zu sein."

Andererseits kann die Selbständigkeit auch einer nicht gänzlich freien Entscheidung entsprungen sein, sondern resultiert aus einem Mangel an Alternativen auf dem Arbeitsmarkt der unselbständigen Erwerbstätigkeit oder der Hoffnung, sich bzw. der Familie ein ausreichendes Auskommen zu verschaffen:

„,Wer eine gute Position in einem Unternehmen innehat, will in der Regel auch nicht selbständig werden. Selbständigkeit ist oft auch Flucht, weil keine anderen Alternativen da sind. Ich komme selbst aus einer Familie mit einer Erfahrung in Selbständigkeit. “

,,Viele machen sich auch deshalb selbständig, um die Familie zu unterstützen. Hier geht es nicht um die eigenen Bedürfnisse, sondern schon um das Kollektive, also zu sagen, wenn ich das tue, ziehe ich die Familie mit hinein. "

Von großer Wichtigkeit sind bestehende Erfahrungen und fachspezifische Praxis, v.a. aus unselbständiger Erwerbstätigkeit in bestimmten Branchen. Vorhandene Erfahrungen repräsentieren nicht nur einen wichtigen Motivator für die Entscheidung pro 
Selbständigkeit im Allgemeinen, sondern sie determinieren auch entscheidend die Branchenwahl. Somit wird ein Teil der Start-up-Barrieren ausgeschaltet und bloß die Perspektive gewechselt: vom unselbständig Erwerbstätigen zum „Chef":

„Ja, weil ich auch mal in dieser Branche gearbeitet habe und mich auskenne; ich wollte es einfach mal probieren. "(T 12)

„Als ich als Friseur gearbeitet habe, habe ich viele Kunden gewonnen, die mich auf die Idee gebracht haben, mich selbständig zu machen bzw. einen eigenen Friseursalon zu eröffnen. " (BKS 11)

„Habe 11 Jahre als Taxilenker gearbeitet. Durch 11 Jahre Erfahrung habe ich mir dann ein eigenes Unternehmen gewünscht und gegründet. Es gab für mich keine großen Auswahlmöglichkeiten; da ich Taxi fahren konnte, habe ich also ein Taxiunternehmen gegründet. " (T 14)

Mitunter werden auch familiäre Konstellationen und auch Zwänge sowie Ratschläge von Freunden für die Wahl der Branche ins Treffen geführt:

„Weil mein Vater jahrelang in einem Reisebüro gearbeitet und es mich einfach interessiert hat. "(T 8)

„Es hat mich nicht wirklich interessiert, aber mein Vater hat mich überredet. Irgendwann später habe ich mich in diese Branche eingelebt und jetzt bin ich zufrieden damit. "(BKS 9)

Die ausgeprägte Branchenorientierung und -konzentration bestimmter Herkunftsgruppen sowie die - häufig auch branchenbezogenen - Fluktuationsphänomene sind ein nicht nur in Wien auftretendes Phänomen. Die dafür maßgeblichen Kausalfaktoren sind vielfältig und manche auch aus der Perspektive der Experten kausal nicht immer eindeutig zu explizieren:

„Die Konzentrationen sind im Textilbereich, Kebabverkauf, Teppichhandel, Friseure und Dienstleistungen. Da werden keine marktanalytisch-sachlichen Kriterien angewendet. Da bilden sich Nischen und die werden einfach besetzt. Da gibt es auch Unterschiede nach Herkunftsgruppen: Zum Beispiel sind die Chinesen meist Großhändler, zum Beispiel im Textilsektor, die importieren das alles en gros aus China. Der Handel mit diversem Zubehör in diversen Sektoren ist dagegen fest in türkischer Hand. "

„Diese Effekte sind ganz deutlich an diesen türkischen Bäckereien erkennbar. Das Prinzip ist in jeder Bäckerei gleich, [...]. “

„Interessant ist für mich, warum es einen so ausgeprägten türkischen Lebensmittelhandel gibt, aber keinen serbischen Lebensmittelhandel. Warum gibt es diese spezialisierten Branchen? Bei mir ums Eck hat vor einem halben Jahr ein polnischer Lebensmittelhändler auf-und mittlerweile wieder zugesperrt. Es wäre auch interessant, ob es in der Fluktuation communityspezifische Unterschiede gibt. "

„Es gibt den Balkanboom in der Gastronomie, in diesem Bereich gibt es sehr viele Lokale. Im Lebensmittelhandel gibt es diesen nicht. Offensichtlich ist man in 
der exjugoslawischen Community eher bereit, in einem österreichischen Supermarkt einzukaufen und legt auf Produkte aus der Heimat nicht so viel Wert. Deshalb gibt es in diesen Communities auch weniger Motivation, sich in diesen Branchen selbständig zu machen."

„,Möglicherweise die reale Befürchtung, dass keine Kunden und keine Landsleute kommen und den Österreichern das Sortiment nicht exotisch genug ist. "

„Kleine Lebensmittelläden können nicht überleben, wenn sie sich nicht anpassen. In der exjugoslawischen Community wird ein Lebensmittelladen vorausschauenderweise gar nicht eröffnet, weil dies befürchtet wird. "

„Das kombiniert sich. Das Service, die lokalen Konzentrationen und die Bedürfnisstruktur in der türkischen Community unterscheiden sich von der jugoslawischen. [...] Konzentration bei kritischer Größe der Gruppen, wo ein kritisches Maß der Nachfrage und ähnliches mehr entsteht. Bei den Jugoslawen war das etwas weniger ausgeprägt. Früher gab Shops mit Videos und Musikkassetten. Diese wurden aufgelöst oder sind mit der Zeit mitgegangen und gehen heute Richtung Handy und Satellitenanlagen. Heute ist das Montieren von Satellitenanlagen stark in jugoslawischer Hand. Auch in diesem Bereich hat es Nischen gegeben, wie Busreisen und das Transportwesen. "

„Es gibt sicher einen Trend von Unternehmern mit BKS-Hintergrund, die am Schreibtisch sitzen. Auch im Baubereich gibt viele aus dem BKS-Bereich, wie auch im Bereich Werbung und Marketing. Es ist ein sehr neuer Trend, gerade was die jüngere Generation mit Migrationshintergrund angeht. "

Die Branchenkonzentration bedingt zwar einerseits einen starken Konkurrenzdruck, findet auf Expertenseite jedoch auch positive Bewertungen:

„[...] es ist legitim, dass die türkische Community im Bereich Handel sehr stark vertreten ist. Wir dürfen nicht außer Acht lassen, dass es gerade auch hier eine sehr, sehr neue, moderne Entwicklung gibt. "

Die Standortentscheidung, eine Frage, die beim Start-up in Bezug auf viele (jedoch nicht alle) Branchen, zu den wichtigsten überhaupt zählt, wird häufig nicht nach analytischen Kriterien oder nach eingehender Sondierung der Marktgegebenheiten getroffen, stellen einige der dazu befragten Experten fest:

„Es macht einen Unterschied, was mein Angebot ist. Wenn ich eine Baufirma besitze, habe ich andere Anforderungen an meinen Unternehmensstandort und meine Klientel. Ab dem Moment, wo ich einen Gastronomiebetrieb oder einen Einzelhandel besitze, der wirklich physisch und nicht online existiert, ist der Standort einfach eine Frage. "

„Die Standortentscheidung wird nicht nach Marktanalyse, sondern aus materiellen Beschränkungen heraus getroffen. Dies gilt nicht für die türkischen Supermarktketten und die großen Bäckereien und Betriebe, die das durchaus strategisch angehen. ETSAN hat 16 Filialen in Österreich und überlegt sich ganz genau, wo diese positioniert werden." 
In der jungen Unternehmergeneration oder bei Personen, die direkt aus dem Bildungssystem in eine selbständige Erwerbstätigkeit einsteigen, die also zuvor noch keinerlei Berufserfahrung aufweisen, trifft man aber auch auf Entscheidungsfindungsabläufe nach stringent unternehmerisch-sachlogischen Kriterien, wie zum Beispiel in Orientierung an der existierenden Geschäftsinfrastruktur in einem Viertel, an nachweisbar vorhandenen Marktlücken und an besonders vielversprechenden standörtlichen Parametern:

„Ich habe bemerkt, dass es in Wien wenige Ex-Jugo-Lokale mit Live Musik gibt und somit habe ich entschlossen, eines zu eröffnen. " (BKS 8)

„Als ich den Laden aufmachte, gab es noch keine Geschäfte, die das alles angeboten haben. So war ich auch einer der Ersten. " (T 15)

„Als Student, neben dem Studium, gab es nicht viel Auswahl an Arbeitsstellen und ein Freund hat mir geraten, den Taxischein zu machen und entschloss mich somit. Es war die leichteste Art, neben dem Studium Geld zu verdienen. Die meisten Freunde in der Uni hatten denselben Job, was ebenfalls ausschlaggebend war. " (T 14)

Etwas widersprüchlich wird das innovative Hineingehen in neue und weitgehend unbekannte Branchen bewertet. Dies ist einerseits notwendig, um aus der „Nische“ herauszukommen, birgt jedoch ein nicht unwesentliches unternehmerisches Existenzrisiko, wie eine Expertin ausführt:

„Ich glaube schon, dass es auch ein Motiv ist zu sagen, ich möchte nachhaltig bestehen. [...] Das Experimentieren mit neuen Ideen in einer Branche, wo ich rundherum keine vergleichbaren Beispiele habe, ist viel riskanter als das Hineinspringen in einen Bereich, wo schon relativ viele sind und ihre Erfahrungen haben. [...]Auf der einen Seite geht es wirklich darum, dass die Leute in einer bestimmten Branche auch nachhaltig bestehen und deshalb kein Branchenrisiko auf sich nehmen wollen [...]. Weil es ja immer heißt, ethnische Ökonomien sind sehr risikofreudig. Das glaube ich nicht. Sie sind sehr wohl risikofreudig, was das Tun anbelangt, aber bei der Entscheidung fallen sie trotzdem in klassische Ideen hinein. Risikofreudig wäre für mich jemand, der eine Branche ausprobiert, von der er keinen blassen Schimmer hat und die bis dato niemand ausprobiert hat. Was die Ideen angeht sind sie total konservativ. Das hat nichts mit Risiko zu tun. "

Analysiert man das gesamte Sample, so zeigt sich, dass die überwiegende Mehrzahl der befragten Unternehmer (insgesamt 21) vor ihrem Start-up bereits die branchenbezogen gleichen oder sehr ähnliche Berufe, jedoch in Positionen als unselbständig Beschäftigte, ausgeübt haben. Dies trifft vor allem auf handwerkliche Professionen (Bodenleger, Maler und Anstreicher etc.), die spezifische Qualifikationen und Lehrabschlüsse erfordern, sowie auf Friseure zu und hierbei sind auch keinerlei Unterschiede zwischen Unternehmern mit türkischem und solchen mit exjugoslawischem Migrationshintergrund festzustellen. Anders präsentiert sich der Zugang zum Gastgewerbe: 
Der Gang in die Gastronomie erfolgt zwar mitunter auch aus dem Beruf des Kellners, oftmals aber auch aus völlig gastronomiefremden Branchen und Berufen:

„Ja, natürlich. Dieser Bereich hat mich sehr interessiert und es war mein größter Wunsch, ein eigenes Lokal zu eröffnen. “ (T 2)

,Ja, die Baubranche war und ist der für mich beste Sektor als Unternehmer. Die Rollen, welche ich in meinen früheren Firmen ausübte, waren äußerst lehrreich, merke ich. "(T 6)

„Ja, ich war schon zwei Jahre in dieser Branche tätig und habe einiges lernen können. Ich wollte dann aber mehr verdienen und habe mich deswegen für ein eigenes Unternehmen in diesem Bereich entschieden. " (BKS 7)

Natürlich spielen in der Kleingastronomie auch die niedrigeren Zugangsschwellen, was den Nachweis von speziellen Befähigungen und Qualifikationen anbelangt, eine nicht zu unterschätzende Rolle, wie eine Expertin ausführt:

„Es gibt wenig Restaurants, aber sehr viele Imbisse. Es ist ja nicht so, dass die Imbissbetreiber nicht imstande wären, ein Restaurant zu führen. Nur die Frage der Befähigung ist natürlich eine sehr zentrale. Das heißt, der Zugang im Imbiss als natürlich freies Gewerbe ist mit acht Sitz- und Stehplätzen durchaus einfacher. Die Fixkosten, die finanziellen Ressourcen, das Eigenkapital in einem durchschaubaren Bereich. Natürlich ist die Motivation und die Entscheidung, in diese Richtung zu gehen, eine größere. [...] Man kann nicht sagen, alle wollen das unbedingt, sondern das ist halt das, was geht, ganz profan ausgedrückt. Es ist nicht so, dass jeder sagt, ich möchte unbedingt einen Imbiss betreiben - unterstelle ich jetzt einmal - sondern das ist halt das, was geht."

\subsubsection{Problemkonstellationen im Kontext der Betriebsgründung}

Aus zahlreichen Studien (Czingon 2012; Dabringer \& Trupp 2012; Hillmann 2011, Hillmann \& Sommer 2011; Rath 2009; Rath \& Swagerman 2011 u.v.a.) ist bekannt, dass sich in der Gründungsphase besonders viele Probleme akkumulieren - dies gilt für Jungunternehmer allgemein, solche mit Migrationshintergrund haben in der Regel noch spezifische zusätzliche Barrieren zu überwinden. Diese können sich im sprachlichen Bereich, in Problemen der Anerkennung formaler Bildungsabschlüsse, in unbekannten regulativen Rahmenbedingungen etc. manifestieren. Man muss betonen, dass nur eine geringe Zahl an Unternehmern explizit von gravierenden Problemen mit der Bürokratie berichtete. Allerdings wurde die Gründungsphase als die schwierigste auch in bürokratischer Hinsicht - charakterisiert. Den Informationen des Gründerservice der WK Wien gemäß sind es vor allem ein Wissensdefizit bezüglich der administrativen Procederes sowie das Unwissen darüber, wo welche Informationen eingeholt werden können, die die hauptsächlichen Barrieren für Unternehmer mit Migrationshintergrund im Umgang mit der Bürokratie darstellen. Ein weiteres Problem manifestiert sich darin, dass nicht wenige Migranten die WKW nicht als ihre eigene Interes- 
senvertretung betrachten, sondern vielmehr als eine Kontrollinstanz. Dies resultiert aus dem Faktum, dass in vielen Herkunftsländern dieser Zuwanderer vergleichbare Institutionen zur Wahrung unternehmerischer Interessen gänzlich fehlen.

In den Interviews wurde das Problem von Informationsdefiziten über vorhandene Fördermöglichkeiten häufiger verbalisiert als Probleme mit bürokratischen Hürden. Als eine Folge daraus erfolgt ein Teil der Start-ups nach wie vor, ohne dass von vorhandenen Förderungen Gebrauch gemacht würde. Dieses Phänomen ist seltener bei Selbständigen aus ost(mittel)europäischen Staaten als bei Türken oder Asiaten zu finden. Die Hauptursache dafür sind Sprachbarrieren, denn die zweite Generation verfügt fast durchwegs über den nötigen Informationsbackground (vgl. auch Rusinovic 2006). Unternehmer mit höherem Bildungsniveau haben hier auch geringere Schwierigkeiten des Informationszugangs.

Bezüglich der Bürokatie wurde sowohl von Unternehmern als auch Experten ein Bedarf nach stärkerer ,, Realisierung der Diversität " durch das Personal der unternehmensrelevanten Institutionen in Magistrat, Kammer, Finanzamt etc. verbalisiert. Nach wie vor besteht ein Mangel an Personal mit Migrationshintergrund und damit Native Speakers in einigen relevanten Institutionen, obwohl die einhellige Meinung besteht, dass sich in den vergangenen Jahren die Situation merklich gebessert hat.

Faktum ist, viele (aber bei weitem nicht alle) Befragten artikulierten, dass ihnen die Betriebsgründung eine Reihe von Problemen bereitete, wobei hier natürlich das Ausmaß der Möglichkeiten zur systematischen Vorbereitung auf die Selbständigkeit eine enorme Rolle spielt:

„Am schwersten ist mir der Papierkram gefallen und der Prozess mit den Ämtern. Wenn man die Sprache nicht so gut kann und gewisse Begriffe aus dem Wirtschaftswesen nicht kennt, ist man manchmal echt verloren Ich bin deswegen meistens mit einer Begleitperson zu den Ämtern gegangen. " (BKS 2)

„Die Bürokratie hat mich fertig gemacht. Ich wusste nicht, dass man so viele Unterlagen braucht." (BKS 9).

So gut wie alle befragten türkischen Unternehmer verbalisierten Probleme, während immerhin vier exjugoslawische Unternehmer von keinerlei Schwierigkeiten berichteten, wobei dies sowohl auf Personen mit höherem Schulabschluss als auch auf solche mit geringem Bildungslevel zutraf. Es ist allerdings hervorzuheben, dass das Ausbildungslevel der türkischen Befragten ein wenig unter jenem der Exjugoslawen rangiert, aber dennoch deutlich höher ist als jenes der in Wien lebenden türkischen Erwerbsbevölkerung im Durchschnitt:

„Eigentlich gab es keine Probleme; es hat alles so funktioniert bzw. ist so gelaufen, wie ich es mir vorgestellt habe. " (BKS 1)

„Eigentlich keine Probleme, aber man muss mit viel Bürokratie rechnen. Man muss wissen, dass man sehr viel herumlaufen muss, also unglaublich oft zum Magistrat und Ämtern und das ist eines der größten Hindernisse. Es ist kein Leckerli, aber wenn man es geschafft hat, weiß man wofür es gut war. Es ist halt ein notwendiges Übel, das einfach dazu gehört. " (BKS 3) 
Die bürokratischen Hürden und etwaige Schwierigkeiten im Umgang mit österreichischen Behörden werden seitens der Experten sehr divergent bewertet und von einigen sogar auch in Frage gestellt:

„Die Selbständigkeit ist in der Türkei und auch in Griechenland enorm hoch. Diese kleine Selbständigkeit ist dort viel alltäglicher und normaler [...]. Viele haben den kulturellen Unterschied zu Österreich nicht realisiert - die viel komplexeren Regelungen und komplizierteren Strukturen. In der Türkei hat man damals eine bestimmte Zahlung geleistet, womit die Steuer erledigt war. Viele Probleme kommen dann zusammen, wie das Durchlaufen eines nicht österreichischen Schulwesens, Sprachprobleme, das Stoßen auf völlig fremde Rahmenbedingungen. Auch der Unterschied zwischen Buchhalter und Steuerberater war nicht bewusst. Alle hatten einen Rechtsanwalt und einen Steuerberater für Dinge, die eigentlich ein Klacks sind. “

„Rein formal ist es schon ein Unterschied, ob EU- oder Drittstaatsangehöriger. Was sich in den letzten Jahren in der Gewerbeordnung getan hat, passt auch zu diesem Paradigmenwechsel. Es sind ja doch einige Erleichterungen gekommen. [...] Bei der Fragestellung, wo die Probleme waren, war für uns in allen Projekten die Bürokratie augenscheinlich. Hier spreche ich vor allem für die türkischen Unternehmer. Hier ist diese extreme Bürokratie unglaublich abschreckend und wird mit jener im Herkunftsland verglichen. Weil dies auseinanderklafft, wird es stärker als Barriere wahrgenommen. Es wäre interessant zu vergleichen, wie das in den jeweiligen Ländern ist. "

Ein - selbst türkischstämmiger - Experte und Entrepreneur zieht die Existenz einer spezifischen Benachteiligungssituation türkischer Unternehmer in Wien grundsätzlich in Zweifel:

„Also, die Ämter machen den Türken keine besonderen Schwierigkeiten. Die sagen das zwar immer wieder, aber das stimmt nicht. Da kenne ich zum Beispiel einen Restaurantbesitzer, der bietet schlechtes Essen an und dann ist seine Unternehmensführung äußerst unprofessionell und dann beklagt er sich, dass er nichts verdient, aber das hat nichts mit den Ämtern oder der Lebensmittelpolizei zu tun, sondern mit ihm selbst und der Qualität seines Angebotes. [...] Aber die Türken werden nicht benachteiligt, weil sie Türken sind - das ist ein Unterschied. Da gibt es ja die Beispiele von erfolgreichen türkischen Unternehmen. “

„Aber nur ein Beispiel. Für eine Betriebsanlagengenehmigung braucht man in Österreich Bescheide von insgesamt sieben Behörden. Natürlich ist so eine Sache kompliziert und unangenehm, aber das müssen alle machen und nicht nur türkische Unternehmer, da kann man nicht sagen, dass da die Türken besonders benachteiligt wären. "

Seitens der Experten eines Personalberatungs- und -vermittlungsunternehmens wird das klischeehafte Bild von den extremen bürokratischen Hürden in Österreich sogar insoweit korrigiert, 
„,[...] dass es in Österreich immerhin leichter ist, ein Unternehmen zu gründen, als in Frankreich."

Es existiert in den diversen Immigrantencommunities inzwischen eine sehr professionell agierende Kategorie von Unternehmensgründern, vor allem wenn es sich um Gründer handelt, die mit einem hohen Ausmaß an unternehmerischem Fachwissen, fachspezifischem Ausbildungsbackground, exzellenten Sprachkenntnissen und Versiertheit im Umgang mit den österreichischen Behörden ausgestattet sind:

„Für intelligente Leute bestehen in Wien keine großen Hürden auf dem Weg zum Unternehmer. Ich habe die Formalitäten für die Gründung nicht schwierig gefunden. War keine extreme Bürokratie. "

„Ich habe meine Firma 2004 relativ problemlos gegründet. Bin mit dem Businessplan zur Bank, habe alles schnell gemacht, ohne Probleme. Viele haben das nicht, da ist das Scheitern dann verzögert, aber vorprogrammiert. "

Ein wichtiges und immer wieder auftretendes Problem ist allerdings die Anerkennung von im Herkunftsland erworbenen Qualifikationen:

„Weil natürlich die Frage der Nostrifikation eine sehr spezifische Frage ist, die die ethnischen Ökonomien betrifft. Ob das, was ich mitgebracht habe, hier gerade beim reglementierten Gewerbe anerkannt wird oder nicht, die Frage wie viel ist logischerweise natürlich eine. Die betrifft ja in Wirklichkeit alle. In der Differenzierung würde man sehr wohl sagen können, dass halt diverse Communities eher im freien - also nicht reglementierten - Gewerbe sind, wo natürlich die Frage der Befähigung keine sehr zentrale Rolle oder eigentlich gar keine Rolle spielt. Bei den Communities, die eher im reglementierten Gewerbe tätig sind, gibt es logischerweise diverse Hürden, wie die Nostrifizierung und das Aufstellen eines gewerberechtlichen Geschäftsführers, wenn die Befähigung vom Unternehmer aus nicht in die Firma mitgebracht wird. "

Einige Informanten berichteten über Ausweichstrategien zur Umgehung formaler Erfordernisse. Nicht selten ist es so, dass die ausbildungsmäßigen Voraussetzungen für die Ausübung bestimmter Gewerbe nicht vorhanden sind. Aus diesem Grund wird eine $\mathrm{GmbH}$ gegründet und ein Geschäftsführer eingesetzt, der qualifiziert genug ist, um die Gewerbeberechtigung zu erlangen. Dies verursacht natürlich höhere Kosten (etwa Gehalt des Geschäftsführers), die für die erste Generation von Unternehmern in der Regel nicht leistbar waren. Selbst zahlreiche Marktstände werden heute als GmbHs geführt.

Seitens etlicher Experten wurde auch keineswegs für eine Simplifizierung oder eine Reduktion von mit der Unternehmensgründung verbundenen Hürden plädiert, sondern - ganz im Gegenteil - die Einschätzung geäußert, dass ein Zuwenig an Gründungsbarrieren auch negative Auswirkungen haben kann. Dies sei daher nicht im Interesse der Förderung der urbanen Wirtschaftskraft sowie letztlich auch nicht im Interesse des einzelnen Entrepreneurs:

„Ich meine auch, man sollte es den Leuten aber nicht zu leicht machen, sonst glaubt jeder, er kann ein Unternehmen gründen und das ist einfach nicht gut. " 
„Derzeit gibt es die Möglichkeit, eine Konzession auszuleihen. Man muss einen verantwortlichen Geschäftsführer anmelden, dieser hat dann keine eigene Konzession und oft auch keine Fachkompetenz. Da ist das Scheitern dann oft nur verzögert. “

„Das glaube ich nicht, dass zu viele Hürden sind. Denn was bringt es, wenn das alles viel zu leicht ist. Wer gebildet und motiviert ist, der überwindet die auch. Nur die Starken überleben und wenn schon für die Gründung viele Hürden sind, dann gibt es auch nicht so viele Unternehmen, die wieder in Konkurs gehen. Dann später als Unternehmer muss man auch Stärke haben, das ist nicht immer leicht. Viele stellen sich das viel zu leicht vor und sind dann überrascht. "

,,Wenn ich den Zugang zu sehr erleichtere, kann es sehr leicht nach hinten losgehen. Wenn es schief geht, kosten die Menschen dem Staat etwas. Weil sie sich mit den Abgaben, die nicht entrichtet worden sind, verabschieden. Ich bin keine Anhängerin davon, es zu locker zu machen. [...] Ich würde aber auch nicht meinen, dass es in Österreich unglaublich schwierig ist, sich selbständig zu machen. Weil die Regelung, einen gewerberechtlichen Geschäftsführer anzustellen, sehr viel Bewegungsfreiheit bietet [...]. “

Wie eigentlich zu erwarten ist, reduziert der Faktor der höheren Bildung die Sprachbarriere merklich und erleichtert den Umgang mit Formalitäten und institutionellen Hindernissen. Zudem bestehen Divergenzen zwischen den beiden Herkunftsgruppen. Dazu aus der Perspektive der Experten:

,Wenn die Leute Deutsch sprechen würden, dann wäre alles schon viel besser. Dann ginge nicht so viel an Potential verloren, denn das Potential ist ja da. Hätten die Kinder - so wie ich damals - schon Deutsch gesprochen, so wären sie heute auch in Österreich in den Ministerien tätig. Es geht in erster Linie um die Sprache."

„Ja, das sind wieder die Sprachprobleme, die kulturellen Probleme. Aber ich sage, wenn jemand wo leben möchte, dann muss er sich mit der dortigen Kultur anfreunden. Und oft ist es die eigene Unfähigkeit und nicht wie man so oft hört: ,Wir werden benachteiligt, weil wir Türken sind" ".

„Die Sprache ist ein Türöffner. “

Zum Unterschied vom Problemkomplex Bürokratie, der seitens der Selbständigen ambivalent beurteilt wurde, positionierten sich Finanzierungsschwierigkeiten in der Rangliste der Probleme an der ersten Stelle. Beträchtliche Unterschiede zwischen Unternehmern mit und ohne Migrationshintergrund manifestieren sich hinsichtlich der Inanspruchnahme von Bankkrediten. Migranten nehmen viel seltener Bankdarlehen in Anspruch, sondern häufiger informell ausgehandelte Darlehen von Familienmitgliedern, Freunden, Partnern etc. Die Vorteile solcher Darlehen liegen auf der Hand: häufig niedrigere Zinssätze, keine fixen Rückzahlungsraten und -fristen - die Unternehmer zahlen gerade so viel zurück, wie sie können. Ein damit einhergehender Nachteil ist aber ein Gefühl der Verpflichtung bzw. eine emotionale oder De-facto-Abhän- 
gigkeit. Eltern oder Ehepartner versuchen zudem mitunter, in unternehmensinterne Entscheidungsprozesse Einfluss zu nehmen. Vor allem die hohe, konstante Zinsbelastung von Bankdarlehen wirkt abschreckend. Die Nichtinanspruchnahme von Bankdarlehen ist in der Regel keine Folge von Informationsdefiziten, wie dies immer wieder angenommen wird. Auch berichtete so gut wie kein Respondent oder Experte von negativen Erfahrungen, die Migranten mit Mitarbeitern von Wiener Banken gemacht hätten, es ist jedoch nicht auszuschließen, dass Banken ausländischen Staatsbürgern gegenüber strikter hinsichtlich der nötigen Garantien agieren. Eine wiederholt (z.B. seitens MINGO) angesprochene Hürde besteht darin, dass Unternehmer mit Migrationshintergrund häufig über keinen Businessplan verfügen. Darüber hinaus können sie im Kreditantragsprocedere öfter keine konkreten Angaben zum Rückzahlungsplan machen. Die gesamte Antragsprozedur ist jedoch überaus aufwendig und selbst für Antragsteller mit guten Deutschkenntnissen ist die facheinschlägige Terminologie schwer verständlich:

„Ja, am Anfang gab es sehr viele Probleme vor allem mit dem Geld. Sogar jetzt noch; trotz vieler Stunden Arbeit habe ich wenig Geld. " (T 11)

„Wenn man Neueinsteiger ist, hat man große Schwierigkeiten mit der Buchhaltung. Entweder muss man jemanden einstellen, der das für einen macht oder man lernt es selbst, was ziemlich schwierig für mich war. Für Taxis braucht man spezielles Equipment und das kostet wiederum viel Geld. Also braucht man sehr viel Eigenkapital, um so ein Unternehmen zu führen. Es gibt zu viele Ausgaben am Anfang, die schwer zu kontrollieren sind. Autoversicherungen sind ebenso sehr schwer zu kriegen. " (T 1) fiziert:

Die Eigenkapitalfrage wird auch von den interviewten Experten als wichtig klassi-

„Die Türken haben ja auch kein Kapital, die Chinesen die kommen bereits mit dem Kapital für eine Unternehmensgründung aus China hierher [...] “.

„Wir wissen, dass sehr viele Menschen mit Migrationshintergrund im Rahmen ihrer unselbständigen Erwerbstätigkeit im Verhältnis zur Mehrheitsgesellschaft weniger verdienen. Daher ist die Wahrscheinlichkeit relativ gering, mit einem guten Eigenkapital durchzustarten. Richtig, das Risiko ist höher. Die Bereitschaft der Banken, etwas dazuzugeben, ist relativ geringer. Es schaukelt sich hoch. Wenn die Menschen ein Eigenkapital haben, versuchen sie eine Geschäftsidee zu realisieren, die dann auch im jeweiligen Rahmen bleibt. Es wird jetzt kein großer Betrieb werden, wo man sehr viel produziert. Es wird in einem kleinen überschaubaren Bereich bleiben. "

Ebenso problematisch war für manche Starter aber auch die Mitarbeiterakquisition, wobei diese vielfach in einem Spannungsfeld zwischen den aus betriebswirtschaftlicher Perspektive erforderlichen Qualifikationen einerseits und familiären Obligationen andererseits stattfindet. Darin manifestiert sich eine spezifische Problemlage der Ökonomie der Migranten. Wie die umfangreiche Mannheimer Studie feststellte (Leicht 
et al. 2012), bestehen hinsichtlich der Mitarbeiterakquisition beträchtliche Unterschiede zwischen den Herkunftsgruppen, vor allem die Mitarbeitersuche innerhalb der eigenen Migrant Community betreffend. Einige Facetten der diesbezüglichen Probleme beschrieben unsere Experten folgendermaßen:

„Eine Geschichte, die sich gerade bei der Unternehmensführung manchmal als fast fatal entpuppt, ist die Frage der Personalentscheidung. [...] Die Gründe und die Motivation für Personalentscheidungen werden ja in den unterschiedlichen Communities ein bisschen anders getroffen. Das heißt, sie werden zum Beispiel den Grund dafür haben, dass eine Person aus meinem Dorf kommt und ich kenne die Eltern und sie braucht halt einen Job [...]. "

„Wir haben unser Personal aus vielen unterschiedlichen Ländern und eigentlich nur wenige aus Jugoslawien. Auch bildungsmäßig sind wir ganz verschieden, das müssen keine WU-Absolventen sein. "

„Die mangelnde Qualifikation schaukelt sich in diesem Gesamtbild hoch. Wenn ich mit unqualifizierten Mitarbeitern arbeite, ist die Wahrscheinlichkeit, dass ich irgendwann einmal ins Schleudern komme, viel, viel höher. Auch die Wahrscheinlichkeit, dass ich mich von einem Mitarbeiter, der mir Probleme macht, trennen muss, ohne meine sozialen Netzwerke oder meine persönlichen Beziehungen zu beleidigen, ist eine schwierige Entscheidung. Das ist sicher etwas, was gerade im Bereich der ethnischen Ökonomien ein Problem darstellt, wie ich das schon beobachte. "

„,Der Druck ist enorm hoch und die Kompetenzen innerhalb der Familie werden nicht in Frage gestellt. “

„Das ist doch ein Spezifikum der türkischen Community. In osteuropäischen Communities oder BKS-Communities [...] entscheidet man doch eher nach Qualifikationskriterien, wenn man neues Personal akquiriert. Weniger nach Verwandtschaft, was auch vorkommen kann, aber eher untergeordnet sein wird. "

„Das deckt sich doch mit der Wahrnehmung, dass sich diese Gruppen [gemeint: Osteuropäer] durchdachter an die Sache heranbewegen und die Dinge besser abwägen. Vielleicht sind sie sich dessen sehr bewusst, dass man unterschiedlichste Fähigkeiten und Qualifikationen selbst als Unternehmer mitbringen muss, um nicht auf die Schnauze zu fallen. “

Die Sprachbarrieren machen sich in der Gründungsphase besonders negativ bemerkbar. Ein Respondent mit niedrigem Bildungsabschluss beschrieb diese Problematik folgendermaßen:

„,Ich hatte keine anderen Probleme außer mit der Verständigung. Die deutsche Sprache ist eine schwere Sprache! Dabei haben mir meine Freunde geholfen, ich meine mit Übersetzungen usw. " (BKS 12)

Die sich im Zuge der Anwerbung von Kunden aus der Mehrheitsgesellschaft ergebenden Problemkonstellationen, vor allem in Bezug auf die Sortimentsauswahl, werden seitens der Experten unterschiedlich dargestellt: 


\begin{abstract}
„Interessant ist, welche Strategien Unternehmer anwenden, um auch Kunden der Mehrheitsgesellschaft anzusprechen. Konkret wurde dies an türkischen Lebensmittelhändlern durchgespielt. Wir haben festgestellt, dass eine vorhandene Strategie noch lange nicht zum Erfolg führt. Umgekehrt gibt es Unternehmen, die überhaupt keine Ambitionen haben, Break-Out zu betreiben. Zufällig haben sie ihr Geschäft in der Brunnengasse, wo bevorzugt Studenten hinkommen und dort einkaufen. Damit wird dieses Unternehmen mitunter zu einem BreakoutUnternehmen, obwohl es nie intendiert war. Häufiger war zu beobachten, dass es durchaus Ambitionen gibt, es allerdings nicht funktioniert. "

„Probleme gibt es speziell in der türkischen Community, wenn Strategien angewandt werden, die Veränderungen im Produktsortiment betreffen. "

„Ein klassischer Fall ist das Angebot von Alkohol. Damit wird versucht, auch Österreicher und Österreicherinnen anzusprechen. Dies stößt auf großen Widerstand in der Community bzw. wird gar nicht in Betracht gezogen, weil man die in der Community wichtigen religiösen Vorschriften nicht verletzen kann. "
\end{abstract}

\title{
3.5.2.3 Support in der Gründungsphase
}

Die auf Unternehmensgründer und -gründerinnen zukommenden vielfältigen Anforderungen bringen es mit sich, dass kein Gründer auf Unterstützungen seitens seines privaten Netzwerkes und/oder institutionalisierter Fördergeber verzichten kann, will er/sie längerfristig erfolgreich sein. Die diesbezügliche Frage richtete sich auf drei Teilaspekte im Kontext der Supportleistungen: „Wer hat Sie am Anfang, also in der Gründungsphase, unterstützt? Wie lange brauchten Sie die Hilfe und welche Gegenleistung haben Sie dafür erbringen müssen, wenn es sich um Personen oder andere Firmen handelte?"“

Die überragende Rolle des familiären Netzwerkes als Unterstützung in der Gründungsphase vor allem für die türkischen Unternehmer im Sample ist evident (vgl. auch Leicht et al. 2006). Bei zwölf von ihnen gingen die wichtigsten Hilfestellungen von Familienangehörigen aus. Auch aus der Perspektive der Experten repräsentieren die Netzwerke einen ganz zentralen Faktor, der die Gründungsbereitschaft sowie den Gründungserfolg innerhalb der betreffenden Community in entscheidender Weise determiniert:

„Das heißt, ein türkischer Unternehmer hat es in der Regel sicherlich geschafft, im Rahmen seiner unternehmerischen Tätigkeit, dass er entweder innerhalb seines Familienverbandes oder innerhalb seiner Umgebung ein paar andere noch , angesteckt' hat, die sich dann letztendlich auch dafür entschieden haben, sich selbständig zu machen. Das heißt, in diversen Communities funktionieren die Netzwerke, wo es dann vielleicht doch ein bisschen leichter ist, sich selbständig zu machen. [...] Außer in den Bereichen oder in den Communities, wo sie von Haus aus aufgrund ihrer geringen Anzahl es ein bisschen schwieriger haben, wie die Afghanen zum Beispiel. Dieses Netz ist sehr unmoderiert, sehr klein, sehr unstrukturiert und deshalb müssen sie sich dann halt selbst auf die Beine stellen. " 
Allerdings sind den Netzwerken aus der Expertenperspektive keineswegs ausschließlich positive Effekte zuzuschreiben:

„Es werden immer diese Netzwerke als Erklärung erwähnt, warum es zum Beispiel bei den Chinesen und Chinesinnen dichte Netzwerke gibt und deshalb alle in die Gastronomie gehen. Zum einen ist es etwas kurz gegriffen, dies auf diese Art und Weise zu erklären. Zum anderen finde ich bei diesem Ressourcenansatz bemerkenswert, dass es schon eine Idealisierung dieser Netzwerke gibt, was unter Sozialkapitalromantik auch in der Literatur zu finden ist. Da haben wir schon ganz deutlich gesehen, dass es durchaus negative Effekte von diesem Sozialkapital geben kann oder Barriere für Unternehmensexpansion gesehen. "

Anders gestaltet sich die Relevanz des familiären Umfelds bei Gründern mit hoher Professionalität. Diese sind kaum bis gar nicht auf privat-familiäre Unterstützung angewiesen, da sie über alle erforderlichen Kompetenzen und oftmals auch über entsprechende Kapitalausstattung verfügen.

„Bei den türkischen Unternehmern ist vieles nicht Planung, sondern mehr Improvisation und Zufall. Ich selber bin ja sozusagen in Japan angelernt worden. Ich habe vieles aus meiner Tätigkeit in einem japanischen Betrieb gelernt und daher einen ganz anderen Zugang als die ,typischen' türkischen Unternehmer. Bei mir war vieles eigentlich ganz anders. “

Ein Unterschied zwischen den beiden Herkunftsgruppen besteht allerdings darin, dass bei den türkischen Befragten die Familie auch im weiteren Verlauf der Unternehmensführung nach wie vor eine wichtige Rolle spielt, während sie bei den exjugoslawischen Respondenten viel häufiger nur für einen begrenzten Zeitraum am Beginn Hilfestellungen zur Verfügung gestellt hat und familiäre Unterstützungsleistungen mit zunehmender Etablierung des Unternehmens immer mehr in den Hintergrund treten. Mehrere exjugoslawische Unternehmer wandten sich zwecks Unterstützung an ihr Kreditinstitut, einer an einen Vertreter der rechtskundigen Berufe und einer hat das Angebot der Jungunternehmerförderung in Anspruch genommen.

Zum Zwecke der Finanzierung der Unternehmensgründung griffen sechs der 30 Unternehmer ausschließlich auf einen Bankkredit zurück, darunter vier türkische und zwei exjugoslawische Befragte. Familie und Freunde spielten ebenfalls eine gewisse Rolle als alleinige (temporäre) Geldgeber beim Gang in die Selbständigkeit, und zwar im Fall von sechs Unternehmern (jeweils drei Befragte je Gruppe). Zehn Unternehmer (sechs türkische und vier exjugoslawische) haben ausschließlich durch eigenständiges Ansparen das nötige Eigenkapital zusammenbekommen. Sieben Befragte haben mehr als eine Geldquelle für die Unternehmensgründung kombiniert, die meisten hatten Eigenmittel zur Verfügung und besorgten sich das restliche Kapital von ihrer Familie oder in Form eines Bankkredits. Mit der familiären Kreditgewährung ist nicht selten auch das Eingehen von Verbindlichkeiten verbunden:

„Oft ist es eine Gegenleistung dafür, dass von den Verwandten ein Kredit gegeben wird. Im Gegenzug soll dafür der Neffe angestellt werden. " 
Gerade im muslimischen Bereich stellt die Kreditaufnahme in religiös geprägten Kreisen ein Problem dar. In Städten wie Amsterdam, Frankfurt oder Birmingham hat sich das Ethnobanking in vielen Kreditinstituten bereits fest etabliert, in Österreich besteht diesbezüglich noch Aufholbedarf, meinten einige Experten:

„Es gibt vielleicht auch religiöse Probleme bei der Kreditvergabe. Mittlerweile gibt es auch Banken, die das Ethnic Banking betreiben. "

Die Finanzierung von Vorhaben in der laufenden Unternehmensführung kann von den meisten befragten Entrepreneurs ausschließlich aus den erwirtschafteten Eigenmitteln bestritten werden, wobei dies auf BKS-Befragte um einiges häufiger (13) zutrifft als auf türkische Unternehmer (7). In der letztgenannten Gruppe erhalten einige Selbständige nach wie vor finanzielle Hilfe von Familienangehörigen und Freunden oder von einer Bank. Da die Antworten im Rahmen dieser Frage zumeist aus einer unkommentierten Aufzählung der unterstützenden Personen/Institutionen bestanden, wird an dieser Stelle auf die - nicht aussagekräftige - Zitation aus den Interviews verzichtet.

\subsubsection{Inanspruchnahme von Beratung und Förderung}

\subsubsection{Private und institutionelle Beratung vor der Unternehmensgründung}

Neben der Unterstützung in finanzieller Form oder durch konkrete Arbeitsleistungen spielt selbstverständlich auch Beratung in der Gründungsphase eine erhebliche Rolle. Ausgehend von der Relevanz institutionalisierter Beratungsangebote, die sich entweder an alle Gründer unabhängig von ihrer Herkunft oder speziell an Selbständige mit Migrationshintergrund richten (sollten), erschien es uns wichtig, den Aspekt der faktischen Inanspruchnahme vorhandener Beratungs- und Informationsangebote durch die Befragten aus beiden Herkunftsgruppen näher zu beleuchten.

Da bei dieser Frage seitens der Unternehmer zumeist nur Aufzählungen verbalisiert wurden, jedoch keine inhaltsanalytisch aussagekräftigen Zitate, erfolgt die nachstehende Analyse auf Basis der wichtigsten Nennungen. Trotz der Heterogenität der Angaben lassen sich aus unserem Sample Trends herauslesen. Keinerlei Beratung hat nur eine kleine Minorität von drei Befragten eingeholt, wobei es sich durchwegs um türkische Unternehmer handelte. Familienmitglieder, Freunde und Bekannte spielen als Berater vor allem in der türkischen Herkunftsgruppe eine dominierende Rolle und dies unabhängig vom Bildungsniveau des Gründers.

Der ehemalige Arbeitgeber, frühere Arbeitskollegen sowie andere Selbständige treten in erster Linie in der BKS-Gruppe als private Ratgeber hervor. Sechs von sieben Angaben in dieser Kategorie stammen von Personen aus dem BKS-Raum. Ebenfalls siebenmal wird die Wirtschaftskammer mit ihren zahlreichen Beratungsangeboten angeführt. Es hat also immerhin ein rundes Viertel der Unternehmer ein Beratungsangebot dieser offiziellen Interessenvertretung in Anspruch genommen. Türkische (fünf) und BKS-Respondenten (vier) sind in dieser Kategorie in nahezu analoger Häufigkeit vertreten, vor allem, wenn man jenen Fall eines bosnischen Gastronomen hinzuzählt, der 
Informationseinholung über das Internet plus die WKW angegeben hat, sowie jenen türkischen Großgastronomen, der die Kammer und eine große Bandbreite weiterer Informationsquellen in seine Aufzählung einbezog. Die Konsultationsleistungen der Kammer werden in vier Fällen auch ergänzt durch Beratung seitens Kollegen, Freunden oder anderer Unternehmer. Das Internet als Informationsquelle scheint sich überraschenderweise noch nicht sehr stark etabliert zu haben. Es findet nur dreimal Erwähnung und dies ausschließlich seitens exjugoslawischer Respondenten. Zwei Selbständige haben eine Kombination einer Vielzahl an Beratungsmöglichkeiten, private wie institutionelle, angegeben.

Die befragten Experten wiesen in Bezug auf die Problematik der mangelnden Inanspruchnahme von Beratung auf einige Aspekte hin: das lange bestehende Defizit an muttersprachlichen Beratungsangeboten, die herkunftsgruppenspezifischen Unterschiede, aber auch eine gewisse Schwellenangst, die doch einige daran hindert, existente Angebote auch wirklich zu nutzen:

„Lange Zeit wurde überhaupt nicht auf die Bedürfnisse von migrantischen Unternehmern Rücksicht genommen. Mehrsprachige Folder gibt es ja noch nicht so lange. Hier finde ich nicht nur den Vergleich mit den Communities spannend, sondern auch jenen mit der Mehrheitsgesellschaft. Laut einer Studie wissen 40\% überhaupt nichts von diesen Unterstützungsleistungen und nur ganz wenige lassen sich beraten. Es wurde aber nicht mit den heimischen Unternehmen verglichen."

„Bevor diese Initiativen in der Wirtschaftskammer gesetzt wurden, wurde die Wirtschaftskammer von den türkischen und exjugoslawischen Unternehmern als eine österreichische Einrichtung für Österreicher wahrgenommen. Sie haben sich hier in keiner Art und Weise wiedergefunden und es war auch so. Das hat in der Wirtschaftskammer seinerzeit niemand als Problem gesehen. Die Migranten haben das ganz realistisch gesehen und eine sehr konkrete Einschätzung der Lage vorgenommen."

Allerdings werden auch (inzwischen) vorhandene Angebote nur bedingt angenommen. Laut L\&R-Studie (2007: 97 ff.) etwa hatten beispielsweise nur 19\% der Unternehmer Gebrauch von Jungunternehmerförderung bzw. Jungunternehmerkrediten o. Ä. gemacht. Die befragten Experten führten dazu weiters aus:

„Also ich habe den Eindruck, dass diese Hilfen nicht so sehr in Anspruch genommen werden von der türkischen Community. Das liegt zum einen an der Sprache und dann ist es nötig, die Schwelle zu überschreiten zwischen diesen beiden Kulturen und das wollen viele nicht."

„Bei den Netzwerken der eigenen Community gibt es schon communityspezifische Unterschiede, wo eher auf Informationen der eigenen Community vertraut wird und deshalb gar kein Bedarf besteht, zu einer Beratung zu gehen. In der chinesischen Gastronomie gibt es unglaublich viel communityspezifisches Wissen über den Aufbau eines Lokals. Hier besteht gar kein Bedarf, irgendwo hinzugehen. “ 
„Das [Anm.: Beratung] ist die eine Variante. Die andere ist durchaus der Ehrgeiz, alles alleine und selber machen zu wollen. Das haben wir in Interviews sehr oft gehört. Man ist zu stolz, um sich helfen zu lassen. Vielleicht gibt es in Wirklichkeit auch diverse Hemmungen und Angst vor der Bürokratie, zu einer Beratung zu gehen. Bei allen geführten Interviews aus der chinesischen, türkischen und indischen Community hat niemand erzählt, großartig Beratung in Anspruch genommen zu haben. Sie haben von der WKO Einladungen erhalten, eine Gründungsberatung in Anspruch zu nehmen. Wirklich hingegangen ist dann niemand. "

„Unterschiedliche Communities nehmen MINGO in unterschiedlichem Ausmaß in Anspruch. Von der russischen Community kommt kaum Resonanz, obwohl sie 23.000 Mitglieder umfasst. “

Ein wichtiges Resultat unserer Interviews war, dass die Dauer des Aufenthalts in Österreich und die Zugehörigkeit zur ersten oder zweiten Generation weitere relevante Determinanten der Inanspruchnahme von Beratung und Förderungen sind. Mit zunehmender Dauer des Aufenthaltes steigt auch die Wahrscheinlichkeit, sich um Förderungen zu bemühen. Unternehmer der zweiten Generation erweisen sich als besser informiert und bewerben sich auch aktiv um Förderung. In der Gruppe der österreichischen Staatsbürger scheint der Anteil der sich erfolgreich um Beratung und Fördergelder Bemühenden tendenziell etwas höher zu sein als bei den Ausländern, jedoch kann dies nicht exakt nachgewiesen werden. Mit Sicherheit haben sich jedoch Unternehmer der 1970er- und 1980er-Jahre so gut wie gar nicht um finanzielle Förderungen bemüht. Allerdings ist aus heutiger Perspektive nicht nachzuweisen, ob dies primär an einem Mangel an Fördermöglichkeiten lag oder durch Informationsdefizite verursacht war. Laut L\&R-Studie (Enzenhofer et al. 2007: 98 f.) ist es vor allem die Motivationsstruktur, die eine wichtige Rolle für die Entscheidung spielt, in welchem Ausmaß Förderungen in Anspruch genommen werden. Das Bildungsniveau sowie die Deutschkenntnisse sind jedenfalls wesentliche Einflussfaktoren.

\subsubsection{Private und institutionelle Beratung nach der Start-up-Phase: Situation zum Erhebungszeitpunkt}

Keiner der befragten Unternehmer befand sich zum Zeitpunkt der Befragung in der Gründungsphase, alle führten ihren Betrieb bereits seit einiger Zeit. Aber auch bei bereits länger auf dem Markt etablierten Unternehmen können Probleme auftreten, die die Einholung von Ratschlägen opportun erscheinen lassen. Es wurde daher auch nachgefragt, an wen sich die Unternehmer bei aktuellen Problemen wenden.

Es waren drei Personen, die durchwegs keinerlei Beratungsleistungen einholten. In 13 Fällen (sechs türkische und sieben exjugoslawische Respondenten) traten private Netzwerke von Familienangehörigen sowie Bekannte oder Freunde als Ratgeber in Erscheinung. 
„Hauptsächlich meine Freunde, die auch in dieser Branche selbständig sind. Die haben die meiste Erfahrung und oft mit denselben Problemen zu kämpfen wie ich. " (BKS 5)

„, Meine Gattin und mein Vater sind lange in der Branche tätig gewesen und somit kann mir keiner einen besseren Rat geben, als die beiden geben können. “ (BKS 11)

Eine zusätzliche Kategorie von Beratern, die in der Gründungsphase so gut wie gar nicht aktiv wird, erhält bei bereits eingeführten Unternehmen allerdings zunehmende Wichtigkeit und wird von sechs Befragten angeführt. Es sind dies Professionisten wie Anwälte, Steuerberater sowie Buchhaltungsexperten. Dazu eine Auswahl von Expertenstatements:

„Jetzt ein neuer Trend, dass sich viele als Unternehmensberater selbständig machen, als Wirtschaftsprüfer und Steuerberater - aber das ist eher in der türkischen Community zu beobachten als bei Exjugoslawen. "

„Das, was mir sehr stark auffällt, ist alles was im Bereich Marketing und Werbung passiert, aber auch Beratung und Entwicklung von Konzepten. Das Lustige an der ganzen Geschichte ist, man macht das ja auch für die eigene Community und man weiß, wie die eigene Community tickt und wie die eigenen UnternehmerInnen aus der jeweiligen Community ihre Kunden und Kundinnen ansprechen wollen und bietet aber auch dementsprechende Angebote an. "

Des Weiteren wird die Inanspruchnahme offizieller Beratungsstellen und -institutionen ins Treffen geführt. Hier dominiert, der Zahl der Nennungen gemäß, die Wirtschaftskammer Wien:

„Am besten für mich ist es, direkt zur Wirtschaftskammer zu gehen und selbst die nötigen Auskünfte einzuholen. " (BKS 13)

Allerdings bestehen über Ziele und Funktionen der Kammer mitunter sehr unklare Vorstellungen, wie das Statement einer Expertin illustriert:

„Die haben die Vorstellung, die Wirtschaftskammer ist eine Art von Finanzamt.

Da haben sie wirklich Angst vor Beratung. “

Nur zwei Respondenten geben eine größere Zahl von Beratungshilfen an, wobei auch hier Freunde und Verwandte (neben anderen) aufgezählt werden. Einerseits werden im Falle von Beratungsbedarf also nach wie vor in erster Linie Personen, zu denen der Unternehmer in einem persönlichen Naheverhältnis steht, zu Rate gezogen, andererseits wird auch die WKW in sechs Fällen als relevant angeführt. Dies zum Teil in Kombination mit weiteren Personen oder Institutionen.

Wir haben des Weiteren auch nach der Herkunft der Ratgeber und Ratgeberinnen gefragt, da es uns interessierte, inwieweit dabei die Grenzen der eigenen ethnischen Community überschritten werden oder nicht. Im Vergleich der beiden Herkunftsgruppen zeigt sich, dass exjugoslawische Unternehmer sehr viel häufiger als türkische Selbständige Ratgeber involvieren, die nicht ihrer eigenen Herkunftsgruppe angehören. Nur ein Respondent hat angegeben, von überhaupt niemandem Ratschläge zu benö- 
tigen, denn er hat sein Unternehmen bereits 1973 gegründet und einen profunden Erfahrungshintergrund:

„Ich bin eine Person, die nur auf sich selbst hört und Entscheidungen trifft. “(T 9)

Als primäre Begründungen der Präferenz für Ratgeber aus der eigenen Migrant Community werden der Aspekt der gemeinsamen Sprache sowie manchmal auch das ausgeprägtere Vertrauen in die eigenen Landsleute besonders hervorgehoben:

„Durch die gleiche Sprache bzw. Religion ist es natürlich leichter, Hilfe zu kriegen von diesen Menschen. Man hilft sich gerne und sieht es auch als gute Tat im religiösen Sinne an. " (T 15)

„Ja, ich informiere mich gerne bei meinen Leuten. Ich weiß, ich kann ihnen vertrauen und dass sie aus eigener Erfahrung sprechen. " (BKS 2)

Einige Unternehmer haben aber ihre Bereitschaft signalisiert, auch Ratschläge und Informationen von Personen außerhalb der eigenen Herkunftscommunity einzuholen:

„Ich mache da keinen Unterschied, ob ich die Informationen von einem meiner Herkunftsgruppe oder einem Österreicher bekomme. Hauptsache ich kann mit der Information etwas anfangen und sie hilft mir weiter. " (BKS 3)

„Ich hole mir bei verschiedenen Leuten Informationen und diese stammen aus verschiedenen Gruppen und nicht nur aus meiner. " (BKS 10)

Eine Expertin aus einer Beratungsinstitution machte überdies zur Frage der institutionellen Beratung detaillierte Angaben, von denen auszugsweise die Folgende angeführt werden soll:

„Sie werden schon mit den Hürden und Herausforderungen, die hundertprozentig auftauchen werden, konfrontiert. Unser Ziel ist schon, dass die Leute nachhaltig zu uns kommen. Das ist uns sehr wichtig, und deshalb führen wir auch persönliche Orientierungsgespräche mit den Menschen und den Gründern und Gründerinnen durch, weil wir sie in einem Face-to-Face-Gespräch abklopfen möchten, wie ernst sie sind und welche Motive es gibt, und ob es aufgrund der Idee eine Chance gibt."

\subsubsection{Diverse Aspekte der unternehmerischen Performance}

\subsubsection{Probleme der Unternehmensführung}

Von Problemen, die in der laufenden Unternehmensführung nach der Phase der Gründung auftreten, waren und sind die meisten Unternehmer im Sample betroffen. Unterschiede zwischen exjugoslawischen und türkischen Entrepreneurs oder nach dem Bildungsniveau sind kaum nachweisbar. Es besteht eine schwach ausgeprägte Tendenz, dass ein höheres Bildungsniveau mit einer etwas geringeren Problemvirulenz einhergeht. Ein Experte gab zur Problematik der Unternehmensführung das folgende Statement ab: 
„Es geht in erster Linie um die unternehmerische Compliance und um die Kenntnis der wichtigen Regeln, denn Österreich hat eine sehr gut funktionierende Unternehmensgesetzgebung. "

Insgesamt haben neun Unternehmer (vier aus der Türkei und fünf aus dem ehemaligen Jugoslawien) angegeben, keinerlei Schwierigkeiten in der laufenden Unternehmensführung gehabt zu haben. Gemessen an der Zahl der Nennungen scheinen die Personalakquisition sowie die Etablierung eines ausreichenden Kundenstocks (auch in Kombination) die beiden schwerwiegendsten Problemfelder für Unternehmer in beiden Herkunftsgruppen zu sein:

„Ein Problem war es, Köche zu finden, die die türkische Küche beherrschen und sich auskennen, weil damals noch ganz wenige in Wien lebten. "(T 1)

„Mir fiel es mir besonders schwer, Kunden zu gewinnen. Mein Konzept war unterschiedlich von anderen, deswegen ist die Kundengewinnung sehr schwer gewesen. " (BKS 8)

Sogar wenn das Geschäft sich bereits einigermaßen etabliert hat, stellen Kunden und Mitarbeiter, d.h. deren Wünsche und Ansprüche, stets neue Herausforderungen an den Unternehmer:

„Später war es schwer, qualifizierte Arbeiter zu finden. Oft gab es auch Probleme mit den Kunden. Gute Rohstoffe für Süßwaren sind extrem schwer aufzufinden. Ich vertraute meinen Söhnen, sonst hätte ich das Geschäft überhaupt nicht eröffnen können. Wir wollten die Waren nach islamischer Art zubereiten (kein Alkohol usw.) und das war ebenfalls schwer. " (T 15)

Ein Experte und Unternehmer meinte dazu:

„Leider kommt es aber oft auch dazu, dass sich die türkischen Mitarbeiter mehr als Chefs aufführen, wenn sie länger da sind. Die denken sich, ,das ist ein türkisches Unternehmen und die Geschäftsführer sind Türken, da kann ich mich auch wie ein Chef aufführen: Das haben wir daher später zurückgeschraubt auf die Schlüsselstellen. Jetzt sind in unserem Team auch viele Österreicher, auch viele Jugoslawen, Polen und auch Deutsche. "

Die Barrieren seitens der Bürokratie sowie der (steuer)rechtlichen Rahmenbedingungen wurden ebenfalls genannt:

„Die Auflagen bzw. Verträge sind ein Problem, die Wirtschaftskammer hilft uns dabei nicht sehr viel. Wir brauchen mehr Hilfe. “ (T 10)

„Am schwersten ist mir der Papierkram gefallen und der Prozess mit den Ämtern. Wenn man die Sprache nicht so gut kann und gewisse Begriffe aus dem Wirtschaftswesen nicht kennt, ist man manchmal echt verloren. Ich bin deswegen meistens mit einer Begleitperson zu den Ämtern gegangen. “ (BKS 2)

Legistische Hürden und Defizite an diesbezüglichem Fachwissen werden auch in Expertenaussagen angesprochen: 


\begin{abstract}
„Da nenne ich nur ein Beispiel: zum Beispiel die Körperschaftssteuern. Da gibt es ein großes Unwissen der türkischen Unternehmer. Da fehlt einfach die Auseinandersetzung damit, welche Infrastruktur eigentlich notwendig ist. Es gibt nur eine reine Orientierung am Gewinn: ,Da verkaufe ich etwas um 10.000 und mach dabei 5.000 Euro Gewinn! - so denken diese Leute. Und dabei ist eine fehlende Orientierung und völliges Unwissen über die ganze Stenergesetzgebung. “

Als weiteres Problemfeld wurden einmal mehr auch die Finanzen aufgezählt:

„Das Schwierigste war, dass man dafür sorgt, dass möglichst viel Kapital hereinkommt. Wir hatten zwar unser eigenes Standbein (kleine eigene Projekte), jedoch weiß man nie genau, ob diese Erfolg haben werden oder nicht. Am wichtigsten war es, einen Spagat zu schaffen zwischen dem, was man machen will und machen muss. "(BKS 3)
\end{abstract}

\title{
3.5.4.2 Kundenstruktur und -akquisition
}

Ein hohes Ausmaß an Flexibilität in der Reaktion auf sich rasch wandelnde Marktverhältnisse wurde immer wieder als die wichtigste Voraussetzung erfolgreicher Marketingstrategien genannt. Es besteht ein komplexes Interaktionsverhältnis zwischen der Kundenstruktur, dem Angebot, den individuellen Businesskonzepten und den bevorzugten Marketingstrategien der Unternehmer. Die Mehrheit der Migrantenunternehmen versucht, möglichst den Nachfragewünschen aller Kunden gerecht zu werden und artikuliert ein Profitinteresse, welches weit über den Markt der eigenen ethnischen Community hinausgeht. Klassische Nischenökonomie ist zwar nach wie vor existent, repräsentiert jedoch nur einen Teil der in unserem Sample abgebildeten Migrant Economy. Unternehmen, die keine spezifisch auf eine Community zugeschnittenen Dienste offerieren, greifen zu Werbestrategien, die sich in keiner Weise von jenen der österreichischen Unternehmen unterscheiden. Wangs (2008) Analysen ergaben, dass die chinesischen Gastronomen der zweiten Generation vor allem Marketingstrategien wählen, die bewusst eine Grenze zu den Restaurantbetreibern der ersten Generation ziehen.

Viele Respondenten gaben an, dass vor allem in der Start-up-Phase die generelle Qualität der Einbettung des Unternehmers in seine Herkunftscommunity eine wichtige Rolle im Rahmen der Etablierung von Absatzmärkten und des Kundenstocks spielt. Soziale Netzwerke und Marketingstrategien sind häufig mehr oder minder stark ineinander verwoben. Freundes- und Familiennetzwerke spielen eine Mediatorenrolle in der Initiierung von Kontakten im Start-up-Prozess. Diese Solidarität ist ein Element von beträchtlicher Stabilität für jedes sich neu auf dem Markt etablierende Unternehmen, tritt in den einzelnen Zuwanderercommunities aber unterschiedlich stark in Erscheinung. Starke Netzwerke existieren in der türkischen, indischen und chinesischen Gruppe, sind aber, und darin waren sich alle befragten Experten einig, bei BKSImmigranten viel schwächer ausgeprägt.

Die Marktpositionierung eines Unternehmens findet ihre deutlichste Widerspiegelung vor allem in den Kundenstrukturen. In unserem Sample spielt die ethnische Ni- 
schenökonomie offensichtlich eine nur mehr sehr untergeordnete Rolle, zumindest was die ausschließliche oder überwiegende Orientierung an bestimmten ,ethnisch“ definierten Kundenstocks anbelangt. Ohne die Resultate unserer Zufallsstichprobe überinterpretieren zu wollen, dürfte die Schlussfolgerung dennoch zulässig sein, dass sich darin das Bestreben zahlreicher Unternehmer mit Migrationshintergrund, aus der Nische hinauszugelangen und sich als gleichberechtigter Teil der Wiener Geschäftswelt zu etablieren, dokumentiert. Dies ist auch ein Indiz dafür, dass sich die bis in die 1990er-Jahre noch dominierende so genannte ,ethnische“ Ökonomie im urbanen Kontext Wiens immer stärker in Richtung auf eine breit gefächerte und keineswegs unbedingt ,ethnisch“ definierte Migrantenökonomie verändert, wobei aber selbst der Migrationshintergrund der Selbständigen immer mehr in den Hintergrund rückt und vor allem im Umgang mit den Kunden zunehmend an Bedeutung verliert. Eine Expertin beschreibt das Spannungsfeld zwischen dem ,ethnischen“ Aspekt des Verbleibs in der Nische und der Marktpositionierung unabhängig von einer „ethnisch“ determinierten Unternehmensorientierung folgendermaßen:

„Auf der anderen Seite ist es auch unglaublich widersprüchlich. Wenn ich selbst von Haus aus meine Zielgruppe so einenge und eingrenze, ist die Wahrscheinlichkeit, dass ich eine Gewinn- und Umsatzsteigerung erziele unrealistisch. Wenn ich grundsätzlich sage, mein Migrationshintergrund oder meine ethnische Zugehörigkeit spielt jetzt keine Rolle. Ich versuche mich am Markt zu positionieren mit dem, was ich kann. Und das ist etwas, wo ich mir schon oft denke, warum macht man das? Letztendlich geht es schon darauf hinaus, dass sie sich nicht fit genug fühlen."

Faktum ist, die überwältigende Mehrheit der befragten Unternehmer (24 von 30) ist an keiner „ethnisch“ definierten und damit deutlich eingegrenzten Kundengruppe orientiert. Die Mehrheit bietet auch kein auf Herkunftsgruppen speziell ausgerichtetes Warensortiment bzw. spezifische Leistungen an. Aus einem strikt profitorientierten Kalkül heraus ist diese Strategie für die überwiegende Mehrzahl der Wirtschaftsbranchen auch die rationalste und umsatzträchtigste:

„Für mich ist jeder Kunde gleich. Kunde ist Kunde, es werden keine Unterschiede gemacht. " (T 12)

„Die Nationalität der Kunden ist mir unwichtig. Je mehr Kunden, desto besser für das Geschäft. “ (BKS 13)

„Es ist mir eigentlich ziemlich egal; meine Herkunftsgruppe ist mir nicht so wichtig, weil alle meine Filialen im Bereich Gastronomie liegen und jeder Kunde wichtig ist. "(T 1)

Aus der unternehmerischen und Expertenperspektive verlautet dazu:

„Wir sind kein klassisches Migrationsunternehmen. Unsere Kunden sind in Schweden, Norwegen, Bulgarien. Österreich macht nur 5\% unserer Kunden aus. [...] Was unsere Kundenstruktur betrifft, so haben wir eigentlich fast keine Kun- 
den aus exjugoslawischen Nachfolgerepubliken, sehr wohl aber Lieferanten, d.h., Landsleute sind als Kunden nicht von Bedeutung. "

Nur zwei Respondenten konzentrieren sich explizit auf die eigene Herkunftsgruppe (eine türkische Friseurin und eine Barinhaberin aus Exjugoslawien), zwei weitere geben an, hauptsächlich für österreichische Kunden zu arbeiten. Darüber hinaus findet sich auch ein türkischer Gastronom, dessen Lokal hauptsächlich von Gästen aus dem ehemaligen Jugoslawien frequentiert wird:

„Die Live-Musik und die Musik, die im Lokal gespielt wird, kommt aus Exjugoslawien und daher kommen hauptsächlich nur Leute aus meiner eigenen Herkunftsgruppe. “(BKS 8)

„Meine Kunden sind hauptsächlich aus dem Balkan. Ich bin sehr zufrieden damit, da sie mehr als meine eigene Herkunftsgruppe konsumieren und sich benehmen können. Mir ist es daher eigentlich egal, ob meine Kunden aus meiner Herkunftsgruppe sind oder nicht. "(T 7)

\subsubsection{Geschäftsbeziehungen und informelle Kontakte: die Rolle der eigenen Community}

Wie die vorhergehenden Analysen gezeigt haben, hat die Mehrzahl der befragten Unternehmer in Bezug auf die Kundenorientierung die „ethnische“ Nische längst verlassen bzw. hat in vielen Fälle im Verlauf ihrer unternehmerischen Karriere keine Orientierung an „ethnischen“ Kriterien stattgefunden (vgl. Haberfellner \& Böse 1999; Haberfellner 2011; Haberfellner \& Koldas 2002; Leicht 2012; Segert 2010). Was für die Kundenstruktur gilt, muss aber nicht automatisch für informelle Kontakte und Geschäftsbeziehungen angenommen werden. Denn tendenziell zeigt sich im Vergleich der Unternehmer aus den beiden Herkunftsgruppen und für die drei Subfragen zusammenfassend, dass die türkischen Unternehmer ihren Landsleuten in Bezug auf Geschäftserfolg und Informationsaustausch etwas mehr Relevanz beimessen als die BKS-Gruppe. ${ }^{24}$ Für sieben türkische und fünf BKS-Firmeninhaber sind Landsleute für den Geschäftserfolg sehr wichtig, von drei türkischen und sechs exjugoslawischen Unternehmern werden diese hingegen als unwichtig klassifiziert. Das Bildungsniveau scheint nur eine geringe Rolle zu spielen:

„Ich habe nicht nur mit meinen eigenen Leuten, sondern mit verschiedenen Unternehmen Geschäftsbeziehungen. “(T 1)

24 „Wie sehen Sie die Wichtigkeit Ihrer eigenen Herkunftsgruppe für Ihren Geschäftserfolg? A) Haben Sie vor allem Geschäftsbeziehungen zu UnternehmerInnen, die auch Ihrer eigenen Herkunftsgruppe angehören? B) Bekommen Sie wichtige Geschäftsinformationen von Personen aus Ihrer eigenen Herkunftsgruppe? C) Wie und in welchem Ausmaß ist Ihre eigene Herkunftsgruppe für Ihren Geschäftserfolg wichtig?" 
„Ein Großhandel schaut nicht auf die Herkunft, sondern es geht nur um Verkaufsstrategien; [...] weil meine Geschäftsbeziehungen und Personen, die für den Erfolg meiner Firma notwendig sind, aus verschiedenen Herkunftsgruppen stammen " (T 9).

„Ich habe mich auch nie wirklich damit beschäftigt, ob es andere Unternehmen in dieser Branche aus meiner Herkunftsgruppe gibt “ (BKS 6).

Allerdings finden sich unabhängig von Branchenaffiliation und Bildungsstatus auch Unternehmer im Sample, die ihrer Herkunftsgruppe eine wichtige Rolle für ihren Geschäftserfolg beimessen. Individuelles Networking innerhalb der Herkunftsgruppe spielt also von Unternehmen zu Unternehmen eine sehr unterschiedliche Rolle:

„Die eigene Gruppe ist mir sehr wichtig. Ich habe meine Beziehungen zu Unternehmen aus meiner Herkunftsgruppe und tausche mich immer wieder mit ihnen aus. Von meinen Freunden und Geschäftspartnern bekomme ich die Aufträge. Ohne die hätte ich nicht so lange durchgehalten. " (BKS 7)

„Meine eigene Herkunftsgruppe ist sehr wichtig. Ohne diese Geschäftsbeziehungen hätte ich nicht anfangen können. Sogar die besten und Erfolg versprechenden Informationen bekomme ich von Exjugoslawen. “ (BKS 12)

\subsubsection{Unternehmenserfolg und unternehmerische Zufriedenheit}

In wissenschaftlichen Analysen (Haberfellner 2011; Hillmann \& Sommer 2011; Segert 2011; Schmid et al. 2006; Leicht 2012) wird kritisiert, dass der Blick auf die urbane Migrant Economy zu einseitig auf die Start-ups fokussiert sei. Dies gilt vor allem auch für die vielfältigen Maßnahmen der Gründungsförderung, die ihren Erfolg ausschließlich an den schlichten Zahlen faktischer Start-ups messen, die Überlebensdauer der neu gegründeten Unternehmen und deren reale Marktchancen aber außer Acht lassen. Die Experten betrachten die Kategorie „Unternehmenserfolg“ aus einer differenzierten Perspektive:

„Das sind alle, die sich draußen seit mindestens drei oder vier Jahren behaupten. Alle, die ihre Lebenshaltungskosten aus dem Unternehmen bestreiten, sind erfolgreich. Das reicht und das würde ich grundsätzlich schon so sagen. Wobei mit , erfolgreich ' auch andere Bilder gezeichnet werden. Der Do\&Co-Chef, der türkischer Abstammung ist, das Lufthansa-Catering aufkauft und jetzt auch bei der ÖBB einsteigt. "

„Zum einen geht es darum, sich so selbständig zu machen, aber schon die vorhandenen Fixkosten, die sie haben für die Lebenshaltung, decken zu können. Das heißt, die Latte ist auch nicht so hoch gelegt. Es geht ja wirklich nur darum, ,ich möchte selbständig sein und im Rahmen meiner Selbständigkeit fähig sein, meine Miete zu bezahlen, meine Lebenshaltung und meine Familie zu erhalten: Das reicht." 
Der Aspekt des Scheiterns von Unternehmen, die Insolvenz, und vor allem der maßgeblichen Kausalfaktoren ist einer der am wenigsten erforschten im Rahmen der Studien zur Migrant Entrepreneurship. Faktum ist, dass die offiziellen Insolvenzstatistiken nur wenige Rückschlüsse auf die Lebensdauer der Unternehmen von Migranten zulassen und noch weniger die differenzierten Ursachen des Scheiterns dokumentieren:

„Wir wissen in Wahrheit weder etwas über die einen, noch über die anderen. In Österreich gibt es solche Daten nicht, die die Insolvenzen betreffen. “

„Bei den Unternehmern gibt es keine Kontrollgruppe an Gescheiterten. Es kann sein, dass sie genauso geplant und die gleiche Ausbildung haben wie andere. Den Punkt, an dem sie gescheitert sind, kennt man nicht genau. Es gibt hier keinen Vergleich."

„Es wäre sehr interessant, gescheiterte Unternehmen zu befragen, weil es dazu sehr wenige Daten gibt. Der Zugang ist schwierig und die Leute sprechen vielleicht nicht gerne darüber. Überzogene Erwartungen in Verbindung mit fehlendem Knowhow führen oft zum Scheitern. In der türkischen Community basieren die Geschäfte oft auf Strukturen, die nicht unbedingt den Entwicklungen in bestimmten Märkten gerecht werden. Türkische CD-Händler haben in relativ kleinen Läden CDs verkauft. Im Untersuchungszeitraum sind viele pleite gegangen. Gerade in diesem Medien- und CD-Bereich kann mittlerweile kein Geschäft mehr überleben. SATURN zieht alle an. “

„Bei den Fällen von Konkurs oder Ausgleich ist die Frage der Rücklage eine sehr problematische. Die Verwechslung von Gewinn und Umsatz ist der Klassiker. Ich habe eher das Gefühl, dort wo Geld sehr schnell im Umlauf ist. Diese Gruppen bzw. Branchen, wo ich eine Kassa, habe sind viel gefährdeter. Es ist sehr stark gruppen- und branchenabhängig. “

„Ich glaube, dass das Problem daran liegt, dass sie ziemlich schnell resignieren. Ich kenne eine Buchhalterin, die gerade solche Fälle betreut und sagt, dass sie ab einem bestimmten Punkt die Post nicht mehr aufmachen. Es wird aufgegeben und sie machen nicht einmal die Post auf. Sie geben viel zu schnell auf, wenn sie merken dass es bergab geht. Dann denken sie, sie können eh nichts mehr retten."

Eine Expertin ortet vor dem Hintergrund ihrer langjährigen Erfahrung seitens mancher Unternehmer mit Migrationshintergrund Verhaltensweisen, die sich in Insolvenzsituationen kontraproduktiv auswirken:

„Es stellt sich auch die Frage, ob ich es abwenden kann und wie engagiert die Menschen sind, um auch dagegen zu werken. Ich weiß es von der gewerblichen Sozialversicherung, wo sie sagen, dass die Leute in Zahlungsverzug sind, ist das eine. Das betrifft auch einen Österreicher genauso und ist nichts typisch Ethnisches. In diversen Gruppen ist es schon so, dass sie nicht einmal den Weg suchen, um diverse Prozesse zu verlangsamen oder das Gefühl zu vermitteln, wir sind dahinter und wir wollen diverse Ausgänge verhindern. Wir versuchen auch hier zu vermitteln, dass man auch in diversen Situationen an Lösungen arbeiten kann. “ 
Die Ursachen für das unternehmerische Scheitern werden seitens der Experten aber nicht nur in Defiziten der Entrepreneurs, sondern auch in Kampagnen gesucht, die undifferenziert die Selbständigkeit als erstrebenswerte Alternative propagieren:

„Ende der 90er-Jahre war das Thema: Mehr Gründer braucht das Land. Ich kann dem absolut zustimmen, es hat seine Richtigkeit. Es wurde sehr unkritisch und in vielen Hinsichten unbegleitet kommuniziert. Für viele war es nicht leicht und man muss auch etwas tun, wenn es nicht gut läuft. Wann und was kann man auffangen? Dies gilt für alle Bereiche und alle Gruppierungen gleichermaßen. "

Abgesehen vom Worst-Case-Szenario der Insolvenz repräsentiert der allgemeine Geschäftserfolg aber ein wichtiges Kriterium, da sich über diesen auch das Einkommen des Unternehmers bemisst. Wir haben unsere Respondenten also um eine Selbsteinschätzung ihres Unternehmenserfolges gebeten und darauf - erwartungsgemäß stark divergierende Antworten erhalten: Insgesamt schätzen die türkischen Befragten den Erfolg ihres Unternehmens öfter als „sehr gut“ ein (sechs Mal, im Vergleich zu zwei Mal „sehr gut“ bei exjugoslawischen Unternehmern), nur zwei Unternehmer insgesamt klassifizieren ihren Unternehmenserfolg als „eher schlecht“. Die Mehrheit der befragten Selbständigen in beiden Gruppen gibt mittelmäßige Bewertungen ab. In einigen Fällen wurden für diese selbst getroffenen Einschätzungen auch entsprechende Begründungen abgegeben.

„Erfolg“ repräsentiert aber (vgl. die Expertenstatements oben) eine Kategorie, die subjektiv divergierenden Bewertungen unterliegt und eng an individuelle Aspirationsniveaus geknüpft ist. Manche bewerten ihr Unternehmen bereits als „erfolgreich“, wenn sie daraus die basalen Lebenshaltungskosten für ihre Familie abdecken können. Darüber hinausgehende Ambitionen sind einigen fremd:

,Meine Mitarbeiter sind zufrieden, der Umsatz ist gut, die Kunden kommen immer wieder gerne, also kann ich nur zufrieden sein. “ (BKS 2)

„Im Verhältnis mit anderen Freunden, die auch selbständig sind, geht es mir deutlich besser. " (BKS 5)

,,Viel Arbeit für wenig Geld. So habe ich es mir überhaupt nicht vorgestellt. “ (T 11)

Umsatz und Unternehmenserfolg repräsentieren zwei eng miteinander verwobene Kategorien, wobei selbstverständlich konkrete Umsatzzahlen nicht erhoben werden konnten. Als objektive Messlatte zielte bereits die Formulierung der Frage darauf ab, ob mit dem erwirtschafteten Geld der Lebensunterhalt bestreitbar sei. Es stellte sich heraus, dass die überwiegende Mehrzahl der Unternehmer sehr zufrieden oder zumindest zufrieden mit ihren Umsatzzahlen ist. Dass es natürlich ,,immer mehr “ sein könnte und man ,nie genug Geld haben kann“, schränkt bei vielen die auf realistischen Einschätzungen und Erwartungen basierende, grundsätzliche Zufriedenheit nicht nennenswert ein. Zufrieden sind immerhin elf von 15 türkischen und 13 von 15 BKSUnternehmern:

„Ich bin sehr zufrieden. [...] Ja, ich verdiene ganz gut. Jeden Monat erhöht sich mein Umsatz. “( (T 1) 
„Ja, derzeit zahlen wir uns nur das aus, was möglich ist. Da wir aber schon einige Zeit vorher die Gründung geplant hatten, konnten wir uns bereits eigene Finanzpolster aufbauen und so den eigenen Lebensunterhalt sichern. "(BKS 3)

„Es kann natürlich immer mehr sein, aber ich bin zufrieden, so wie es momentan läuft. Es hängt vor allem vom Lebensstil ab, ob man mit dem Verdienst gut auskommt oder nicht. " (BKS 5)

Bemerkenswert ist vielleicht, dass kein einziger der sechs Unternehmer, die ihr Auslangen nicht vollständig finden bzw. die um die Existenz kämpfen, ein höheres Bildungsniveau aufweist. Ein Faktum, welches doch auf die Relevanz des Bildungsniveaus hinweist:

„Nein, ich bin nicht zufrieden, weil mir nicht viel Geld vom Umsatz übrig bleibt.“ (T 11)

„Eher nicht, weil ich leider wenig Umsatz mache.“ (T 12)

„Nein, ich muss meine Schulden/Kredite abbezahlen und es bleibt mir daher nichts übrig. Ich verdiene gerade so viel, dass ich meine monatlichen Raten bezahlen kann. " (BKS 7)

In einer individuell variierenden Relation zum Unternehmenserfolg steht die $\mathrm{Zu}-$ friedenheit des Unternehmers mit seiner Tätigkeit sowie mit seinen Umsatzzahlen. Wie oben bereits erwähnt, sind die diesbezüglichen Aspirationsniveaus sehr unterschiedlich, der Zusammenhang zwischen Erfolg und Zufriedenheit ist daher nicht immer stringent. Zufriedenheit mit der unternehmerischen Tätigkeit setzt also nicht immer ein herausragend erfolgreiches Unternehmen voraus. Im Allgemeinen erweisen sich die meisten der Befragten als zufrieden mit ihrer Tätigkeit, wobei in einigen Fällen aber auch Einschränkungen zum Ausdruck gebracht werden, indem diese Migranten die Sicherheit des Angestelltendaseins vermissen, sich über ihre dauerhafte Marktpositionierung berechtigte Sorgen machen oder über Probleme im Krankheitsfall berichten:

„Sehr zufrieden. Nur wenn ich mal krank bin, da denke ich mir, Krankenstand wäre nicht schlecht. "(T 5)

„Ich würde lieber wieder angestellt sein. Dann hätte ich alle diese Sorgen nicht. “ (BKS 7)

In einem Konnex zu den Zufriedenheitsparametern steht auch die Frage, ob die Migranten sich, hypothetisch nochmals vor die Wahl gestellt, neuerlich für die selbständige Erwerbstätigkeit entscheiden würden, ob also die Selbständigkeit aus ihrer Perspektive die richtige berufsbiographische Orientierung war. Das Resultat unterstreicht das beträchtliche Ausmaß an Zufriedenheit und die hohe Identifikation mit der unternehmerischen Tätigkeit. Nur fünf von 30 befragten Unternehmern würden sich nicht noch einmal selbständig machen. Interessant ist in diesem Punkt eine genauere Analyse der Bewertung des Unternehmerdaseins:

T 3 würde nicht noch einmal den Weg in die Selbständigkeit beschreiten, weil es „dann doch ein bisschen zu stressig ist". Aufgrund der sonstigen Antworten, die sie 
gegeben hat, kann man aber davon ausgehen, dass ihr Geschäft gut läuft, der Umsatz ist zufriedenstellend, der einzige Faktor, der Unzufriedenheit schürt, ist der Stress.

T 11 scheint dagegen ernsthafte ökonomische Probleme bis zur existenziellen Bedrohung zu haben und würde sich nicht noch einmal selbständig machen, weil er ,arbeite sehr viel und bekommt wenig Geld dafür". Er schätzt den Erfolg seines Unternehmens als eher schlecht ein und ist allgemein sehr unzufrieden mit seiner Entscheidung für ein eigenes Unternehmen.

BKS 7 artikuliert ebenfalls eine negative Einstellung, die er folgendermaßen begründet: „Es ist viel Arbeitsaufwand, der nichts einbringt. Ich habe nur Schulden und Arbeit und sonst nichts". Er hat beträchtliche existenzielle Sorgen und einen nur bescheidenen Umsatz und kann nahezu nur seine Schulden bedienen. Er würde eine Angestelltentätigkeit seiner aktuellen Situation vorziehen.

BKS 9, ein Unternehmer, der von seinem Vater überredet worden war, die Firma von seinem ehemaligen Chef zu übernehmen, antwortet: „Ich war zufrieden und ohne Sorge als ich von 8-15 Uhr gearbeitet habe. Fixer Lohn und fixe Arbeitszeiten." Diese kritische Einschätzung kontrastiert zu dem von ihm artikulierten Erfolg seines Unternehmens, denn andererseits verdient er ausreichend und trotzdem würde er es vorziehen, eine andere Berufslaufbahn einzuschlagen.

BKS 12 würde sich nicht mehr selbständig machen, weil es ihm ,zu anstrengend und zu stressig“ ist, wie er es begründet. Er ist zwar sehr zufrieden mit dem Umsatz und bewertet auch den Erfolg seines Unternehmens als gut, aber aus seiner vormaligen Tätigkeit als Beamter (er war bei der Exekutive) bringt er die Erfahrung mit, er habe zwar ,weniger verdient, aber auch weniger Sorgen gehabt“.

Die (wenigen) Unzufriedenen sollen auch nicht von dem Faktum ablenken, dass eine überwiegende Mehrheit ihre Entscheidung nicht bereut und jederzeit wieder in die Selbständigkeit gehen würde. Die wichtigsten und am häufigsten angeführten Begründungen liegen in dem Faktum, dass man ,, sein eigener Chef" sein kann und „,von niemandem abhängig“ ist (insgesamt neun Nennungen). Die Bandbreite der Argumente reicht weiters von den besseren Verdienstmöglichkeiten bis zu dem simplen Wunsch, selbständig zu sein:

„Ja, denn ich lasse mir nicht gerne etwas sagen, ich arbeite lieber so wie ich es will. " (T 5)

„Jeder sollte wenigstens einmal im Leben versuchen, keinen Chef zu haben und auf eigenen Beinen zu stehen. Mir ist es gut gegangen und ich würde mich sicher noch mal selbständig machen. " (BKS 15)

\subsubsection{Mitgliedschaft in wirtschaftlichen Verbänden}

Der Organisationsgrad der Unternehmer mit Migrationshintergrund variiert in $\mathrm{Ab}$ hängigkeit von den Branchen und Herkunftscommunities. Dabei ist zwischen institutionalisierten Zusammenschlüssen offizieller unternehmerischer Interessenvertretungen und den auf der Eigeninitiative einzelner Personen, Immigrantengruppen oder -vereinen 
basierenden Verbänden zu unterscheiden. In Städten mit längerer Immigrationsgeschichte, wie etwa Wien, existieren meist mehrere solche Organisationen, deren Aktivitäten die Tätigkeit der offiziellen Wirtschaftskammern ergänzen. Einer der von uns interviewten Experten ist der frühere Präsident des Verbandes österreichischer und türkischer Unternehmer und Industrieller (ATIS = Avusturya Türk Işsadamları ve Sanayicileri Derneği). Auch in den BKS-Herkunftsgruppen haben sich zusätzlich zu den früher dominierenden Kulturvereinen inzwischen Organisationen mit unternehmerischer Ausrichtung (z.B. der BKS Business $\mathrm{Club}^{25}$ ) etabliert. Allerdings ist hier der Organisationsgrad in Wien nach wie vor geringer als in der türkischen Herkunftsgruppe.

In unserem Sample sind Mitgliedschaften in Unternehmensverbänden, abgesehen von der Pflichtmitgliedschaft in der WKW, nicht weit verbreitet: Nur drei türkische und vier exjugoslawische Befragte haben angegeben, Mitglied in einem unternehmerischen Fachverband zu sein. Die betreffenden Unternehmer mit türkischem Migrationshintergrund weisen durchwegs höhere Bildung auf. Nachfolgend einige illustrative Beispiele für Begründungen pro oder kontra eine solche Mitgliedschaft:

T 4 ist Mitglied der Wirtschaftskammer, aber offensichtlich nicht sehr zufrieden damit. Auf die Frage, was er von der Mitgliedschaft hält, antwortet er: „Bis jetzt nichts Positives, es ist nur eine Geldverschwendung".

Positiv äußert sich BKS 1. Er ist Mitglied der Wirtschaftskammer und der Metallerverbände und hält von der Mitgliedschaft „Viel. Man hat durch so eine Mitgliedschaft nur Vorteile“.

BKS 3 äußert allgemein: „Wenn es eine Win-Win-Situation für beide ist und alle dadurch Vorteile haben, dann finde ich es gut."

Insgesamt sind viele Respondenten skeptisch, inwieweit sie von einer derartigen Mitgliedschaft überhaupt profitieren sollten. Andere bewerten zwar eine Partizipation in einer unternehmerischen Organisation prinzipiell positiv, ziehen eine solche für sich selbst allerdings nicht in Betracht:

„Die Zusammenarbeit mit meiner Familie funktioniert sehr gut. Davon halte ich viel. Mitgliedschaft habe ich keine, also kann ich auch nicht viel dazu sagen. "(T 2)

„Damit habe ich mich nie wirklich beschäftigt, da ich so etwas eigentlich nicht brauche. "(T 7)

„Ich kann mir nicht vorstellen, dass aus einer Mitgliedschaft nur Vorteile gezogen werden können. " (BKS 15)

Ohne aus unserem kleinen Sample zu weitreichende Schlussfolgerungen ableiten zu wollen, erscheint uns in dieser Hinsicht noch Überzeugungs- und Aufklärungsarbeit vonnöten zu sein. Hier sind die institutionalisierten Interessenvertretungen gefordert, ihre Wichtigkeit den Unternehmern mit Migrationshintergrund deutlicher nahezubringen.

\footnotetext{
${ }^{25}$ http://www.bksbc.at/de/.
} 


\subsubsection{Der Entrepreneur als positives Role Model - Das Sozialprestige des Unternehmers in den Migrant Communities}

Analysen zur Entrepreneurship von Migranten stehen immer wieder vor dem Problem, das in allen Städten Europas verbreitete Phänomen der krass divergierenden Selbständigenanteile in den unterschiedlichen Immigrant Communities hinsichtlich seiner Kausalität zu erklären (Hillmann 2011; Leicht 2012; Rath \& Swagerman 2011). Zwar lässt sich, wie im einleitenden Teil dieses Reports bereits erläutert, ein erheblicher Teil dieser Unterschiede aus divergierenden Opportunity Structures herleiten, dennoch darf die Explikation dieses Phänomens auch die etablierten, communityinternen Bewertungen der Entrepreneurship nicht außer Acht lassen - denn diese divergieren zwischen den Herkunftsgruppen mitunter beträchtlich. Aus empirischen Analysen (Leicht 2012; Rath \& Swagerman 2011) ist bekannt, dass hierbei vor allem das Sozialprestige des Unternehmers, die Selbständigkeit als „Normalität“ und als Role Model im Zusammenspiel mit anderen Determinanten eine wichtige Rolle spielen. Einige Experten haben sich diesbezüglich folgendermaßen geäußert:

„So ist es ja nicht. Ich würde sagen, dass die Chinesen weniger bereit sind, Dienste zu verrichten, die andere Communities tun. Ich glaube auch, dass natürlich in diversen Communities Selbständigkeit per se einen anderen Stellenwert hat. Ich weiß es aus der Türkei [...] Mietverhältnisse hat man nicht gekannt, das gibt es nicht. Ähnlich ist es auch in den diversen Ökonomien, in diversen Communities, wo man das Unselbständigsein nicht kennt, weil man eher zur Selbständigkeit neigt. Das ist mein Aufstieg, wo zum Beispiel das Unselbständigsein eine Zwischenlösung ist, eine Brücke zu einem anderen Zustand ist, wo sie sehr wohl einen eigenen Aufstieg sozusagen damit manifestieren. Das merke ich schon und dem kann man sicherlich auch zustimmen, dass es gerade bei chinesischen und anderen Communities der Zustand ist. "

„Das Unternehmertum wird als Mittel angesehen, die gläserne Decke zu durchbrechen und einen sozialen Aufstieg zu erreichen. “

Allerdings orientieren sich Immigranten nicht nur an Role Models innerhalb der eigenen Community, sondern es besteht ein enger Konnex zwischen den Selbständigenanteilen in den Aufnahmegesellschaften und jenen in den lokalen, aber zugewanderten Gruppen, wie ein Experte ausführte:

„Die EU-Statistiken zeigen, dass die unternehmerische Neigung in Österreich und Deutschland am niedrigsten ist. Das gilt ähnlich aber auch für Schweden und Dänemark. Es gibt also so etwas wie eine Overall-Neigung zur Unternehmertätigkeit in Ländern bzw. Städten. Und die Motivation der Migranten orientiert sich dann an der geringen Neigung der Mantelbevölkerung in den jeweiligen Staaten. Denn die Gründungsstatistik in Wien weist eine überdurchschnittliche Gründungsneigung der Migranten aus. Da ist die Gründungsneigung höher als bei den Österreichern, wobei die Staatsbürgerschaft das Basiskriterium darstellt. 
2011 waren 42\% Nichtösterreicher in der Gründungsstatistik bei einer unterdurchschnittlichen Repräsentanz der Türken. "

Wir haben daher explizit nach der Bewertung der Entrepreneurship in den beiden Migrant Communities gefragt. Auf den Prestigeaspekt rekurrieren in erster Linie die Statements einiger von uns befragter türkischer Unternehmer. Zum Unterschied von diesen beziehen sich die BKS-Respondenten tendenziell eher auf die nüchterne $\mathrm{Ab}$ wägung der Vor- und Nachteile der Selbständigkeit an sich bzw. geben sie eher eine Beurteilung der Selbständigkeit als solcher ab. In diesem Punkt weichen die Bewertungen der beiden Gruppen also deutlich voneinander ab:

„Man wird groß angesehen und bewundert, wenn man selbständig ist. “(T 1)

„Ziemlich wichtig. Ich persönlich werde nur mit Respekt behandelt. “(T 2)

„Ich glaube, die Leute denken dann, dass man reich ist und drei Autos fährt und mit Geld nur so um sich schmeißt. " (BKS 2)

Negative Allgemeinbewertungen wurden nur von zwei Personen abgegeben. Sehr viel häufiger erfolgten ambivalente Einschätzungen des unternehmerischen Ansehens in der eigenen Community:

„Es geht so, es gibt immer geteilte Meinungen. Die einen finden es super und streben selbst dieses Ziel an, den anderen ist es zu unsicher und aufwändig. "(T 12)

Die Bewertung des Ansehens der Entrepreneurship erfolgte auch kontrastierend im Vergleich mit dem Prestige von unselbständig Beschäftigten. Hierbei haben viele Respondenten ihre eigene Ansicht formuliert und weniger kritisch darüber reflektiert, wie die eigene Herkunftsgruppe dazu steht. Elf Unternehmer stehen der Selbständigkeit im Vergleich zur unselbständigen Beschäftigung durchaus kritisch gegenüber. Dies gilt für türkische wie für exjugoslawische Unternehmer gleichermaßen und widerspricht eigentlich der hohen Wertschätzung, die der Selbständigkeit im Zusammenhang mit der Frage bezüglich der neuerlichen Entscheidung für oder wider Unternehmerberuf entgegengebracht wird. Das am häufigsten ins Treffen geführte Argument ist die (relative) Sicherheit des Daseins als unselbständig Erwerbstätiger:

„Denke nicht. Arbeiter oder angestellt sein bedeutet mehr Sicherheit und weniger Risiko. "(T 11)

19 Respondenten bewerten entweder für sich die Selbständigkeit als besser als das Angestelltendasein oder sie sind der Meinung, dass die meisten ihrer Landsleute ebenso denken. Die Begründungen dafür beziehen sich primär auf finanzielle Aspekte sowie auf das Sozialprestige.

\subsubsection{Existieren Motivationsunterschiede?}

In unserem Projekt gingen wir von der statistisch belegbaren Tatsache aus (vgl. den empirischen Teil dieses Berichts), dass exjugoslawische und türkische Zuwanderer im Vergleich zu anderen Migrantengruppen in Wien seltener selbständig tätig sind 
und wollten den Gründen dafür ,auf die Spur kommen“. Hierbei ist es wichtig anzumerken, dass es sich dabei um keine ,ethnisierenden“ Zuschreibungen handelt, dass aber gruppenspezifische Werthaltungen für die Entscheidung, unternehmerisch tätig zu werden, doch eine Rolle spielen können. Deshalb war es für uns spannend zu analysieren, ob die Migranten aus den genannten Ländern aus ihrer Alltagsperspektive Unterschiede hinsichtlich der Motivation zum Unternehmerberuf wahrnehmen. Die diesbezügliche Frage wurde in drei Teilen ${ }^{26}$ gestellt. Da sich nur wenige Befragte konkret über die Motivation in unterschiedlichen Herkunftsgruppen äußerten, können nur allgemeine Trends abgelesen werden:

Die unternehmerische Motivation ist unabhängig von der Herkunftsgruppe

Diese Gruppe von Respondenten ortet die Motivation zur Selbständigkeit als Beruf eher im persönlich-individuellen Bereich und weniger in der Herkunft. Insgesamt 13 Befragte sind dieser Gruppe zuzuordnen, sechs aus der Türkei und sieben aus dem ehemaligen Jugoslawien:

„, Ob man erfolgreich selbständig ist, hängt nicht von der Herkunftsgruppe ab, sondern von der eigenen Motivation und Anstrengung. Wenn die Motivation nicht ausreicht, dann kann man auch nicht erfolgreich selbständig sein. “ (T 8)

„Ich sehe keine großen Unterschiede. Ein Unternehmen gründen kann man in jeder Herkunftsgruppe und ich denke, es ist immer gleich schwer. “ (T 12)

Die unternehmerische Motivation variiert nach Herkunftsgruppen

15 Unternehmer (sieben mit türkischen Wurzeln und acht aus dem ehemaligen Jugoslawien) argumentieren hier in Richtung herkunftsbezogener Motivationsunterschiede, wobei sich darin divergierende Beobachtungen widerspiegeln. Einige Respondenten bezogen sich auf kulturelle, religiöse oder integrationsbezogene Unterschiede:

„Die Religion wirkt sich meiner Meinung nach positiv auf den Unternehmenserfolg aus; unterschiedliche Kultur = unterschiedliche Einstellung. Die Ursachen sind historisch und kulturell bedingt. " (T 3)

„Es gibt sehr große Unterschiede. Meine Herkunftsgruppe ist nicht so gut integriert und daher fällt manches schwerer. " (T 7)

Eine größere Zahl an Unternehmern hat Motivationsunterschiede nach Herkunftsgruppen wahrgenommen bzw. meint, darüber Aussagen treffen zu können. Die zum Teil sehr detaillierten Antworten können im Folgenden nicht im vollen Wortlaut widergegeben werden:

26 Frage 1 im zweiten Frageblock: 1a: „Wie schätzen Sie ganz allgemein die Motivation in verschiedenen Herkunftsgruppen in Wien ein, UnternehmerIn zu werden?" $1 \mathrm{~b}$ : „Welche Unterschiede bestehen Ihrer Meinung nach zwischen den Herkunftsgruppen?“ 1c: „Welche Ursachen haben diese Unterschiede"? 
„Ausbildung ist in Jugoslawien und in der Türkei leider nicht von so großer Bedeutung wie hier in Österreich. Ursachen also historisch, traditionell bedingt, mangelnde Ausbildung etc. " (T 6)

„Man kann nicht eine ganze Nation einfach beurteilen. Aber hauptsächlich sind Türken viel motivierter und versuchen es einfach. Dadurch, dass wir ehrlicher sind, leider nur mehr wenige, geht es bei den Geschäften besser. "(T 14)

„Oft sehr hoch, nur fehlt bei vielen die Erfahrung und das Können. [...] Die Türken sind gewiefter, haben mehr Mut in ein Geschäft einzusteigen und machen es auch oft. Ebenfalls denke ich, dass unsere Landsleute ehrlicher sind, haben aber eben Probleme in der Firmenführung. " (T 15)

„Ich habe viel mit Menschen aus verschiedenen Herkunftsgruppen zu tun und da sticht manches deutlich heraus, z.B. die Österreicher sind sehr zielstrebig und ehrgeizig, erreichen meistens ihr Ziel. Die Türken sind meiner Meinung nach, was die Integration betrifft, faul und somit nicht so ehrgeizig wie die Österreicher. " (BKS 2)

Aus der Perspektive der Experten wurden in diesem Zusammenhang weitere Aspekte, wie spezifische Orientierungen oder Veränderungen hinsichtlich der unternehmerischen Motivation bedingt durch geänderte Bleibeabsichten, angesprochen:

„Die Risikobereitschaft, die ist unter allen Migrantengruppen bei den Türken am höchsten, das sehe ich immer wieder. "

„,Also in den 1990er-Jahren da war schon die zweite Generation am Werken, da kam es zu einer Umorientierung und einer stärkeren Orientierung auch an der Unternehmertätigkeit. In den 1990er-Jahren differenzierten sich auch die Orientierungen, weil man feststellte, dass man blieb und nicht mehr in die Türkei zurückging. Damit trat die Rückkehrorientierung in den Hintergrund und wurde durch eine Bleibeorientierung ersetzt. "

\subsubsection{Institutionelle und gruppenspezifische Barrieren auf dem Weg zum Unternehmer}

In zahlreichen Analysen werden die vielfältigen Hindernisse, mit denen sich Migranten konfrontiert sehen, wenn sie den Weg zum Entrepreneur wählen, angeführt (Hillmann 2011; Hillmann \& Sommer 2011, Segert 2012, Rath \& Swagerman 2011). Diese Barrieren können institutionelle oder legistische Rahmenbedingungen sein oder sich auf den Zugang zu relevanten Ressourcen beziehen und bilden jedenfalls einen Teilaspekt der Opportunity Structures. Aufgrund der Fokussierung unserer Projektfragestellung galt unser primäres Interesse selbstverständlich etwaigen Barrieren, welche die beiden befragten Herkunftsgruppen im Besonderen betreffen könnten. In diesem Zusammenhang manifestieren sich deutliche Unterschiede zwischen den türkischen und exjugoslawischen Unternehmern. Die überwiegende Majorität der türkischen Entrepreneurs äußerte die Ansicht, dass keine Unterschiede hinsichtlich der Schwie- 
rigkeiten, ein Unternehmen zu gründen und erfolgreich zu führen, zwischen den Migrantengruppen bestünden. Im Folgenden ein typisches Zitat aus einem der Interviews:

„Nein, offiziell gibt es keinen Unterschied zwischen Menschen aus verschiedenen

Ländern. Wenn es einer nicht schafft, liegt es daran, dass er zu blöd ist und nicht weil er Türke, Serbe oder Kroate ist. " (T 14)

Bei den exjugoslawischen Unternehmern zeigen sich diesbezüglich differenziertere Einschätzungen. So haben immerhin neun von ihnen die Ansicht geäußert, dass es für manche Gruppen leichter und für andere schwieriger sei, sich als Unternehmer in Wien zu etablieren. Hohe Zustimmung fand hierbei die Ansicht, dass es in erster Linie die Österreicher (ohne Migrationshintergrund) am leichtesten hätten sowie des Weiteren EU-Bürger allgemein. Etliche Male wurde auch auf die Wichtigkeit der gemeinsamen Sprache bzw. guter Sprachkenntnisse rekurriert. Bemerkenswert ist, dass vor allem von den Exjugoslawen auch die Integrationsbereitschaft als wesentliches Kriterium für den Erfolg in der Selbständigkeit angesprochen wurde. Ein hohes Ausmaß an Integrationsorientierung verhindert weitgehend, so sind etliche der Ansicht, Barrieren bei der Geschäftsgründung und -führung. In diesem Zusammenhang wiesen die exjugoslawischen Entrepreneurs auf die Integrationsmotivation der BKS-Community hin:

„Diejenigen, die Deutsch sprechen können und gut etabliert sind, haben einen Vorteil denen gegenüber, die nicht aus Österreich kommen und sich nicht anpassen wollen, obwohl sie ihren Hauptwohnsitz hier haben. “ (BKS 15)

„Exjugoslawen sind nicht so distanziert von Österreichern im Gegensatz zu anderen Herkunftsgruppen. " (BKS 14)

Auf den Aspekt der Wichtigkeit der Integrationsorientierung und vor allem des Spracherwerbs haben die Experten mit Nachdruck hingewiesen:

„Den Leuten muss man einfach klar machen, und das in ihrer eigenen Sprache, dass sie die Sprache hier gut lernen müssen. Das geht aber nur im Rahmen einer Generationenarbeit. “

Daneben haben einige exjugoslawische Respondenten aber auch verneint, dass herkunftsgruppenspezifische Erschwernisse die Unternehmensgründung behindern könnten:

„Es hängt von der Motivation und nicht von der Herkunft ab. Falls jemand genug motiviert ist, dann ist es egal aus welcher Herkunftsgruppe er stammt. " (BKS 10)

„Nein, ich bin ein gutes Beispiel! Ohne gute Deutschkenntnisse habe ich es geschafft, mein eigenes Unternehmen zu gründen. Wieso wäre es leichter oder schwerer für Bulgaren, Türken, Rumänen usw.?" (BKS 12)

Ein Experte meinte dazu:

„Ach wo, das hat mit der Türkei oder Österreich gar nichts zu tun. In der Türkei ist auch alles genauso kompliziert, aber der war ja kein Unternehmer in der Türkei, der kennt ja die türkischen Steuergesetze auch nicht, denn eine Unternehmertätigkeit ist auch in der Türkei nicht leichter, aber der war ja dort nur einfacher ,Hackler"“. 


\subsubsection{Die Attraktivität der Entrepreneurship in den Migrant Communities}

Obwohl empirisch schwer messbar, sprechen die ausgeprägten Unterschiede im Zulauf zur Selbständigkeit in verschiedenen Herkunftsgruppen doch dafür, dass der Selbständigkeit in verschiedenen Aufnahme- sowie Herkunftsstaaten und -gesellschaften eine unterschiedliche Attraktivität beigemessen wird. Klassisch sind die Klagen in den österreichischen Medien über die $\mathrm{zu}$ geringe Unternehmungsgründungsneigung und schwache unternehmerische Gesinnung großer Teile der österreichischen Bevölkerung ${ }^{27}$. Ähnliche Unterschiede wurden seitens der Experten auch für die Migranten-Communities verbalisiert:

„Natürlich spielt es eine Rolle und deshalb versuchen wir - im Rahmen von unseren Beratern - uns den Fokus der ethnischen Idee näher anzusehen. Nicht jeder mit einem Migrationshintergrund möchte sich mit einer Gründungsidee selbständig machen. Es ist sehr typisch für die mitgebrachte Kultur. "

„Wenn wir merken, hier spielt Kultur eine wesentliche Rolle, ist der Fokus der gesamten Beratung eher auf der kulturellen Ebene zu besetzen. Wenn es die Sprache ist, ist es eher die Kombination. Wir fragen das auch ab. [...] Es ist alles vielschichtiger, als man glaubt."

Neun von 15 türkischen Unternehmern glauben dezidiert nicht, dass es in Wien für manche Migrantengruppen attraktiver ist als für andere, Unternehmer zu sein. Es gibt aber auch gegenteilige Ansichten, die mit der Tatsache argumentieren, dass es (mit Blick auf das Potential möglicher Kunden und Netzwerkvorteile) profitabel sei, einer der in Wien größeren Communities anzugehören.

Von den 15 exjugoslawischen Unternehmern denken 13 nicht, dass es Unterschiede in der Attraktivität einer Unternehmertätigkeit in unterschiedlichen Herkunftsgruppen gibt. Denn, wie BKS 3 meint:

„Es kommt darauf an, ob man einen Traum hat und die finanziellen Mittel und nicht auf die Herkunft".

\subsubsection{Die Kausalfaktoren unternehmerischen Erfolgs oder Misserfolgs}

Die Frage, ob sich in bestimmten Herkunftsgruppen mehr erfolgreiche Unternehmer finden als in anderen, wird von der Majorität der Befragten (neun türkische Unternehmer und neun Exjugoslawen) klar abgelehnt. Aus ihrer Perspektive determiniert ein bestimmter Migrationshintergrund in keinster Weise das unternehmerische Talent.

27 So wurde, um nur ein Beispiel unter vielen anzuführen, in einer Diskussionsreihe der Industriellenvereinigung die ,,erschreckend niedrige Neigung erwachsener Österreicher zur unternehmerischen Selbständigkeit" 2010 als ein Schwerpunkt thematisiert (http://www2.iv-eventnet.at/upload/doc/1006/einl_aufbrueche_NOV_2010_mail_rem_3.pdf). 
Dazu formulieren etwa BKS 15, ein Gastronom aus Serbien, sowie T 15, ein Konditor mit türkischem Migrationshintergrund sehr skeptisch:

,,Wie ich schon gesagt habe, die Herkunft ist nicht abhängig vom Fleiß und den Ideen ".

„Es ist sehr verschieden, manche schaffen es aus einem Land und andere nicht. Unter den Ausländern ist es vielleicht leichter aufzusteigen durch hohe Motivation und Bekanntenkreise, die helfen ".

Seitens der befragten Experten wurden sehr wohl Argumente verbalisiert, die für doch vorhandene Divergenzen hinsichtlich der Erfolgs- oder Misserfolgsgeschichten auf dem Sektor der Selbständigkeit sprechen. Dabei wurden in den Experteninterviews vor allem Defizite hinsichtlich des unternehmerischen Fachwissens und der Kompetenzen, aber auch häufiger anzutreffende Einstellungen (z.B. reine Gewinnorientierung) hervorgehoben:

„Bei den Unterschieden spielt auch die Religion eine große Rolle. “

„Diese Probleme sind immer die gleichen, da werden keine überlegten oder analytisch guten Entscheidungen getroffen und die könnte man mit Maßnahmen bekämpfen, d.h., die Leute informieren und informieren, was auf sie zukommt. Buchhaltung, Bilanzieren, welche Rechtsformen ein Unternehmen haben kann. Die wissen darüber oft gar nichts. "

„Der einfache Türke denkt sich: Da zahle ich 25.000 Ablöse für das Standl und dann mache ich einen Kebabstand auf und da mache ich diesen oder jenen Gewinn. Von Mehrwertsteuer oder gar Cash Flow hat der doch noch nie was gehört und das wird auch nicht einkalkuliert. "

„Bei den türkischen Unternehmern ist vieles nicht Planung, sondern mehr Improvisation und Zufall. “

„Es geht in erster Linie um die unternehmerische Compliance und um die Kenntnis der wichtigen Regeln. [...] Da gibt es ein großes Unwissen der türkischen Unternehmer. Da fehlt einfach die Auseinandersetzung damit, welche Infrastruktur eigentlich notwendig ist. Es gibt nur eine reine Orientierung am Gewinn. "

Auch einige Vertreter unseres Entrepreneur-Samples beziehen eine analoge Position wie unsere Experten. Sie verbalisieren allerdings - zum Unterschied von den Experten - auch Kriterien, weshalb die eigene Gruppe ihren subjektiven Einschätzungen gemäß komparativ erfolgreicher sei als Mitbewerber auf dem Markt. Bei den BKSUnternehmern stößt man signifikant öfter auf die Ansicht, dass im Vergleich Österreicher, Deutsche und ganz allgemein EU-Bürger erfolgreicher sind, da die kulturellen Unterschiede sowie die Hürden auf dem Weg zur Selbständigkeit geringer sind:

„Ja, Österreicher und Deutsche. Das hat vor allem kulturelle Ursachen. Kunden vertrauen eigenen Landsleuten bzw. Leuten mit derselben Religion/Kultur eher als anderen Herkunftsgruppen. " (BKS 4) 
„,Meistens sind die Unternehmer aus der EU erfolgreicher als Unternehmer aus Drittländern. Sie wissen schon, wie das System funktioniert. " (BKS 5)

„Österreicher, diese haben in Österreich erfolgreichere Unternehmen als Migranten. Ursachen: Politik, Diskriminierung, Kultur usw. “(BKS 9)

Als Gründe für den Erfolg von Unternehmern mit Migrationshintergrund wird eine äußerst heterogene Palette an Faktoren angeführt (Familie(nzusammenhalt), Disziplin, Verzicht auf Freizeit, Fleiß, Lernbereitschaft, Glück, Talent, Mut, Motivation, Kenntnis von Marketing- und Verkaufsstrategien), die es nicht erlauben, nach Antwortkategorien klassifiziert zu werden.

\subsubsection{BKS-, türkische und österreichische Unternehmer im Vergleich}

Um etwaige Unterschiede nochmals pointiert zu erheben, haben wir nachgefragt, wie die Unternehmer konkret Unterschiede zwischen exjugoslawischen und österreichischen, türkischen und österreichischen sowie exjugoslawischen und türkischen Unternehmern erleben und einschätzen. Unsere Absicht war dabei, bestehende Erfahrungen im Geschäftsleben, in unternehmerischen Interaktionen, aber auch etwaige Vorurteile abzufragen.

$\mathrm{Zu}$ Beginn einige Statements jener Befragten, die ausschließlich allgemeine Aussagen abgegeben und zu den einzelnen Subfragen nichts gesagt haben. Sie alle gehen nicht davon aus, dass es nennenswerte Unterschiede zwischen Türken, Exjugoslawen und Österreichern im Geschäftsleben gibt:

„,Wenn sie ihre Arbeit gut machen, dann hat jeder Erfolg. Das hat nichts mit der Herkunft, sondern eher mit der Motivation zu tun "(T 1).

„Ich denke nicht, dass es viele Unterschiede zwischen Türken, Österreichern oder Exjugoslawen gibt. Das Einzige, was ein Problem sein könnte, sind Sprachprobleme. Mit Mut, Geschick, einer guten Fachausbildung etc. kann aber jeder ein Unternehmer sein, egal woher man kommt" (T 9).

Die BKS- und österreichischen Unternehmer im Vergleich

Aus der Perspektive unserer Projektfragestellungen fanden wir es aufschlussreich, den Selbsteinschätzungen der beiden Herkunftsgruppen im Vergleich mit der jeweils anderen sowie in Gegenüberstellung zu österreichischen Entrepreneurs nachzugehen. Nur zwei Exjugoslawen äußerten sich dahingehend, dass in Bezug auf das unternehmerische Pouvoir sowie eine Reihe weiterer Aspekte im Zusammenhang mit dem Start-Up und der Unternehmensgründung (konkret angegeben waren: Unterschiede bei der Wahl der Branche, bei Problemen in der Gründungsphase, beim Management, bei der Suche nach Mitarbeitern, bei der Arbeitszeit, bei der Nutzung von Beratungsmöglichkeiten) keine Unterschiede zwischen Exjugoslawen und Österreichern existieren. Eine gewichtige Argumentationsschiene bezog sich hierbei auf die Startvorteile von Österreichern in sprachlicher und legistischer Hinsicht: 
„Die Österreicher haben den Vorteil, dass sie die Sprache perfekt können und es so nicht schwer ist, [...] Informationen über Management, Wahl der Branche etc. zu bekommen. Die Meisten, die aus Jugoslawien kommen, beherrschen die Sprache nicht so gut und sind so in jeglicher Hinsicht im Nachteil. “ (BKS 2)

„Für Österreicher ist es einfacher, weil sie die Sprache sprechen und weniger Probleme mit den verschiedenen Dokumenten haben. Außerdem bekommen sie leichter einen Kredit bei einer Bank, als ein Exjugoslawe. Wir müssen uns sehr bemühen und anstrengen, um selbständig zu werden, weil es viele Barrieren gibt" (BKS 14).

„Die Österreicher haben eine bürokratische Kultur, meine Gruppe ist eher gelassen, nimmt es nicht so genau " (BKS 4).

Aus türkischer Perspektive stellen sich die Unterschiede zwischen exjugoslawischen und österreichischen Unternehmen etwas anders dar, die Bereiche Professionalität, Disziplin, sozialer Umgang und Korrektheit wurden angesprochen:

„Österreicher arbeiten disziplinierter als Jugoslawen und bei der Bezahlung gibt es keine Probleme. “ (T 2)

„Ich denke, dass österreichische Unternehmer erfolgreicher sind, weil sie sehr gute Unternehmerkenntnisse mitbringen zu Beginn. “ (T 15)

„Bei der Gründungsphase und beim Management gibt es keine Unterschiede. Österreicher machen es professioneller bei Mitarbeitersuche. Jugoslawen sagen es nur weiter. Ein Österreicher hält sich an die vorgegebenen Arbeitszeiten, Jugoslawen haben ihre Arbeitszeit je nach Arbeit. " (T 13)

„, [...] beim Management gibt's keine Unterschiede. Bei der Suche nach Mitarbeitern haben Österreicher mehr Chancen, ein Österreicher würde nicht bei einem Exjugoslawen arbeiten. Bei österreichischen Firmen sind die Arbeitszeiten genau geregelt, bei Jugoslawen nicht. “ (T 4)

Die türkischen und österreichischen Unternehmer im Vergleich

Als eine weitere Facette der Selbsteinschätzung der Entrepreneurs wurde recherchiert, wie sich türkische Unternehmer selbst im Vergleich zu Österreichern sehen. Ein häufig verbalisiertes Argument bezieht sich auf das Networking, das nachweisbar die türkischen Unternehmer von den österreichischen unterscheidet:

„,Viel Familie, die unterstützt; Türken unterstützen sich prinzipiell viel, weil es viele gibt. "( T 3)

„Im Grunde keine, außer dass die Türken ein großes Umfeld (Familie, Freundeskreis etc.) hat und somit viel mehr Unterstützung. " (T 8)

Die „ethnische“ Ausrichtung des Warensortiments sowie die Einhaltung religiöser Regeln wurden selten angesprochen:

„Für ein Getränk könnte ich bei Österreichern vorbeischauen, aber für das Essen würde ich mich für einen Türken entscheiden, weil das Essen der Religion ange- 
passt sein sollte. Türken wählen lieber ihre eigenen Landsleute, wenn es um Essen etc. geht. " (T 2)

Aus der Sicht von Experten spielt der religiöse Faktor aber eine wichtigere Rolle, als dies seitens der befragten Unternehmer der Fall ist:

„,Der Bremser bei den Türken ist die eigene Kultur, das heißt, eigentlich der Islam. Denn da ist alles Sünde und es ist eigentlich alles verboten. “

„Aber wo waren die ersten Unternehmer? Ja, in den Moscheen 80 bis $90 \%$ der Entwicklungen innerhalb der türkischen Community sind eigentlich in den Moscheen passiert und das war nicht immer so positiv. Ich meine, für die soziale Entwicklung sollte die Religion eigentlich nicht der Bremser sein. “

Einige türkische Unternehmer argumentieren entlang konkreter Beispiele aus dem Management, der Einhaltung von Normen bezüglich Entlohnung sowie geregelter Arbeitszeiten und leiten hiervon Unterschiede zwischen österreichischen und türkischen Geschäftsleuten ab:

,,Türken haben Schwierigkeiten bei der Mitarbeitersuche, Sprachprobleme in der Gründungsphase, Nachteile bei bestimmten Stellen - ganz im Gegensatz zu österreichischen Unternehmern. " (T 4)

, Türken suchen bestimmte Branche, Probleme in der Gründungsphase, wenn die Familie nicht unterstützt, dann Schwierigkeiten mit der Bank, beim Management genauso. Bei der Suche nach Mitarbeitern: würden fast nur Verwandte oder Bekannte einstellen. Bei der Arbeitszeit: keine Arbeitszeiten, es wird jederzeit gearbeitet; Beratungsmöglichkeiten: nur im Umkreis; [...] Österreich: kann in jeder Branche ein Unternehmen führen und es gibt keine Schwierigkeiten. “ (T 5)

„Österreichische Unternehmen haben ein gutes System und behalten alles, was geschieht, im Auge. Sie bezahlen ihre Angestellten gerecht. Türken haben eher mehr Probleme, auch oft wegen der Sprache usw., also innerhalb des Unternehmens gibt es Verständigungsprobleme. " (T 15)

Selten wird seitens der Unternehmer der Faktor kulturell geprägter Werthaltungen ins Treffen geführt. Ein Experte hat hierzu pointiert gemeint:

„Ja, das sind wieder die Sprachprobleme, die kulturellen Probleme. [...] Die Türken glauben immer, sie müssten unbedingt an der eigenen Identität festhalten und dass sie die andere Seite nicht zulassen dürfen. "

Wie sehen BKS-Unternehmer den Unterschied zwischen Türken und Österreichern in Bezug auf das Unternehmertum? Des Öfteren trifft man auf die Argumentation, dass Österreicher deshalb im Vorteil sind, weil sie in Österreich geboren wurden und die Sprache beherrschen. Auch divergierende Verhaltensweisen wurden angesprochen, so etwa, dass Türken eher ,,gelassen und lockerer seien“, während ,,die Österreicher strikt nach Regeln arbeiten ". 


\section{Die türkischen und BKS-Unternehmer im Vergleich}

Im Vergleich der Eigengruppe mit der Gruppe der „anderen Zugewanderten“ sehen rund zwei Drittel der befragten Unternehmer keine Unterschiede zwischen türkischen und BKS-Unternehmern. Sprach- und allgemeine Anpassungsprobleme dominieren die Argumentationsschiene. Dies wird beispielsweise folgendermaßen verbalisiert:

„Zwischen Türken und Jugoslawen sehe ich keine Unterschiede; sie haben mit denselben Problemen zu kämpfen und organisieren ihre Firmen relativ gleich. " (T 4)

„Sie sind sich ähnlich. Hauptproblem für beide ist die Sprache und Integration. “ (BKS 6)

Türkische Respondenten, die Unterschiede orten, sehen diese vor allem in den Vorteilen begründet, die das Networking der türkischen Herkunftsgruppe bringt:

„Türken haben den Vorteil, dass die eigenen Landsleute zusammenhalten und nur in ihren landestypischen Geschäften einkaufen gehen. “(T 2)

„,Türken haben ein größeres Umfeld, das sie unterstützt. “ (T 8)

BKS-Selbständige wissen um die Netzwerkdefizite innerhalb der eigenen Community und äußerten vor allem auf die Ansicht, dass ihre eigene Gruppe sich durch eine ausgeprägtere „Integrationsorientierung“ auszeichne:

„Nun ja, ich glaube, wie ich vorhin schon gesagt habe, wir wollen uns wirklich integrieren und die Türken nicht so ganz. Zumindest habe ich so den Eindruck und deshalb ist es auch für uns z.B. einfacher, Beratungsmöglichkeiten zu nutzen. " (BKS 2)

Seitens der Experten wurden einige zusätzliche Schwächen der BKS-Entrepreneurs angesprochen, wie etwa die Zersplitterung der BKS-Communities oder die geringere Verfügbarkeit von gruppeninternen Experten, die beim Start-up oder der Unternehmensführung als professionelle Berater zur Verfügung stehen:

„, Gerade die türkische Gruppe war stärker als die exjugoslawische. Branchenmäßig gibt es einfach recht deutliche Unterschiede, was auch damit zu tun hat, welche Opportunitäten sie vorfinden. Es finden eben nicht alle Gruppen die gleichen Opportunitäten vor. Bei den Türken ist es das Service der eigenen Gruppe, das Verkaufen von Kultur. "

„Netzwerke sind immer eine große Hilfe. Bei den Türken gibt es eine neue Branche von Steuerberatern und Anwälten, die nehmen den türkischen Unternehmensgründern die gesamte Bürokatie ab. Bei den Exjugoslawen gibt es das nicht so, es gibt aber spezielle Firmen für Steuerberatung. "

„Ein exjugoslawisches Informationssystem gibt es auch deshalb nicht, weil es so viele unterschiedliche Communities gibt. Bei den Türken nicht. “

„Die Türken haben ein internes, gutes Informationssystem innerhalb ihrer Community. Die wissen alles und einer hilft und berät den anderen. Damit tun die sich wesentlich leichter. Das fehlt in der exjugoslawischen Community, dieses Netz- 
werk. Da ist eher so eine Konkurrenz nicht dieser enge Zusammenhalt wie bei den Türken."

„,Mir fällt im BKS-Bereich auf, dass eine Stärke ist, sich sehr realitätsnahe in das Geschehen einzulassen. Sie wissen mittlerweile, was auf sie zukommt und kennen all die Hürden. Dass das Finanzamt in Österreich ein sehr mächtiger Partner ist, auch die gewerbliche Sozialversicherung. Sie wissen schon, worauf es ankommt und auch, wie die Mentalität ist. Ich glaube, dass die BKS-Szene schon diese Stärke besitzt, das sehr realistisch einzuschätzen. “

„,Bei den türkischen Unternehmen habe ich eher das Gefühl, dass sie leider ziemlich stark mit den türkischen Verhältnissen vergleichen. Ihnen ist nicht bewusst, dass der österreichische Staat viele Bereiche sehr gut reglementiert hat und dass der österreichische Staat schon Mechanismen hat, Unternehmen gut regulieren zu können. [...]. “.

\subsubsection{Maßnahmen zur Förderung der Selbständigkeit bei Immigranten}

Im Zusammenhang mit den zu überwindenden Hürden der kaufmännischen Existenzgründung stehen auch Maßnahmen, die das diesbezügliche Procedere erleichtern. Es war unser Ziel, aus der Perspektive des betroffenen Personenkreises zu erfahren, welche Maßnahmen sie selbst als hilfreich klassifizieren und welche ihnen die eigene Unternehmensgründung erleichtert hatten, um Aufschluss darüber zu erhalten, was von institutioneller Seite getan werden könnte, um hier korrigierend einzugreifen und den beiden Migrant Communities den Weg in die Selbständigkeit nachhaltig zu erleichtern. Hier ist anzumerken, dass gruppenspezifische Fördermaßnahmen aufgrund der ihnen inhärenten Bevorzugungs-Benachteiligungs-Konstellation auch international sehr umstritten sind. In vielen europäischen Metropolen setzt man mehr auf ein möglichst hohes Ausmaß man individueller „tailor made“ Beratung und Förderung, welches optimal auf die spezifische Bedürfnisstruktur jedes einzelnen Unternehmers zugeschnitten ist (vgl. Rath \& Swagerman 2011), wie eine Expertin meinte:

„Es ist aber problematisch zu sagen, dieses Angebot ist zugeschnitten für diese oder jene Community. Ich würde eher sagen, es ist wichtig, sehr stark individuelle Beratungen durchzuführen. "

In der Unternehmerbefragung war die Antwortbereitschaft auf die Frage der Fördermaßnahmen überdurchschnittlich hoch. Türkische Unternehmer haben in erster Linie finanzielle Aspekte angesprochen, bei deren Überwindung es aktuell noch an Unterstützung mangelt, d. h. günstigere, leichter zugängliche Kredite, ausreichendes Startkapital sowie des Weiteren auch staatliche Förderungen:

,,Türken wissen, wie sie ein Unternehmen eröffnen, wenn sie kein Problem mit Krediten haben. " (T 2)

„Durch mehr Unterstützung durch den Staat. Momentan finanziert man sich hauptsächlich mit dem eigenen, gesparten Geld. " (T 10) 
„Die Banken könnten den Unternehmensgründern leichter einen Kredit geben. Es ist schwer, einen Kredit zu kriegen für ein Unternehmen. " (T 14)

Diese türkischen Selbständigen wünschen sich zusätzlich zum finanziellen Support noch Motivationskurse, konkrete Unterstützung seitens der Stadt Wien, Seminare in unternehmensbezogenen Teilbereichen, ein Mehr an Ausbildungsangeboten und zusätzliche Beratung.

Im Vergleich zeigt sich bei den BKS-Unternehmern ein anderes Bild. Dies weist auf Unterschiede in den Voraussetzungen von Gründern und Gründerinnen in den beiden Herkunftsgruppen hin. Der Aspekt der finanziellen Unterstützung wird nur von wenigen angeführt, dafür kommen die wichtigen Aspekte der Bildung und Ausbildung sowie die Rahmenbedingungen der Migrations- und Integrationspolitik zur Sprache:

„, Steuerliche Vorteile in den ersten Gründungsjahren; für die Leute mit Migrationshintergrund Kurse anbieten, wo man hilfreiche Informationen über Unternehmensführung bekommt, jedoch in beiden Sprachen und eine Beratungsstelle. “ (BKS 3)

Wir haben auch eine Frage inkludiert, die die Möglichkeit beinhaltete, Wünsche nach speziellen Maßnahmen zur Förderung der Selbständigkeit speziell in der eigenen Herkunftsgruppe zu artikulieren. Es zeigte sich, dass sich die Mehrheit der Unternehmer keine Maßnahmen wünscht, die speziell auf ihre jeweilige Herkunftsgruppe zugeschnitten sind. So erteilen 11 von 15 türkischen Selbständigen den gruppenspezifischen Measures of Support eine Absage. Die Vorschläge beinhalten allgemeine Maßnahmen, von denen, wie schon die oben verbalisierten Vorschläge, eigentlich jeder Gründer/jede Gründerin gleichermaßen profitieren könnte: „Steuern und andere Gebühren etwas senken und damit den Menschen die Gründung erleichtern“, „, mehr Förderung durch Ausbildungsplätze“, ,,mehr Unterstützung, mehr Auskunft und Beratung “, „Organisation von Seminaren“ und ,wenn der Staat mehr Deutschkurse anbieten würde “.

Unter den BKS-Respondenten äußern nur wenige den Wunsch nach auf ihre eigene Herkunftsgruppe abgestimmten Fördermaßnahmen. Die Aussagen bezogen sich auf ein Mehr an Schulungen, Berater aus der eigenen Herkunftsgruppe, um die Hemmschwelle zur Inanspruchnahme zu senken, muttersprachliche Beratung und ebensolche Formulare sowie last, but not least Deutschkurse.

Im Zusammenhang mit Fördermaßnahmen wurde seitens der Experten eine breite und sehr heterogene Palette an Anregungen verbalisiert, wobei die Gründungs- und Gründerförderung im Fokus steht. Von zentraler Bedeutung für die Gründungsberatung ist MINGO (,Move in and Go“), dessen Leiterin im Erhebungszeitraum, Frau Tülay Tuncel, die Aufgaben ihrer Institution folgendermaßen beschrieb:

„Wir sind für Unternehmer und Unternehmerinnen bis zu fünf Jahre zuständig. Wenn ein Unternehmer im dritten Jahr ins Schleudern kommt, kann er sich an uns wenden Das ist in der Regel immer so die kritische Zeit. Die Nachzahlungen sind immer sehr problematisch. Man muss schon fairer Weise dazusagen, dass unser Auftreten in der Öffentlichkeit sehr stark den Eindruck vermittelt, als ob 
wir nur für JungunternehmerInnen zuständig wären. De facto sind wir das auch. Wir versuchen aber im Rahmen von all den Angeboten, die wir haben, die Menschen bestmöglich auszurüsten und wollen das mit der von uns geleisteten Vorarbeit verhindern. "

Was die Erreichbarkeit einzelner Herkunftsgruppen anbelangt, so inseriert MINGO gezielt in einer großen Zahl an Medien der Immigrantencommunities, etwa in der Zeitschrift der exilrussischen Community und in der African Tribune. Vor allem die größeren Herkunftsgruppen werden recht gut durch MINGO erreicht und für sie steht auch umfassende muttersprachliche Beratung zur Verfügung. Etwas anders sieht es bei kleineren Communities aus. Für diese ist vielfach muttersprachliche Beratung nicht vorhanden, was eine gewisse Barriere darstellt:

„Das Problem bei der ganzen Geschichte ist ja, dass - egal wo sie hinsehen-, sei es jetzt das Gründerservice von der Wirtschaftskammer oder auch wir [Anm.: gemeint MINGO], zu wenig Ressourcen für die Kleinen haben“.

Die Resonanz ist auch recht unterschiedlich: So haben die an die russische Community gerichteten Medienkampagnen bislang eher geringe Effekte gezeitigt. Die Kausalfaktoren dafür sind nicht wirklich erforscht. Wenig weiß man bislang auch über die Informationsdiffusion in den Communities. Diese spielt aber eine wichtige Rolle. In Bezug auf die türkische Community wurde von einigen Experten die ihrer Meinung nach zu geringe Inanspruchnahme vorhandener Unterstützungsangebote kritisiert:

„Also ich habe den Eindruck, dass diese Hilfen nicht so sehr in Anspruch genommen werden von der türkischen Community. [...] Man sollte es den Türken mehr schmackhaft machen, die Hilfen auch in Anspruch zu nehmen, denn MINGO etwa kostet gar nichts und die Beratung bei MINGO bekommen sie auch in ihrer Muttersprache."

MINGO greift in die ablaufenden Prozesse jedenfalls moderierend ein:

„,Wir regulieren das Ganze auch ein bisschen selbst. Wir haben eine eigene Strategie, wo wir versuchen, die Communities zu aktivieren, zu beleben und auch diese zu erreichen ".

Immer wieder wurden wir seitens der Unternehmer und der Experten darauf aufmerksam gemacht, dass die Kreditgewährung derzeit insgesamt ein besonders prekäres Feld darstellt und Maßnahmen hier dringend nötig wären. Vor allem wurde kritisiert, dass hinsichtlich der Mikrokredite derzeit in Österreich noch ein beträchtliches Defizit besteht, ganz im Unterschied zu Amsterdam etwa, wo dieses Förderinstrument, auf die individuellen Bedürfnisse besonders abgestimmt, vorliegt. Des Weiteren sollte auch die Bandbreite an unterschiedlichsten Förderungen erweitert werden. Als positive Beispiele wurden Kleinförderungen hervorgehoben, aber auch die Nahversorgerförderung für Kleinunternehmen der gewerblichen Wirtschaft. Von Expertenseite sieht man in der Kreditsituation ebenfalls einen besonders kritischen Punkt: 
„Was ich in Wien und in Österreich generell vermisse, ist diese Mikrokreditierung. Nach einer Untersuchung starten $80 \%$ der Gründer mit einem Kapitalbedarf von bis zu $10.000 €$. Die in Nachrichten und Zeitungen medial vermittelten Förderprogramme sind auf eine Minderheit ausgerichtet. Das löst bei sehr vielen Gründern einen großen Frust aus. Das ist ein Fehler in der Orientierung und Ausrichtung der Förderlandschaft, der in diesen Gruppen weiter wirkt. "

Wiederholt wurde für Vereinfachungen plädiert, um überhaupt an finanzielle Förderungen heranzukommen:

„,Die Leute brauchen in Wahrheit einen Mikrokredit und eine Begleitung, um die

Proforma-Dinge erledigen zu können und zu wissen, welches Geld hereinkommt und wieder an bestimmte Einrichtungen hinausgeht. "

Aus der Expertenperspektive stellt der Businessplan eine schwierige Hürde im Zugang zu Krediten dar, denn jede Bank verlangt als formale Bedingung für eine Kreditgewährung die Vorlage eines solchen Planes. Damit und mit dem Bankgespräch allgemein sind allerdings nicht wenige Gründer und Gründerinnen mit Migrationshintergrund überfordert. Eine Externalisierung der Businessplanerstellung an Professionisten ist in Wien zwar möglich, muss aber finanziell entsprechend abgegolten werden, was für viele KMU nicht leistbar ist. Im Sektor des Ethnobanking ist in den unmittelbar vergangenen Jahren zwar einiges in Bewegung gekommen, eine Erweiterung dieser Möglichkeiten wurde von den Experten als besonders wichtig erachtet.

Positiv hervorgehoben wurde für die WKW, aber auch für andere Organisationen, dass diese nun „selbst zu den Leuten hingehen und nachfragen, was die brauchen“, denn „es ist ein Unterschied, ob ich wo hingehen muss, oder ob man von Seiten der österreichischen Institutionen mehr auf die Unternehmer zugeht". Des Weiteren wurde die Schwierigkeit angesprochen, die bildungsfernen Mikrounternehmer zu erreichen, um sie davon zu überzeugen, dass auch für sie die Einholung von Beratung einen Sinn macht.

Einen wichtigen Teilaspekt der strukturellen Rahmenbedingungen bilden die Migrantenorganisationen. Wie auch das erfolgreiche Beispiel Amsterdam (vgl. Rath \& Swagerman 2011) dokumentiert, wird die effizienteste Förderung des Unternehmertums unter Migranten durch Community-spezifische Organisationen betrieben. Die diesbezüglichen Hilfestellungen sind in der türkischen Community sehr stark ausgeprägt. Daraus resultiert die Schlussfolgerung, dass man diese Organisationen auch in anderen Communities fördern sollte, um zu einer stärkeren Professionalisierung der Selbständigkeit von Migranten zu gelangen. Gerade die Migrantenorganisationen tragen in besonderem Maß dazu bei, ,den Leuten proaktiv die Angst zu nehmen vor Beratung, damit sie diese auch in Anspruch nehmen ", so eine Expertin.

Ein Experte erwähnte ein nachahmenswertes türkisches Fördermodell, in welchem in der Türkei studierenden Ausländern, beispielsweise aus Bosnien oder Bulgarien, ein Kontingent an geförderten Studienplätzen zuerkannt wird. Neben dem Erwerb türkischer Sprachkenntnisse dient dies dem Aufbau und der Etablierung bosnisch- 
türkischer Wirtschaftsnetzwerke nach der Rückkehr der Absolventen. Dieses Modell hat sich als sehr effektiv herausgestellt und könnte sich angesichts der hohen Zahlen ausländischer Studierender an Wiens Universitäten auch in Österreich bewähren und die internationale Wirtschaftsvernetzung fördern.

Als ein weiterer innovativer Aspekt wurde die Förderung unternehmerischer Kultur angesprochen, etwa die Innovationsförderung auf dem Sektor der Nahversorgung sowie die Etablierung einer, wie es eine Expertin bezeichnete, ,freudvolleren Unternehmerkultur", die den USA vergleichbar wäre.

Weiterer Handlungsbedarf wird in der Frage der Nostrifikation im Ausland erworbener Qualifikationen geortet. In diesem Zusammenhang wurden die Beschleunigung und Entbürokratisierung der aktuellen Nostrifikationsverfahren gefordert.

\section{Kausalanalyse und praxisrelevante Maßnahmen}

\subsection{Aus der ,ethnischen Nische“ zu einem wichtigen Teil der Wiener Wirtschaft}

Die Selbständigkeit ist auch unter den in Wien lebenden Migranten zu einem wichtigen „Integrationsvehikel“ (Schuleri-Hartje et al. 2005) geworden. In der Regel bilden kulturelle und sozialschichtspezifische Normen, familiäre Traditionen, individuelle Motivationen, sozialkapitalbezogene Faktoren sowie die Opportunity Structures ein komplexes Geflecht, welches in seiner Gesamtheit den Zugang in die Migrant Economy determiniert. Unseren Analysen und den Einschätzungen der befragten Experten gemäß ist das Unternehmertum von Migranten in Wien längst keine Nischenökonomie mehr und hat die „ethnische“ Ecke in einem hohen Ausmaß verlassen, ist aber dennoch durch eine überproportionale Präsenz bestimmter Herkunftsgruppen in bestimmten Branchen (Kurtoglu 2007; Segert 2010) sowie die Unterrepräsentation mancher Gruppen in einigen zukunftsträchtigen Branchen charakterisiert. Die Bildung und Perpetuierung ,ethnischer“ Nischen in Wien weist aufgrund der Zuwanderungs- und unternehmensrechtlichen Rahmenbedingungen einen gänzlich anderen Charakter auf als etwa in den USA.

Einerseits gibt es migrantische Communities mit einer ausgeprägten Tradition und hohen Wertschätzung des selbständigen Unternehmertums (Lamadem 1995; Pütz et al, 2007; Wang 2008: Yavuzcan 2003). In diesen ist ein unternehmerisches Erfahrungspotential vorhanden, welches die Unternehmensführung erleichtert. Gründer mit solchem Background sind somit häufig erfolgreicher, da sie über profunderes Marktwissen und mehr intergenerational transferiertes unternehmerisches Knowhow verfügen als andere Neueinsteiger. Es lassen sich daher auch Unterschiede im Verlauf der unternehmerischen Karrieren zwischen unterschiedlichen Herkunftsgruppen feststellen (Welter 2005; Rath 2002). Weiters kann man von einem sozialen Selektionsprozess innerhalb der Migrantencommunities sprechen, der es jenen, die über die geeigneten Voraussetzungen verfügen, erleichtert, einer selbständigen Erwerbstätigkeit nachzugehen. 